\title{
Aeolian dust sources, transport and deposition over the Chinese Loess Plateau during 1999-2019: A study using the FLEXDUST and FLEXPART models
}

Two years of work

Ove Haugvaldstad

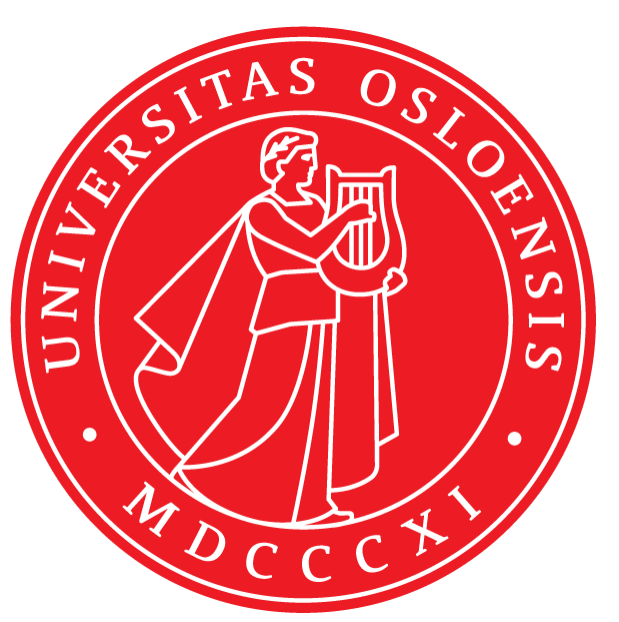

Thesis submitted for the degree of Master in Meteorology and Oceanography 60 credits

Section of Meteorology and Oceanography

Department of Geoscience

Faculty of mathematics and natural sciences

UNIVERSITY OF OSLO 



\section{Aeolian dust sources, transport and deposition over the Chinese Loess Plateau during 1999-2019: A study using the FLEXDUST and FLEXPART models}

Two years of work

Ove Haugvaldstad 

(C) 2021 Ove Haugvaldstad

Aeolian dust sources, transport and deposition over the Chinese Loess Plateau during 1999-2019: A study using the FLEXDUST and FLEXPART models

http://www.duo.uio.no/

Printed: Reprosentralen, University of Oslo 


\section{Abstract}

The aeolian dust deposits over the Chinese Loess Plateau (CLP) contain valuable information about past environmental changes in Asia. Unlocking this information requires understanding the East Asian dust cycle (EADC) and, particularly, the components of the EADC regarding the emissions, transport and deposition of aeolian dust over the CLP. In this work, the dust emission model FLEXDUST and the FLEXible PARTicle Dispersion Model (FLEXPART) were employed to study the dust cycle over the CLP (referred to as the EADC) from 1999 until 2019, during the dust event season March until May. Backward dust transport trajectories were calculated using FLEXPART from seven sites across the CLP. Two particle size bins $1.7 \mu \mathrm{m}-2.5 \mu \mathrm{m}$ representing clay particles and $15 \mu \mathrm{m}-20 \mu \mathrm{m}$ representing silt particles were included to examine the influence of particle size on dust transport and deposition, with wet and dry deposition being simulated, respectively. The trajectory information from FLEXPART is combined with the dust emission field from FLEXDUST to produce a high-resolution map of the source contribution for each deposition site.

The FLEXPART/FLEXDUST modelling setup was found to reasonably represent the EADC compared to observations, especially its spatial and temporal variations. The main source of the dust deposited to CLP is the deserts to the northwest of the CLP. Wet deposition is the major contributor to the deposition of dust particles over the CLP, especially for the coarse silt particles through high-level tropospheric transport. An extensive correlation analysis between spring dust emissions, deposition and several climate indices reveals a strong correlation of dust deposition over the CLP with the winter AO, but not with the EAWM. This contrasts with previous studies presuming a strong control of the EAWM on the dust deposition over the CLP. Our results show that strong dust deposition years were characterised by a negative $\mathrm{AO}$ and an anomaly in the winter $500 \mathrm{hPa}$ geopotential height over Mongolia/Siberia. The location of the geopotential height anomaly was consistent with previous studies on the cold air outbreak (CAOB) paths, indicating a key role of $\mathrm{AO}$ in regulating the frequency, intensity and path of $\mathrm{CAOB}$ intruding into East Asia, which primarily causes dust events in East Asia. 



\section{Acknowledgement}

If there is one thing I know for sure about this thesis is that I could not have done it by myself. In particular, the support and encouragement from my supervisors Hui Tang, Anu Kaakinen and Frode Stordal, have been indispensable. Thank you so much! Especially, I want to thank Anu for helping me out during my Covid disrupted exchange semester in Helsinki. I had a great time while it lasted. Moreover, I want to thank Christine Groot Zwaaftink at NILU for helping with solving the bias in FLEXDUST and Prof. Kazuo Osada at Nagoya University for providing data for model validation. The technical support team at MetOs also deserves praise, especially Anne Fouilloux, for helping with compiling FLEXPART on Saga.

During the past two years, I have been lucky to share office with and become friends with an amazing bunch of fellow master students. Among that bunch, there is one person that has meant a lot to me, Huiying Zhang. The walks, hikes, conversations and dinners we had together made all the difference during an otherwise stressful and isolating, seemingly never-ending pandemic.

I also want to thank everyone who has helped me out throughout my studies at $\mathrm{UiO}$ and finding my place in Oslo. Especially Fysikkforeningen at $\mathrm{UiO}$, which was like a home to me throughout my bachelor studies. Lillefy will always be close to my heart. I will also give a shoutout to Eirik Gallefoss for making the stress of the exams go away with a whiteboard marker and a thermos of coffee.

Last but not least I want to thank my family for their everlasting support and for showing interest in my studies. 



\section{Contents}

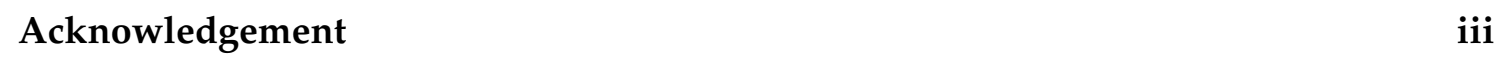

\begin{tabular}{ll}
\hline Acronyms & ix
\end{tabular}

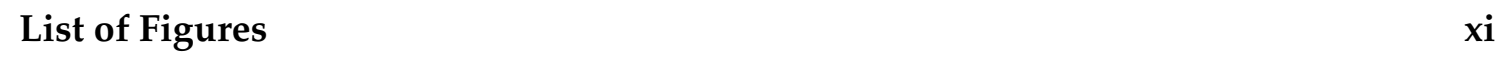

\begin{tabular}{ll} 
List of Tables & XV \\
\hline
\end{tabular}

\begin{tabular}{lll}
\hline & Introduction & 1
\end{tabular}

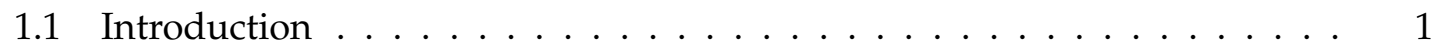

1.2 Outline and research questions $\ldots \ldots \ldots \ldots 2$

\begin{tabular}{|lll}
2 & The roles and physics of aeolian dust & 5
\end{tabular}

2.1 Dust's role in the climate system $\ldots \ldots \ldots \ldots \ldots$

2.1 .1 Climate feedback of dust . . . . . . . . . . . . . . 5

2.1 .2 Dust as a climate archive $\ldots \ldots \ldots \ldots \ldots$

2.2 Dust modelling . . . . . . . . . . . . . . . . 7

2.2 .1 Dust emissions $\ldots \ldots \ldots \ldots \ldots \ldots$

2.2 .2 Dust transport. . . . . . . . . . . . . . . . . 10

2.2 .3 Dust deposition $\ldots \ldots \ldots \ldots \ldots \ldots \ldots \ldots$

\begin{tabular}{lll}
\hline 3 & East Asian dust cycle & 15
\end{tabular}

3.1 Spatial distribution and characteristics of dust sources . . . . . . . . . . 15

3.2 East Asian dust storms and their formation . . . . . . . . . . . 16

3.3 Influence of regional and large-scale climatic factors on dust storms . . . 17

3.4 The Chinese Loess Plateau as a hotspot for East Asian dust deposition . . 20 
4 Models, input data and analysis method 23

$4.1 \quad$ FLEXDUST . . . . . . . . . . . . . . . . . . . . . . . . . . . . . . . . . . . . . . 23

$4.1 .1 \quad$ Identification of dust sources $\ldots \ldots \ldots$. . . . . . . . . . . 23

4.1 .2 Dust mobilisation threshold . . . . . . . . . . . . . . . . . . 24

$4.1 .3 \quad$ Dust flux parameterisation $\ldots \ldots \ldots \ldots . \ldots . \ldots 25$

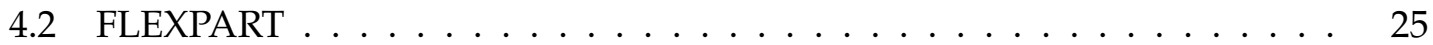

4.2 .1 Dry deposition $\ldots \ldots \ldots \ldots \ldots \ldots$

4.2 .2 Wet deposition $\ldots \ldots \ldots \ldots \ldots$. . . . . . . . . . . . . .

4.3 Model input . . . . . . . . . . . . . . . . . . . 27

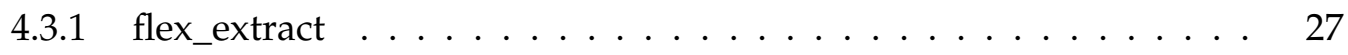

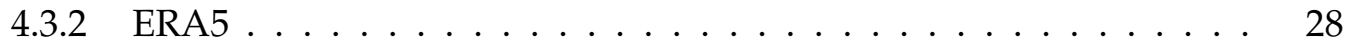

$4.4 \quad$ Model setup . . . . . . . . . . . . . . . . . . . . . . . 28

$4.4 .1 \quad$ FLEXPART $\ldots \ldots \ldots \ldots \ldots \ldots \ldots$

$4.4 .2 \quad$ FLEXDUST $\ldots \ldots \ldots \ldots \ldots \ldots \ldots \ldots$

4.4 .3 Model validation . . . . . . . . . . . . . . . . . . 31

$4.4 .4 \quad$ Model sensitivity experiments . . . . . . . . . . . . . . . . . . 31

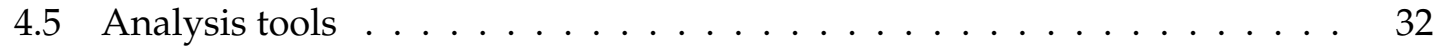

$4.5 .1 \quad$ Post-processing of model output $\ldots \ldots \ldots$. . . . . . . . . 32

$4.5 .2 \quad$ FLEXPART trajectory analysis . . . . . . . . . . . . . . . 33

4.5 .3 Statistical methods . . . . . . . . . . . . . . . . . . . 34

\begin{tabular}{ll|l}
\hline 5 & Results & 37
\end{tabular}

$5.1 \quad$ Model sensitivity to input data and parameters . . . . . . . . . . . . . . . 37

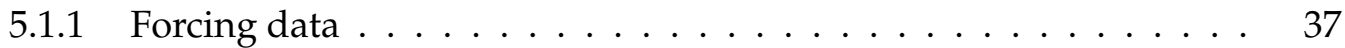

5.1 .2 Soil texture data $\ldots \ldots \ldots \ldots \ldots$. . . . . . . . . . . . . . . . . .

$5.1 .3 \quad$ Particle density $\ldots \ldots \ldots \ldots$. . . . . . . . . . . . . 40

5.1 .4 Below cloud scavenging . . . . . . . . . . . . . . . . 40

5.2 Model evaluation against observation . . . . . . . . . . . . . . . 40

5.3 Climatology of the East Asian dust cycle . . . . . . . . . . . . . . . 43

5.3 .1 Emissions $\ldots \ldots \ldots \ldots \ldots \ldots \ldots$

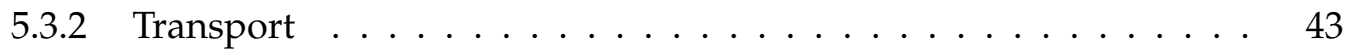

5.3 .3 Deposition . . . . . . . . . . . . . . . . . 44

5.4 Interannual variability of the East Asian dust cycle . . . . . . . . . . . . 45 


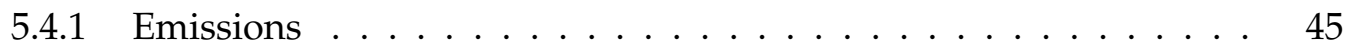

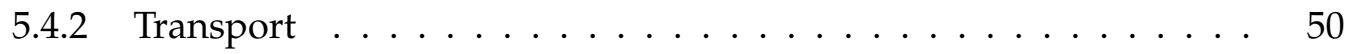

5.4 .3 Source contribution . . . . . . . . . . . . . . . . . . . . . 51

5.4.4 Covariations between deposition and large-scale circulation patterns 51

5.4 .5 Winter circulation and spring deposition . . . . . . . . . . . . 59

$\begin{array}{lll}6 & \text { Discussion } & 69\end{array}$

6.1 Model assessment . . . . . . . . . . . . . . . . . . . . . . . . . . . . 69

$6.1 .1 \quad$ Model representation of dust emission and deposition . . . . . . 69

$6.1 .2 \quad$ Causes of modelled deposition bias $\ldots \ldots \ldots$. . . . . . 70

6.2 Climatology of the East Asian dust cycle . . . . . . . . . . . . . . . . 72

$6.2 .1 \quad$ Dry-versus wet deposition . . . . . . . . . . . . . . . . 72

6.2 .2 Spatial variation of the dust sources to the CLP. . . . . . . . 73

6.2 .3 Fine versus coarse dust . . . . . . . . . . . . . . . 73

6.3 Interannual variability of the East Asian dust cycle . . . . . . . . . . . . . 74

6.3 .1 Dust emissions . . . . . . . . . . . . . . . 74

6.3 .2 Sources and transport in strong versus weak deposition years . . . 75

6.3 .3 Linking winter circulation and spring deposition $\ldots . . \ldots 75$

6.4 Implications for interpreting loess records $\ldots \ldots \ldots \ldots$. . . . . . . . 76

$6.5 \quad$ FLEXDUST/FLEXPART as a tool for studying the dust cycle . . . . . . . . 77

\begin{tabular}{lll}
\hline 7 & Conclusion & 79
\end{tabular}

7.1 Conclusion . . . . . . . . . . . . . . . . . . . . . . . . . . . 79

7.2 Future work $\ldots \ldots \ldots \ldots \ldots \ldots \ldots$

\begin{tabular}{ll}
\hline Appendices & 81
\end{tabular}

\begin{tabular}{|l|l|}
\hline A Supplementary figures and tables & 83
\end{tabular}

B Source receptor relationships within the framework of LPDMs 85

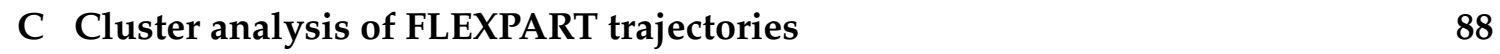

\begin{tabular}{lr}
\hline D Analysis software & 89
\end{tabular} 



\section{Acronyms}

AL Aleutian Low.

AO Arctic Oscillation.

AOD Aerosol optical depth.

APVI Asian polar vortex intensity index.

CAOB cold air outbreak.

CCN cloud condensation nuclei.

CLP Chinese Loess Plateau.

CTWC cloud total water content.

DJF December January February.

EADC East Asian dust cycle.

EAM East Asian monsoon.

EAT East Asian trough.

EATG East Asian temperature gradient.

EAWM East Asian Winter Monsoon.

EAWMI East Asian Winter Monsoon index.

ECWMF European Centre for Medium-Range Weather Forecasts.

EOF Empirical orthogonal functions.

ESM earth system model.

FLEXPART FLEXible PARTicle Dispersion Model.

IFS Integrated Forecast System.

IN ice nuclei.

LPDM Lagrangian particle dispersion model. 
MAM March April May.

MAR mass accumulation rate.

MO Monsoon index.

MSLP mean sea level pressure.

NAO North Atlantic Oscillation.

NIRD National Infrastructure for Research Data.

NTP Northern Tibetan Plateau.

PC principal component.

SAT surface air temperature.

SH Siberian High.

SHI Siberian High index.

TP Tibetan Plateau. 


\section{List of Figures}

$2.1 \quad$ Earth's distribution of arid regions, adopted from Williams (2014) $\ldots . . .6$

2.2 Threshold friction velocity $\mathbf{u}^{*}$ as a function of particle diameter. Points represent measurements from wind tunnel experiments, and the lines represent different semi-empirical expressions for the threshold friction velocity (Kok et al. 2012)] . . . . . . . . . . . . . . . 9

2.3 Different regimes of aeolian transport (Nickling and Neuman 2009) . . . . 11

2.4 Comparison of below cloud scavenging coefficients for three different below-cloud scavenging schemes; $\lambda_{1}$ Jung and Shao (2006), $\lambda_{2}$ Brandt et al. (2002) and $\lambda_{3}$ Laakso et al. (2003). $P$ is the precipitation rate (units: $\mathrm{mm} \mathrm{h}^{-1}$ ) Adopted from Jung and Shao (2006)] . . . . . . . . . . . 13

3.1 The major deserts in East Asia, with the mobile sands, semi-mobile sands

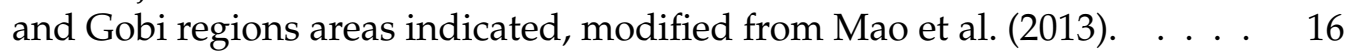

3.2 The 20 year average of winter (DJF) and spring (MAM) circulation from ERA5. (a) Winter and (b) spring MSLP and 850hPa winds climatology. (c) Winter and (b) spring 500hPa geopotential height and winds. (e) winter and (f) spring 200hPa geopotential height and wind speed. . . . . . . . . 18

3.3 The spatial correlation of the leading EOF of 1000hPa geopotential height (a) representing the AO. (b) spatial correlation of the leading EOF of SLP anomalies over the Atlantic sector, $20^{\circ}-80^{\circ} \mathrm{N}, 90^{\circ} \mathrm{W}-40^{\circ}$, representing the

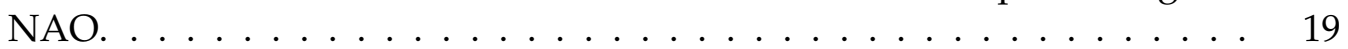

3.4 Circulation composite anomalies of $850 \mathrm{hPa}$ winds (vectors, unit: $\mathrm{m} / \mathrm{s}$ ) and mean sea level pressure for strong (colored, unit: Pa) - weak winter monsoon years and negative - positive winter AO. (a) and (b) is the DJF anomalies and (c) - (d) is MAM anomalies in the following spring $\ldots . .20$

3.5 Circulation composite anomalies of 500hPa winds strength (colored, unit $\mathrm{m} / \mathrm{s}$ ), wind direction (vectors, unit $\mathrm{m} / \mathrm{s}$ ) and geopotential height (contours, unit dam, distance between contours 2 dam) for strong - weak winter monsoon years and negative - positive winter AO. (a) and (b) is the DJF anomalies and (c) - (d) is MAM anomalies in the following spring. Data

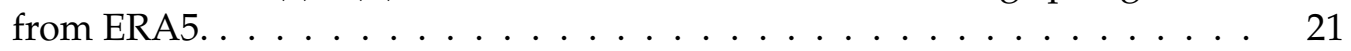

$3.6 \quad$ Map of the CLP, adopted from Spassov (2002). . . . . . . . . . . . . . 22

4.1 The erodible soil fraction from FLEXDUST over East Asia . . . . . . . . . . . 24 
4.2 Flow chart showing the workflow for the modelling analysis. . . . . . . .

4.3 Map of the receptor points, specified in the FLEXPART simulations . . . . 30

4.4 Map of the locations where dust deposition was sampled (Osada et al.2014) 31

4.5 Example rulegraph for generating|Figure 5.22 and |Figure 5.23 . . . . . . 33

5.1 Accumulated emission flux $\left(\mathrm{kg} \mathrm{m}^{-2}\right)$ simulated by FLEXDUST for the spring of 2015. (a) ERA5 $0.3^{\circ}$ resolution and (b) ERA-Interim $1^{\circ}$ resolution. (c) The time series of daily accumulated emissions ERA-interim (red) and

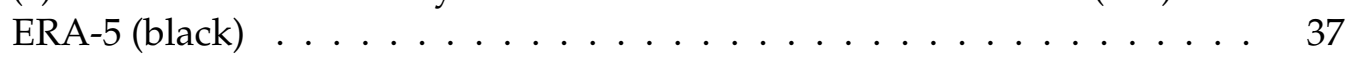

5.2 Accumulated source contribution and emission sensitivity for ERA5 (a),(c) and ERA-interim (b),(d) for total deposition of "silt" during the spring of 2015. (e) time series of daily accumulated deposition flux for ERA5 (red) and ERA-Interim (black). . . . . . . . . . . . . 38

5.3 Clay and sand fraction maps from 3 different data sources: default clay (a), CLM clay (b), ISRIC clay (c), default sand (d), CLM sand (e) and ISRIC sand

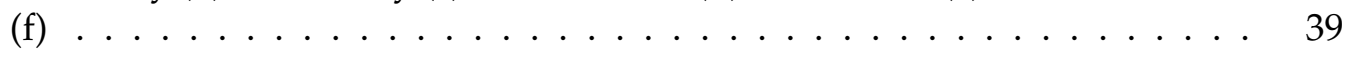

5.4 Accumulated simulated dust emissions for 2019, default soil maps (a), and ISRIC soil maps (b). . . . . . . . . . . . . . . . . . 39

5.5 Dry deposition rate at the SACOL site as a function of dust particle density, (a) clay and (b) silt . . . . . . . . . . . . . . . . . 40

5.6 The wet deposition rate at the SACOL site as a function of dust particle density, (a) clay and (b) silt . . . . . . . . . . . . . . 41

5.7 The difference in the source contribution to the wet deposition at Baode during spring 2019. With below cloud scavenging turned on minus below cloud scavenging turned off. . . . . . . . . . . . . . 41

5.8 Dry deposition flux (orange) simulated at 4 locations by the coast of Japan. The measurements (blue) monthly deposition flux are described by Osada

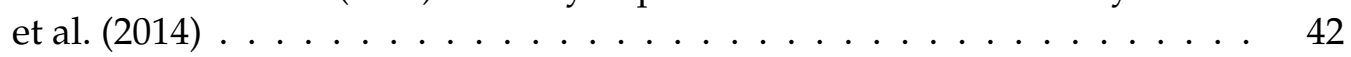

5.9 Wet deposition flux (orange) simulated at 4 locations off the coast of Japan. The measurements (blue) of monthly deposition flux are described by Osada

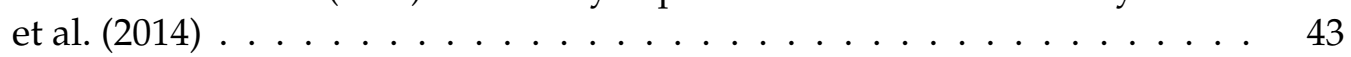

5.10 Map of spring averaged dust emission flux simulated by FLEXDUST. The major source regions are indicated, Junggar Basin (Red), Taklamakan (Blue), Qaidam Basin (Purple), northwest CLP (Green), Mongolia (Orange) . . . . . 45

5.11 The weighted average of centroid dust loading trajectories for all the receptor locations during springtime from 1999-2019. (a) and (b) is the dry deposition dust loading trajectories for "clay" and "silt", respectively, (c) and (d) is their accompanying vertical path. (e)-(h) as (a)-(d) just for wet deposition dust loading trajectories. The red points are spaced at 12 hours apart, indicating the speed of the dust transporting airmasses $\ldots 46$

5.12 Yearly averaged spring source contribution "clay" dust size bin for the seven sites across the CLP (a-g). (h) shows the averaged spring deposition of each site for both wet- and dry deposition $\ldots \ldots \ldots \ldots$. . . . . . . 47 
5.13 Yearly averaged March-May source contribution "silt" size bin for the seven sites across the CLP (a-g). Panel h) shows the averaged spring deposition of each site for both wet- and dry deposition $\ldots \ldots \ldots$. . . . . . . . 48

5.14 Time series of total springtime dust emissions from 1999-2019. The total emission is partitioned into the contribution from the Taklamakan (Blue), North West CLP (Green) and Mongolia (Orange) $\quad$. . . . . . . . . . . . . 49

5.15 The spatial pattern of the leading EOF (a) and second EOF (b). (c) the time series of the normalized principal component of the first (purple) and second (blue) EOFs. . . . . . . . . . . . . . . . . . . . . . . . . . . 49

5.16 DJF composite anomalies of MSLP and 850hPa winds the strong positive minus strong negative EOF1 $(\mathrm{a})$ and EOF2 $(\mathrm{b})$ years $\ldots \ldots . . \ldots 50$

5.17 MAM composite anomalies of MSLP and 850hPa winds the strong positive minus strong negative EOF1 $(\mathrm{a})$ and EOF2 $(\mathrm{b})$ years $\ldots \ldots \ldots 51$

5.18 The weighted average of dry deposited clay dust loading trajectories for strong (red diamonds) and weak deposition (blue circles) years for every location. The standard deviation of the trajectories during the weak deposition and strong deposition years is represented by the blue and red shading. (h) show the difference in the height of the dust transporting air masses during strong and weak deposition years. $\ldots \ldots \ldots 52$

5.19 The weighted average of dry deposited silt dust loading trajectories for strong (red diamonds) and weak deposition (blue circles) years for every location. The standard deviation of the trajectories during the weak deposition and strong deposition years is represented by blue and red shading. (h) show the difference in the height of the dust transporting air masses between strong and weak deposition years. . . . . . . . . . . .

5.20 The weighted average of wet deposited clay dust loading trajectories for strong (red diamonds) and weak deposition (blue circles) years for every location. The standard deviation of the trajectories during the weak deposition and strong deposition years is represented by blue and red shading. (h) show the difference in the height of the dust transporting air masses between strong and weak deposition years. . . . . . . . .

5.21 The weighted average of wet deposited silt dust loading trajectories for (red diamonds) and weak deposition (blue circles) years for every location. The standard deviation of the trajectories during the weak deposition and strong deposition years is represented by blue and red shading. (h) show the difference in the height of the dust transporting air masses between strong and weak deposition years. $\ldots \ldots \ldots \ldots \ldots$

5.22 Normalised source contribution composite anomalies of "clay" particle size bin for all locations, strong - weak deposition years. . . . . . . . . . 56

5.23 Normalised source contribution composite anomalies of "silt" particle size bin for all locations, strong - weak deposition years. . . . . . . . . . 57

5.24 Interannual correlations between deposition and each site and local and large-scale climate indices. The significant correlations are indicated $\ldots 58$ 
5.25 Composite difference anomalies of mean sea level pressure and 850hPa strong minus weak deposition years of the "clay" size bin in winter (DJF) for all the locations (a-g). (h) indicates which years are strong and which

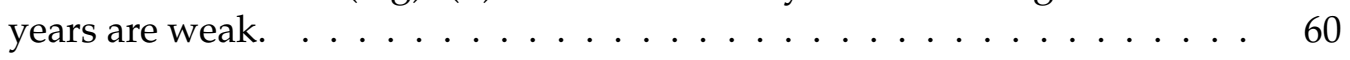

5.26 Composite difference anomalies of mean sea level pressure and 850hPa strong minus weak deposition years of the "silt" size bin in winter (DJF) for all the locations (a-g). (h) indicates which years are strong and which years

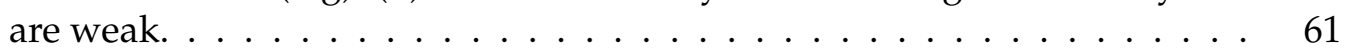

5.27 Composite difference anomalies of mean sea level pressure and $850 \mathrm{hPa}$ strong minus weak deposition years of the "clay" size bin in spring (MAM) for all the locations (a-g). (h) indicates which years are strong and which years are weak. $\ldots \ldots \ldots \ldots \ldots \ldots \ldots$

5.28 Composite difference anomalies of mean sea level pressure and $850 \mathrm{hPa}$ strong minus weak deposition years of the "silt" size bin in spring (MAM) for all the locations $(\mathrm{a}-\mathrm{g})$. (h) indicates which years are strong and which

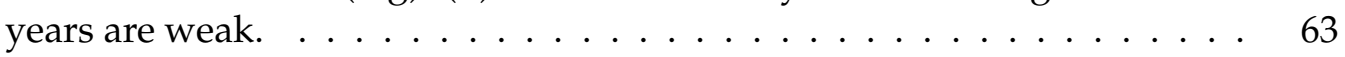

5.29 Winter (DJF) composite difference anomalies of 500hPa geopotential height (contours) and 500hPa wind speed (shading) strong minus weak deposition years of clay in winter (DJF) for all the locations a-g (h) indicates which years are strong and which years are weak. $\ldots \ldots \ldots 64$

5.30 Winter (DJF) composite difference anomalies of 500hPa geopotential height (contours) and 500hPa wind speed (shading) strong minus weak deposition years of silt for all the locations a-g (h) indicates which years are strong and

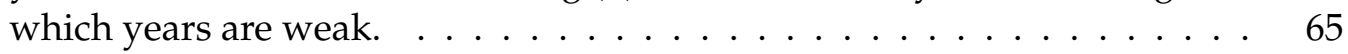

5.31 Spring (MAM) composite difference anomalies of 500hPa geopotential height (contours) and 500hPa wind speed (shading) strong minus weak deposition years of clay for all the locations a-g (h) indicates which years are strong and which years are weak. . . . . . . . . . . . 66

5.32 Spring (MAM) composite difference anomalies of 500hPa geopotential height (contours) and 500hPa wind speed (shading) strong minus weak deposition years of silt for all the locations a-g (h) indicates which years are strong and which years are weak. . . . . . . . . . . . . 67

A.1 The eigenvalues of the 10 first leading EOFs. The error bars correspond to the typical error of each EOF $\ldots \ldots \ldots \ldots \ldots$ 


\section{List of Tables}

$4.1 \quad$ FLEXPART species parameters for "clay" and "silt" particle size bin . . . . 30

4.2 The model sensitivity experiments performed in this study . . . . . . . . . 32

4.3 Assumed size distribution of emitted dust in FLEXPDUST . . . . . . . . . 33

4.4 Definition of the climatic indices used in the correlation analysis. . . . . . 35

5.1 The mean springtime emissions for the three largest source regions . . . . 44

A.1 The coordinates of the locations for where the FLEXPART backward simulations are initiated . . . . . . . . . . . . . . . 83

A.2 Setting specified in the COMMAND file for the main FLEXPART simulations. Dry deposition (Wet deposition) $\ldots \ldots \ldots$. . . . . . . 84 



\section{Chapter 1}

\section{Introduction}

\subsection{Introduction}

The windblown sediments at the Chinese Loess Plateau (CLP) compromise the largest and thickest deposit of Cenozoic windblown dust on Earth. The CLP covers an area of approximately $450000 \mathrm{~km}^{2}$ and is at the thickest, more than $350 \mathrm{~m}$ thick (Liu 1985). Dust from the proximal source regions has been naturally deposited over this region for millennials and faithfully recorded the past environmental history of East Asia. The aeolian dust deposits on the CLP extends back 22Ma (Qiang et al.2011) and in adjecent areas even as far back as 35Ma (Licht et al. 2014; Wasiljeff et al. 2020). The stratigraphy of the Quaternary CLP deposits is composed of alternating loess and palaeosol units (Derbyshire et al. 1995). The palaeosols are linked to the interglacial periods during which East Asia experienced a more humid climate with increased soil formation connected to a stronger East Asian summer monsoon (Maher and Thompson 1992). The loess units deposited during the glacial periods and are considered to be formed during enhanced winter monsoon conditions resulting in increased aridity and increased dust deposition (Xiao et al. 1995). Thus the Chinese loess serves as an important record of Quaternary glacial and interglacial periods in East Asia (An et al. 2014; Kohfeld and Harrison 2003). The older Red Clay sequence situated underneath the Quaternary sequence and is of a similar aeolian origin, however, the Red Clays more contineous without interluding palesol units and is better pedogenically developed. Still, the source regions and transport processes (predominately by westerlies or winter monsoon winds) of Red Clay and Quaternary loess are still debated (Bird et al. 2015; Miao et al. 2004; Shang et al. 2016).

Changes in mass accumulation rate (MAR) and loess grain size have typically been attributed to variations in the EAWM strength (Stevens et al. 2007). Emerging from these studies has the general claim that there is a strengthening of the EAWM during glacial stages, causing an increase in MAR over CLP with a shift towards larger grain sizes. Conversely, the humid interglacial periods are considered periods of significant downturn of EAWM activity. However, this interpretation has been cast under doubt because modern dust emissions and deposition in East Asia are primarily a spring phenomenon (Sun et al. 2001). Moreover, the possible mechanisms linking the EAWM to springtime emissions remains an open question (Roe 2009). In the study by Wyrwoll et al., the linkage between modern dust stroms and the EAWM was investigated by examining the interannual correlations between visibility observations from several meteorological stations across China (a indicator of dust storm) and the frequency of cold wave outbreaks 
over a 40 year period. In their study, the cold wave frequency was used as a proxy for the EAWM strength. The cold wave frequency was found to be strongly correlated with the dust storm frequency in spring. Consequently, Wyrwoll et al. concluded that the CLP serves as a valid record for the variability in the EAWM strength. However, Wyrwoll et al. does not consider that visibility is primarily an indicator of the atmospheric dust concentration rather than dust deposition. Dust concentration and deposition are not necessarily coupled, for instance during wet deposition episodes, which are influenced by other factors in addition to the mean flow (Osada et al. 2014). Moreover, they only consider the frequency of dust events, however single strong dust events may contribute to the majority of the dust deposited (Ta et al. 2004). Thus, the motivation behind this thesis is to address the shortcommings of Wyrwoll et al. (2016) and examine whether the MAR (i.e.,) over the CLP is really linked to EAWM and why.

In this thesis, the state-of-the-art Lagrangian particle dispersion model (LPDM) FLEXible PARTicle Dispersion Model (FLEXPART) (Pisso et al.2019) and the dust emission model FLEXDUST (Groot Zwaaftink et al. 2016) are employed for the first time to simulate East Asian dust cycle (EADC). Whereby dust cycle I refer to the fast processes of dust cycle namely; dust emission from the source regions, dust transport in the atmosphere, and dust removal by wet or dry deposition. Specifically, I will investigate the dust cycle of the dust deposited over the CLP, referred to as the EADC. In contrast to models previously used to study the EADC (Gong et al. 2006b; Liu et al. 2018; Shi and Liu 2011), this model setup is run backwards in time, following the dust from the receptor back to the source. This setup makes it possible to establish a detailed map of how much each source contributes to the deposition at specific location. The backward FLEXPART simulations are done for 7 prominent loess sites across the CLP and two-particle sizes are used to investigate how grain size of the deposited dust is affected by the EAWM strength. All the analyses of the EADC over CLP are based on 20 year simulation of EADC during spring from 1999 to 2019.

This work is a part of a larger research project Tracing the Winds, funded by the Academy of Finland and coordinated by Anu Kaakinen. The main aim of this project is to obtain a comprehensive understanding of the dust signal in the Neogene Red Clay deposits in order to better constrain their interpretation as palaeoclimate proxies. The idea is that a good understanding of the present-day spatio-temporal variation of dust cycle can help better interpretating the long-term variation of the EADC on time scales from millenials to million of years as revealed by the red clay and loess records.

\subsection{Outline and research questions}

The thesis is structured according to three main themes; (1) Model assessment, (2) Spatial pattern of the EADC and the dust source of the loess plateau and (3) Interannual variation of the EADC and the source of the loess plateau. Each of the components of the EADC, emission, transport and deposition will be examined from the perspective of these overarching themes for the selected loess site at the CLP. Moreover, the discussion and analysis of each theme is guided by its own set of research questions:

- Model assessment; How well does FLEXPART and FLEXDUST model represent the EADC, in particular, dust emission, and dry and wet deposition at a location? What are the possible uncertainties and biases? How does the model uncertainties impact 
the interpretation of the model results? What are the advantages/disadvantages of this modelling approach?

- Climatology of the EADC; Is wet or dry deposition the main mode of deposition to the CLP? How do the source areas and dust transport paths among the sites over the loess plateau differ? Are the source areas different for the coarse (dry) and fine (wet) deposited dust?

- Interannual variation of the EADC; What are the differences in circulation patterns, dust transport paths and source regions between strong and weak deposition years? How does the interannual variation of winter circulation affect springtime dust cycle?

The insights from each theme will then be synthesised to discuss the possible implications for the interpretation of the Chinese Red Clays and Loess records.

The remaining sections are organized in the following way: Chapter 2 establishes dust as an important component in the climate system and describe the theory related to dust modelling. Chapter 3 describes the East Asian dust sources and the CLP. The FLEXDUST and FLEXPART models are described in the Chapter 4 , in addition to input data, model set up and analysis methods. The results are presented in Chapter 5 following the three themes of this thesis. The results are then discussed in Chapter 6 , the discussion is guided by the research questions defined above. Finally, Chapter 7 will conclude the thesis by giving a summary of the main findings and provide an outlook for future work. 


\section{Chapter 2}

\section{The roles and physics of aeolian dust}

Aeolian dust is one of the most abundant aerosol species in the atmosphere and accounts for most of the total atmospheric aerosol mass (Adebiyi et al.2020). Aeolian dust refers to dust that is emitted and transport ted by winds and the word aeolian stems from the Greek god Aeolus, which in Greek mythology is the keeper of the winds. Around 1/3 of the earth surface is covered by deserts, that is, regions where the precipitation is too low and evaporation too high to allow plants to grow (Williams 2014). As shown in Figure 2.1 a large portion of the arid regions are located between $20^{\circ}-40^{\circ}$ north/south. This region is known as the dust belt(Williams 2014). The dust belt coincides with the descending part of the Hadley circulation, where the descending motion increases the atmosphere's stability and suppress the formation of rainfall, e.g., Sahara desert. Other areas that typically experience a minimal amount of rainfall are places situated in the rain shadow of the surrounding topography (e.g. Atacama desert) or far in the interior of the continents where there are no proximal sources of moisture (e.g. Gobi desert). The dry conditions produce loose soils that are easily erodible. Thus during periods of strong winds, dust emissions are naturally produced and entrained into the atmosphere. The world's deserts produce an estimated 2000Mt of atmospheric dust globally each year, with around $1500 \mathrm{Mt}$ being deposited on land and about 500Mt being deposited into the ocean (Shao et al.2011).

This chapter aims to examine the different roles of aeolian dust in the climate system, how dust deposits can serve as a valuable record of environmental change, and to describe the physical processes that go into current dust models. In order to give context and motivation to why we study and model dust and to provide prerequisite knowledge to inform the interpretation of the results and discussion in Chapter 5 and Chapter 6.

\subsection{Dust's role in the climate system}

\subsubsection{Climate feedback of dust}

In the atmosphere, the dust particles directly affect the transfer of radiation through the atmosphere. The smallest dust particles between 0.2-2 $\mu \mathrm{m}$ have a size around the same order as the wavelength of visible light and are the most efficient at scattering incoming solar radiation back to space. Accordingly, the smallest particles have a cooling effect on 


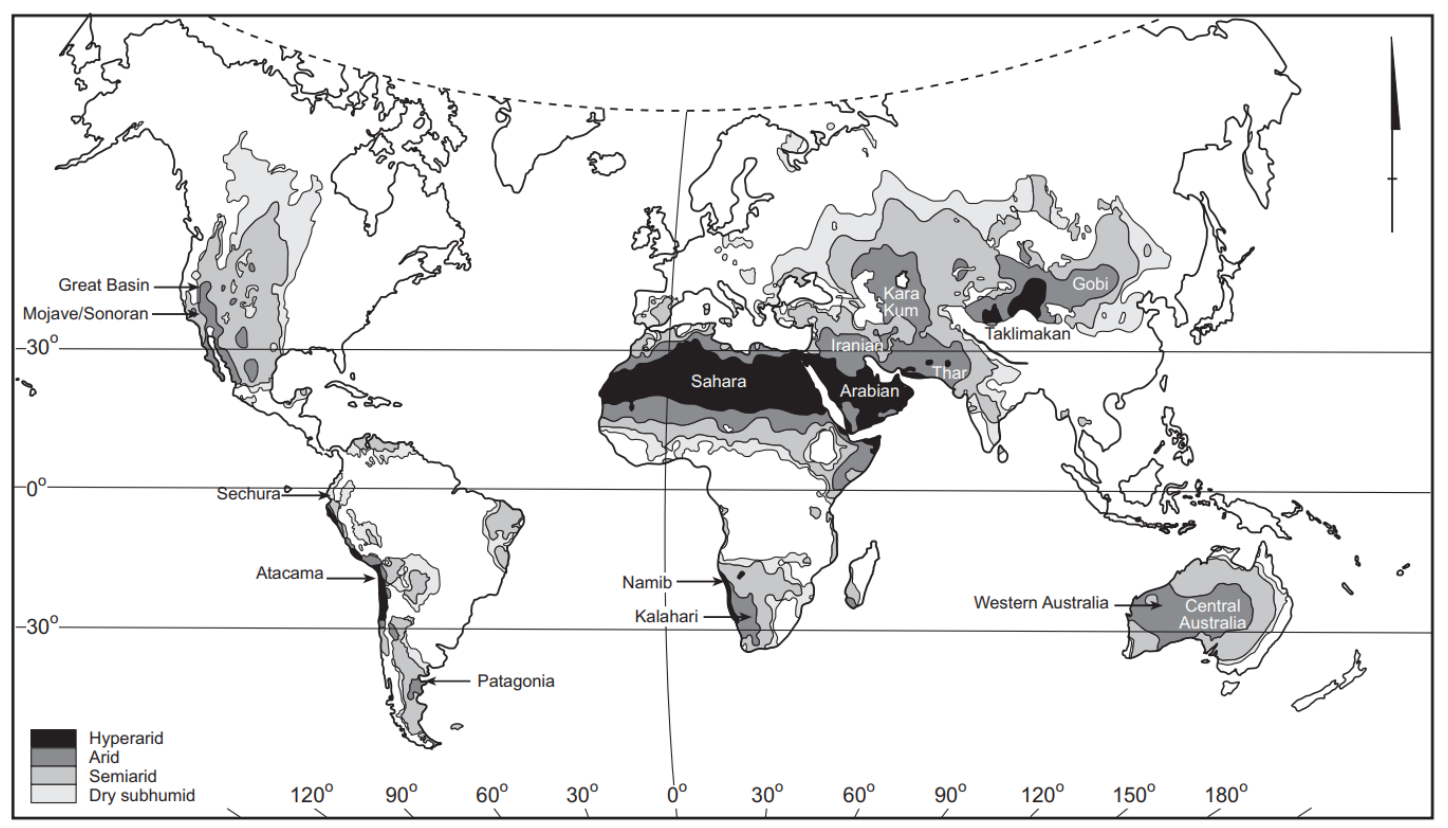

Figure 2.1. Earth's distribution of arid regions, adopted from Williams (2014)

climate. Conversely, the larger particles $(>4 \mu \mathrm{m})$ produces has a warming effect on climate due to their larger size, which makes them efficient at absorbing terrestrial longwave radiation (Choobari et al.2014). The lifetime of the dust aerosols is also strongly dependent on particle size (Mahowald et al.2014). Dust that gets entrained into the upper troposphere can be transported by the winds for thousands of kilometres and stay in the atmosphere for a long time (Yumimoto et al. 2009). Constraining the direct radiative effect of dust aerosols thus requires getting both the magnitude and the size distribution of the emitted dust correct (Adebiyi et al. 2020).

Dust aerosol also interacts with clouds by acting as ice nuclei (IN) and cloud condensation nuclei $(\mathrm{CCN})$ altering the microphysical properties of the clouds (Lohmann and Diehl 2006). Dust aerosols in their unaltered state are usually hydrophobic and thus quite inefficient CCN. However, during transport, dust aerosols can acquire a coating of soluble material, enhancing their ability to act as CCN (Falkovich et al.2001). Dust aerosols have also been suggested to warm the clouds as dusty clouds have been observed to have a lower liquid water path compared to their dust-free counterparts (Huang et al. 2006). The warming of the cloud induced by the dust aerosols might play a role in inhibiting precipitation over the desert regions, reinforcing the aridity of the desert (Shao et al. 2011). However, there are large uncertainties in the radiative impact of dust aerosols on clouds due to how sensitive clouds' radiative effects are to even small changes in their microphysical properties (e.g. droplet size, droplet concentration and cloud phase).

Beyond the time dust reside in the atmosphere, dust deposition also has a large impact on climate through influencing ecosystems and changing the snow surface albedo (Mahowald et al. 2010; Shao et al. 2011; Wittmann et al. 2017). In particular, ocean biomass productivity is dependent on dust as a source of iron. Iron is a limiting factor for phytoplankton production, which is responsible for nearly half of the annual $\mathrm{CO}_{2}$ exchange between the atmosphere and the ocean and the majority of carbon sequestration (Shao et al. 2011). Moreover, African dust has been found to be an important source of nutrients for the 
Amazon rainforest. Yu et al. (2015) estimated about $0.022 \mathrm{Tg}$ of phosphorus is brought to the Amazon through deposition of Sharan dust each year, comparable to the amount washed out by rainfall. Model estimates have shown that the increased dust deposition to the ocean and the corresponding boost of ocean productivity during the 20th century has caused an additional $4 \mathrm{ppm}$ of $\mathrm{CO}_{2}$ to be taken up by the ocean. However, regional shifts in precipitation and temperature due to changes in dust aerosol caused a decrease of 6ppm $\mathrm{CO}_{2}$ in the terrestrial biosphere carbon sink (Mahowald et al. 2010). This highlights the uncertainty of the net influence of dust on the biosphere and the carbon cycle.

\subsubsection{Dust as a climate archive}

Dust emission fluxes, size distribution and mineralogical composition are all strongly influenced by the wind speed, soil moisture and vegetation cover, and therefore indirectly modulating the influence of dust in the climate system. These climatic variables have experienced large changes throughout the history of Earth's climate and, more pressingly, are expected to change under the ongoing human-caused global warming. Dust transport is affected by changes in the atmospheric circulation and wet deposition by precipitation changes. There is, consequently, a potential for feedbacks involving dust and climate change.

Thus dust archives are a window into the past from which the interconnections between climate and dust can be studied and provide insight on how the impact of dust might change in the near future climate.

Arguably the most important dust record is the Loess record. Loess consists of aeolian sediments and is typically heavily sorted dominated by silt-sized $(2-50 \mu \mathrm{m})$ particles (Muhs et al. 2014). Terrestrial loess occupies large areas of North America, China, Central Asia and Europe, with the most prominent Loess deposits located at the Chinese Loess Plateau (CLP). Variations in the mass accumulation rate (MAR) and particle size distribution have been used to reconstruct changes in large scale-circulation patterns and dust transport pathways (Ding et al.2000; Maher 2016), climatic changes in the dust source and deposition areas (Shang et al. 2016; Sun and An 2005), and to provide constraints for model reconstructions of past global climate states (Da et al.2015). In addition to loess, aeolian dust is also found in ice cores and deep-sea records. One of the best-documented features in the dust record is the variation in mass accumulation rate (MAR) between the glacial and interglacial periods. During glacial stages, the earth experienced increased dust loading. Findings from the dust records suggest that during the glacial periods, the high latitude dust loading were up to 25 times the present value and around two times at the lower latitude (Shao et al. 2011).

\subsection{Dust modelling}

The important role of dust in the climate system, as pointed out in the previous section, has inspired researchers across the scientific disciplines to put considerable efforts towards developing global and regional dust models. The field of dust modelling started to take off in the early 1990s when scientists realised that aerosols, including dust, were responsible for a large fraction of the uncertainties in the climate models due to the difficulties in determining the aerosol radiative effect (Tegen et al. 1996), as described in Section 2.1. 
Models have improved since then, and current state of the art models can reproduce large scale patterns of atmospheric dust load (Huneeus et al. 2011). However, uncertainties in the description of source areas and processes controlling dust emission and deposition produce a large spread in simulated dust fluxes (Huneeus et al.2011). This section provides an overview of the parameterisations of the full dust cycle, i.e., dust emissions, transport and deposition processes used in current dust models.

\subsubsection{Dust emissions}

Producing a realistic estimate of the spatial distribution of dust emission flux depends on the model having a realistic representation of both the land surface properties and surface winds. Dust emissions are highly variable both spatially and temporally, which means that the dust model has to account for emissions that occur on scales that might not be explicitly resolved in the model.

Dust is mobilised when the force exerted by the wind on the bare soil exceed the mobilisation threshold (Kok et al. 2012). The forces acting on a dust particle at rest are the aerodynamic force that exerts lift and gravitational and interparticle forces that tend to fix the particle in place. The strength of the aerodynamic force has been widely hypothesized to be governed by the amount of momentum transferred from the atmosphere to the surface, described in terms of a friction velocity $u^{*}$ (Shao 2008).

$$
u_{*}=\sqrt{\tau / \rho}
$$

Here $\tau$ is the vertical component of the momentum flux, and $\rho$ is the air density. The strength of the forces counteracting dust mobilisation primarily depends on the particle size. The effect of the interparticle forces decreases with larger particle size, but the larger particles are also heavier and therefore feel a stronger tug by gravity. Thus the particles most easily mobilised by the wind have a size corresponding to where the interparticle and gravitational forces are approximately equal in magnitude. The amount of force the wind has to exert on the dust particle to exceed the forces counteracting mobilisation is expressed by the threshold friction velocity. The expression obtained by Shao and Lu (2000) is often used in the dust modelling community as it is relatively straightforward.

$$
u_{* t 0}(d)=\sqrt{a_{1}\left(\frac{\rho_{p}}{\rho_{a}} g d+\frac{a_{2}}{\rho_{a} d}\right)}
$$

Here $a_{1}$ is a tuning parameter, $a_{2}$ is the scaling constant for the inter particle forces, $\rho_{p}$ is the particle density and $\rho_{a}$ is the air density. Shao and $\mathrm{Lu}(2000)$ achieved good agreement with observations for $a_{1}=3.0 \mathrm{~kg} \mathrm{~s}^{-2}$ and $a_{2}=0.0123$. The balance between the $u^{*}$ and $u_{t}^{*}$ is sensitive to environmental factors such as weather (e.g. wind, precipitation and temperature), the soil composition, the soil moisture content, soil particle size distribution, vegetation converge and topography (Darmenova et al. 2009). All these factors vary significantly both spatially and temporally, making accurately calculating the threshold friction velocity difficult. Figure 2.2 show the the threshold friction velocity as a function of particle diameter, the coloured lines represent the semi-empirical relations for $u_{t}^{*}$ described in Iversen and White (1982) (pink), Shao and Lu (2000) (green) and Bagnold (1941). The semi-empirical relations and measurement seems to agree on a minimum in $u_{t}^{*}$ around in the range between $75 \mu \mathrm{m}-100 \mu \mathrm{m}$. However, these particles are too heavy to be subject to long-range suspension in the air and will soon after entrainment take on ballistic 


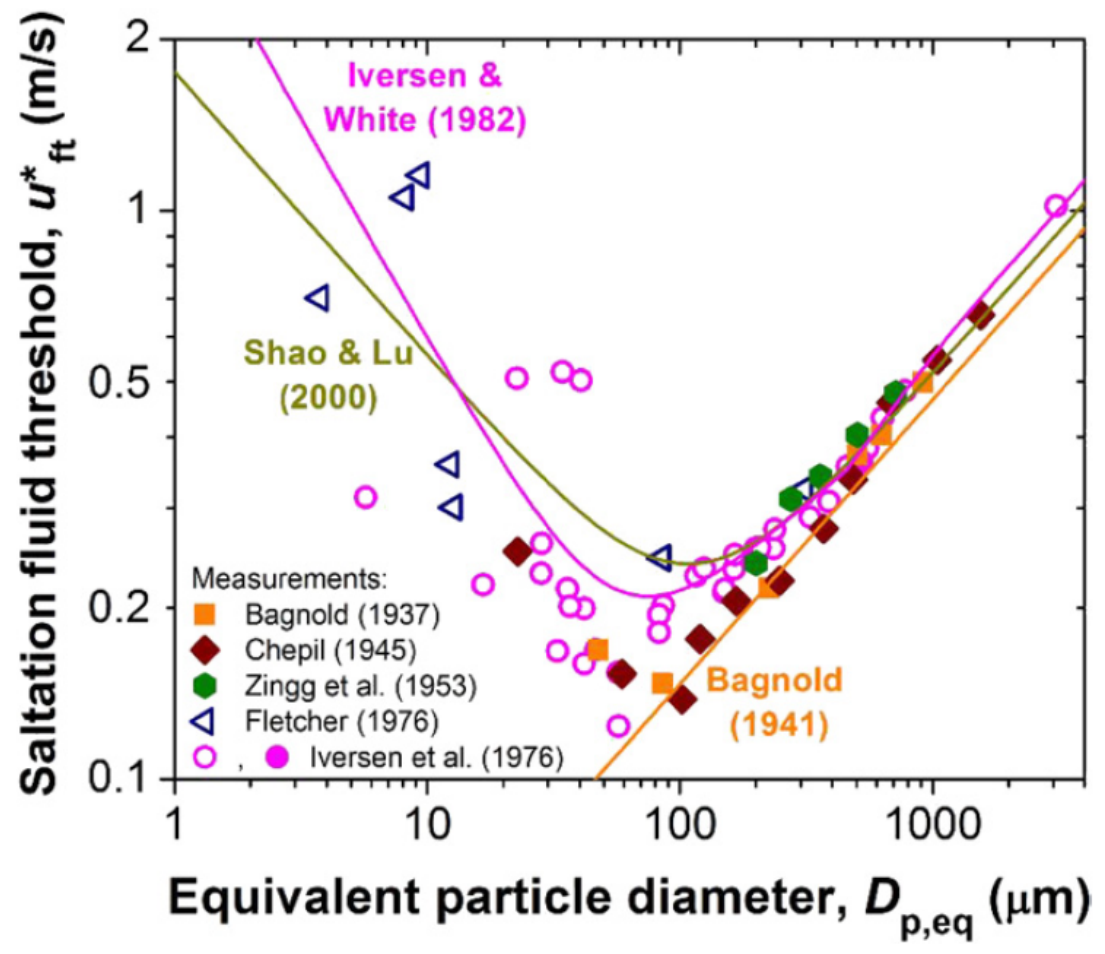

Figure 2.2. Threshold friction velocity $\mathbf{u}^{*}$ as a function of particle diameter. Points represent measurements from wind tunnel experiments, and the lines represent different semi-empirical expressions for the threshold friction velocity (Kok et al. 2012)

trajectories. The process of the wind transporting large dust particles through a series of "jumps" across the surface is called saltation. The impact from the large particle hitting the soil bed ejects smaller dust particles $(20 \mu \mathrm{m}<)$ and these smaller particles can be subjected to long-range transport. This process, known as sandblasting, is the predominant process causing dust emissions (Kok et al. 2012). The direct dust entrainment processes are often minor compared to sandblasting and, therefore, often neglected in dust models.

Several physics-based schemes for estimating the vertical dust emission according to the saltation theory have been proposed (Alfaro and Gomes 2001; Marticorena and Bergametti 1995: Shao 2004). The main distinction between the present schemes lies in how the particle size information is represented. The schemes can be divided into one of two categories, bulk and size resolving dust emission schemes. The bulk schemes (e.g. the emission scheme by (Marticorena and Bergametti 1995)) gives an estimate of the total dust flux, $F$ but provide no information about particle size-resolved dust flux $F(d)$. The bulk dust flux is estimated by first calculating the horizontal saltation flux (i.e. how many large particles there are jumping along the surface) and then deriving the vertical flux from the horizontal dust flux (Tegen and Schulz 2014). The scheme of Marticorena and Bergametti (1995) uses an empirical relation to relate saltation to the bulk dust vertical flux by scaling the saltation flux by a proportionally constant that depends on the clay content of the soil. In bulk emissions schemes, the vertical dust flux $F(d)$ of different particle sizes is inferred by assuming a fixed size distribution of the emitted dust particles $p_{s}(d)$ due to saltation. Based on the theory of brittle fragments Kok (2011) derived theoretical expression of the particle size distribution for dust particles between $0.1 \mu \mathrm{m}-20 \mu \mathrm{m}$ which showed good 
agreement when compared against observed size distributions of emitted dust. The Kok (2011) size distribution has been included in most dust models and has been shown to improve the representation of dust aerosols when compared to observations (Johnson et al. 2012). However, this particle size distribution only applies to dust emission events that are predominantly due to the fragmentation of soil aggregates (Kok et al. 2012).

The particle size resolving schemes, e.g. Shao (2004), can directly derive the size-resolved dust flux $F\left(d_{i}\right)$. This scheme calculates the emissions of particles with a size $d_{i}$ generated by saltating particles of size $d_{s}$. However, these schemes require knowing the parent soil particle size distribution, and measurements of parent soil particle size distributions are not available on a global scale.

Lastly, the surface roughness $z_{0}$ is an important parameter for calculating the friction velocity required for estimating the dust emissions. The $z_{0}$ used in global and regional models contain information about the subgrid-scale topography and vegetation to reproduce realistic grid-scale winds. However, these roughnesses operate on different spatial scales than the physical processes involved in dust emissions, which can introduce biases in the estimated dust flux (Darmenova et al. 2009). Therefore some models employ a satellite-derived dataset of surface roughness to obtain roughness on scales relevant for aeolian processes.

\subsubsection{Dust transport}

Dust transport is divided into several different regimes as illustrated in Figure 2.3, which mode of transport a dust particle is subjected to is predominately determined by the local wind speed and the size of the particle. Among the different modes of transport, only long term suspension is usually considered in current dust models. While dust particles with the longest lifetime in the atmosphere are less than $20 \mu \mathrm{m}$, there is a growing amount of evidence that under the right atmospheric conditions, even giant dust particles larger than $200 \mu \mathrm{m}$ can be transported for thousands of kilometres (Van Der Does et al. 2018). In comparison with observation, current dust models struggle with representing the coarse particle, i.e., severely underestimating the lifetime of the coarse dust particles while overestimating the fine mode (Adebiyi et al. 2020).

Part of the reason why coarse dust is not well represented in current dust models is that they typically are non-spherical. Non-sphericity can have a significant impact on the settling velocity of the particle due to increased aerodynamic drag. The effect of the non-sphericity on settling velocity of dust particles was investigated by Mallios et al. (2020), and they found that non-spherical dust particles could remain significantly longer in the atmosphere compared to spherical particles of equivalent particle diameter. The non-sphericity of dust particles is not included in most dust models (Huang et al. 2020). Moreover, dust models cannot directly model the turbulent properties of the nearsurface flow. The surface turbulence is important for the entrainment of coarse dust (Klose and Shao 2013) and in facilitating the dust to stay aloft longer (Ryder et al. 2013). Electric charging of the dust particles counteracting the gravitational settling has also been proposed to affect the lifetime of large dust particles and remains to be explored in dust models. Lastly, Heisel et al. (2021) suggested that gentle sloping topography increased the chance for the coarse particles to reach higher altitudes.

The transport of atmospheric dust can either be simulated in a Lagrangian or Eulerian framework. In the Lagrangian framework, the dust is treated as a discrete entity 


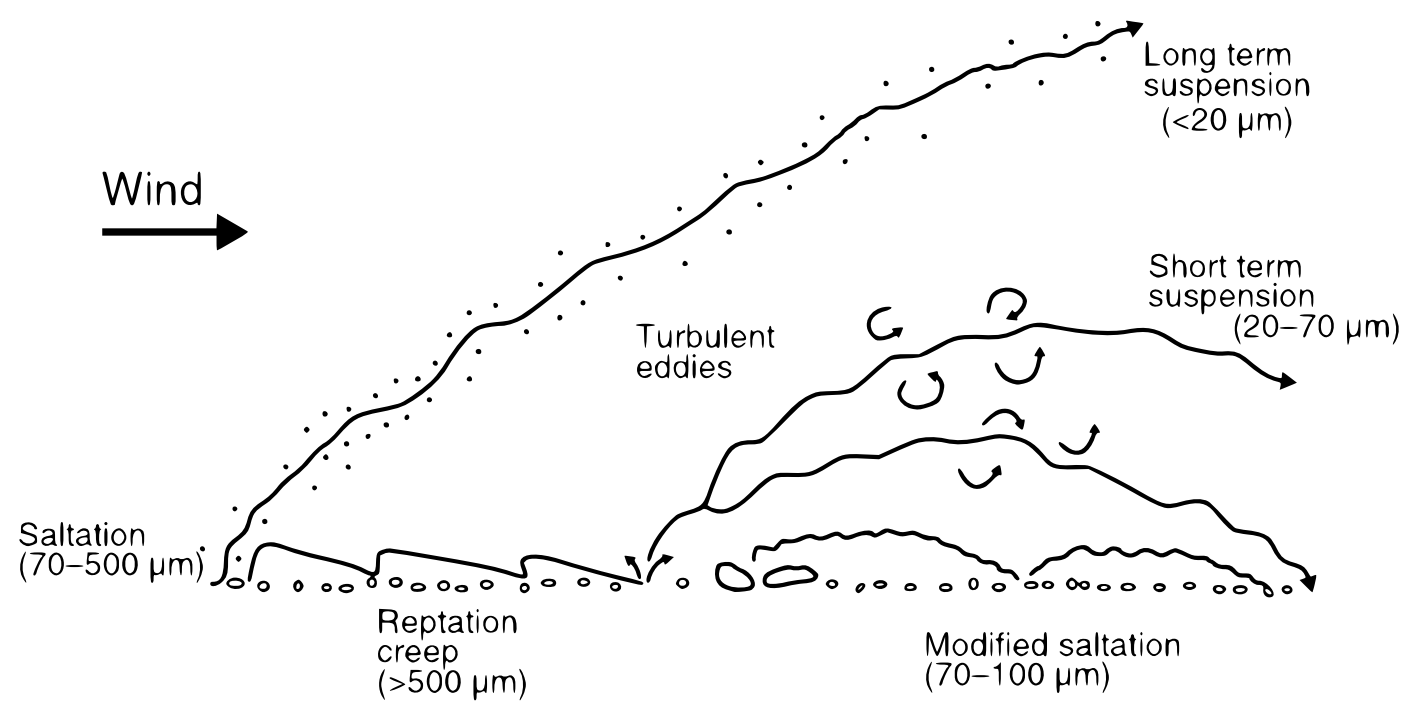

Figure 2.3. Different regimes of aeolian transport (Nickling and Neuman 2009)

represented by many computational particles. The computational particles are suspended with the flow, and their trajectories are determined by integrating the particle motion. The dust concentration rarely exceeds more than several grams per kilogram of air. Therefore, the presence of dust aerosols does not significantly impact the density and dynamics of the flow (Zhuang et al. 2001). Consequently, the motion of the dust particles can be determined separately from fluid motion (Shao 2008). Lagrangian models rely on tracking many computational particles to obtain statistically robust results and can thus be computationally expensive.

In eulerian models implemented in most climate and weather forecast models, the dust aerosols are assumed to behave like a fluid. Therefore, the dust concentration follows the same kind of advection and conservation equations as other scalars in the atmosphere. In an Eulerian dust model, the atmosphere is discretised into grid boxes on a computational grid with a certain resolution, and in each grid box, the model calculates the dust concentration. However, because of the limited resolution of the grid, Eulerian models often suffer from excessive numerical diffusion, which causes filament structure in the transport to be smoothed out (Cassiani et al. 2016). In contrast, Lagrangian models do not require a computational grid and can therefore better preserve such filament structures in the transport (Cassiani et al. 2016).

\subsubsection{Dust deposition}

Dust can be removed from the atmosphere either through dry- or wet deposition. Dry deposition typically is the dominant process close to the source region as there are still many large dust particles present that falls out quickly. As the dust is transported further away from the source region, the larger particles fall out, and the dust size spectrum becomes narrower and the mode finer (Does et al. 2016). Dry deposition becomes less efficient at finer particle sizes, and thus far from the source, wet deposition is usually the 
dominating process (Zhao et al. 2003).

In dust models, the deposition is typically represented by a deposition velocity. The predominant factors deciding the deposition velocity for dry deposition are the dust particle size and the density. A multi-layer resistance scheme is commonly used in dust models to estimate the dry deposition rate. A widely used scheme used for modelling dry deposition is the two-layer resistance model of (Slinn 1982). The resistance model divides the atmosphere into two distinct layers; The quasi-laminar sublayer close to the ground, which has a thickness on the order of centimetres and the constant flux layer above. In the quasi-laminar sublayer, Brownian diffusion and gravitational settling are the two main deposition processes. Within the constant flux layer, turbulent motions and gravitational settling dominate. The gravitational settling velocity can be expressed by the modified stokes law of (Slinn 1982):

$$
v_{g}=\frac{g \rho_{p} d_{p}^{2} C_{c u n}}{18 \mu}
$$

Where $\rho_{p}$ and $d_{p}$ is the particle density and diameter, $\mu$ is the dynamic viscosity of air and $C_{c u n}$ is the Cunningham slip-flow correction. The slip-flow correction accounts for the reduction in the drag force experienced by the smallest particles of sizes comparable to the mean free path of the molecules in air. The dry deposition velocity of a particle with a given size is given by a set of resistances, added to the settling velocity $v_{g}$ :

$$
v_{d}=\left[r_{a}+r_{b}+r_{a} r_{b} v_{g}\right]^{-1}+v_{g}
$$

Here the $r_{a}$ represent the aerodynamic resistance in operating the constant flux layer, and $r_{b}$ represent the resistance in the quasi-laminar surface layer. There have been relatively few theoretical developments since the work of Slinn (1982) even though this model has been shown to reproduce the dependence of $v_{d}$ on particle size, it does not differentiate the deposition velocity between different surfaces (Shao et al. 2011). The difference in deposition rate between different surfaces is expected to be quite large (Bergametti et al. 2018: Zeng et al. 2020).

There are two distinct routes for wet deposition: a dust particle can be wet deposited, in-cloud or below-cloud scavenging: In-cloud scavenging, the dust particles are rained out from the cloud through serving as CCNs or INs or by colliding with existing cloud particles. Below-cloud scavenging involves the dust particles being captured by falling hydrometeors. Many of the mechanisms involved in wet deposition are complex and generally not well understood, and some dust models do not consider wet deposition at all (Zhang et al. 2019). Between below-cloud and in-cloud scavenging, below-cloud scavenging is the simpler and better-studied process. Two mechanisms have been suggested to affect the efficiency of below-cloud scavenging: (1) fine dust particles with diameters less than $2 \mu \mathrm{m}$ tend to follow the streamlines and flow around the droplet, and (2) the dust particles might bounce off after colliding with the droplet. Accordingly, below-cloud scavenging is typically most efficient for the larger dust particles (Jung and Shao 2006). Currently, data is lacking for determining the probability of retention during the collision with the droplet, hence this mechanism is not included in current dust deposition schemes (Shao 2008). Several schemes for estimating the below-cloud scavenging efficiency $\lambda$ of varying levels of complexity have been proposed. The more advanced schemes, e.g. Seinfeld et al. (1998) and Shao (2008), uses semi-empirical relations to explicitly calculate the collection efficiency $E(r, R)$ as a function of both the droplet and dust particle radius. However, these schemes require knowing droplet size distribution 
which is not always available in the model. Therefore empirical below cloud scavenging schemes that directly relate scavenging coefficient to the precipitation rate, e.g. Brandt et al. (2002) have been developed. These schemes avoid uncertainties in determining the collection efficiency (Jung and Shao 2006). Some empirical schemes, e.g. Laakso et al. (2003) also includes a dependence of dust particle size for the scavenging efficiency. A

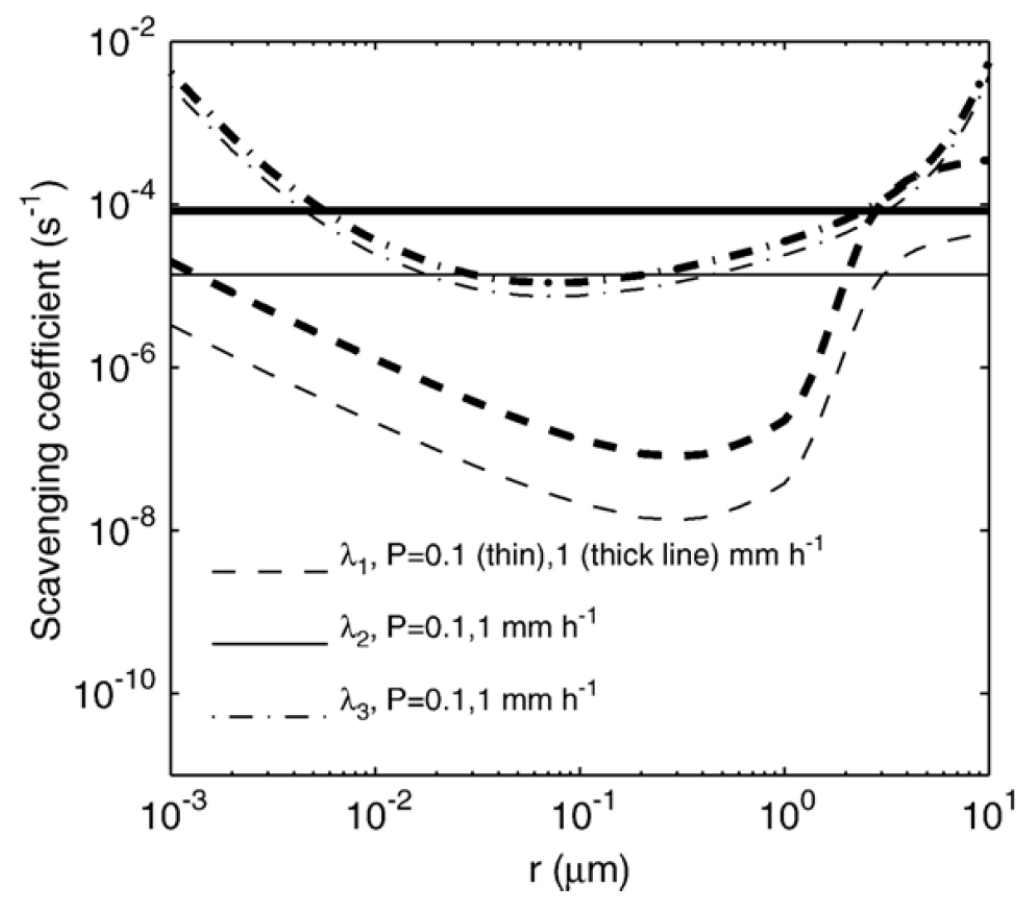

Figure 2.4. Comparison of below cloud scavenging coefficients for three different below-cloud scavenging schemes; $\lambda_{1}$ Jung and Shao (2006), $\lambda_{2}$ Brandt et al. (2002) and $\lambda_{3}$ Laakso et al. (2003). $P$ is the precipitation rate (units: $\mathrm{mm} \mathrm{h}^{-1}$ ) Adopted from Jung and Shao (2006)

comparison of the semi-empirical Shao (2008) scheme and empirical Brandt et al. (2002) and Laakso et al. (2003) are shown in Figure 2.4. For all the schemes, $\lambda$ increases for larger precipitation rates. Moreover, in the two schemes where $\lambda$ depends on the size of the dust particle, the scavenging coefficient decreases towards the $1 \mu \mathrm{m}$ mark and then increase again for the dust particles larger than $2 \mu \mathrm{m}$.

Present understanding of in-cloud processing and especially for dust aerosols, is lacking. Thus the representation of in-cloud removal of dust in models remains crude. Some dust models represent the dust as purely hydrophobic and neglect in-cloud scavenging entirely, while other models assume dust scavenging efficiency to be that of sulphate (Bergametti and Forêt 2014). Yet deposition is a key aspect of the dust cycle and cannot be represented without an adequate representation of the wet removal process. 


\section{Chapter 3}

\section{East Asian dust cycle}

The previous chapter described the important role of dust in the climate system and the physical processes included in current dust models. This chapter will narrow down the scope and bring the CLP in focus. The first section will describe spatial distribution and characteristics of the dust sources of CLP, and broadly in East Asia. The next two sections will look into what kind of weather produces dust storms in the region and the climatic factors that decide the frequency of dust storms. The last section will introduce the CLP and examine how dust deposited over the CLP can record and reflect the East Asian dust cycle.

\subsection{Spatial distribution and characteristics of dust sources}

The majority of the East Asian deserts are located in the Northern part of China and Mongolia, as shown in Figure 3.1, including deserts such as the Taklamakan, Badain Jaran, Tenger, Mu Us. The precipitation patterns predominately determine the distribution of the deserts. Situated in the interior of the Eurasian continent, the deserts are far away from the moisture of the Pacific Ocean. The dry conditions are exacerbated by the Tibetan Plateau and the Himalayas, inhibiting the transport of moist air masses from the southwest and moisture convection over the desert region. In total, the East Asian deserts make up the second-largest source of atmospheric dust on the planet, with estimated annual dust emissions of $2000 \mathrm{Mt}$ (Chen et al.2017).

In terms of the morphology and composition of the surface soil, the East Asian deserts can be separated into two classes gobi-deserts and sand deserts (Xuan and Sokolik 2002). The Gobi is characterised by regions consisting of pebbles, gravel and rock debris. Accordingly, the Gobi desert refers to an area consisting of interluding regions of sandy deserts, gobies and grasslands. Gobies and the Gobi desert mainly cover the northern region of the Inner Mongolia Plateau and the southern part of Mongolia (Figure 3.1p).

The interior of East Asia also fosters many sand deserts that mainly consists of loose sand. The loose sand facilitates dune formation, and the worlds tallest dunes are situated in the Badain Jaran desert. The Badain Jaran desert has dunes so large that they can generate their own weather (Dong et al. 2013). The most significant sand desert in the region is the Taklamakan desert, located in the Tarim Basin. The Tarim Basin is extremely dry, 


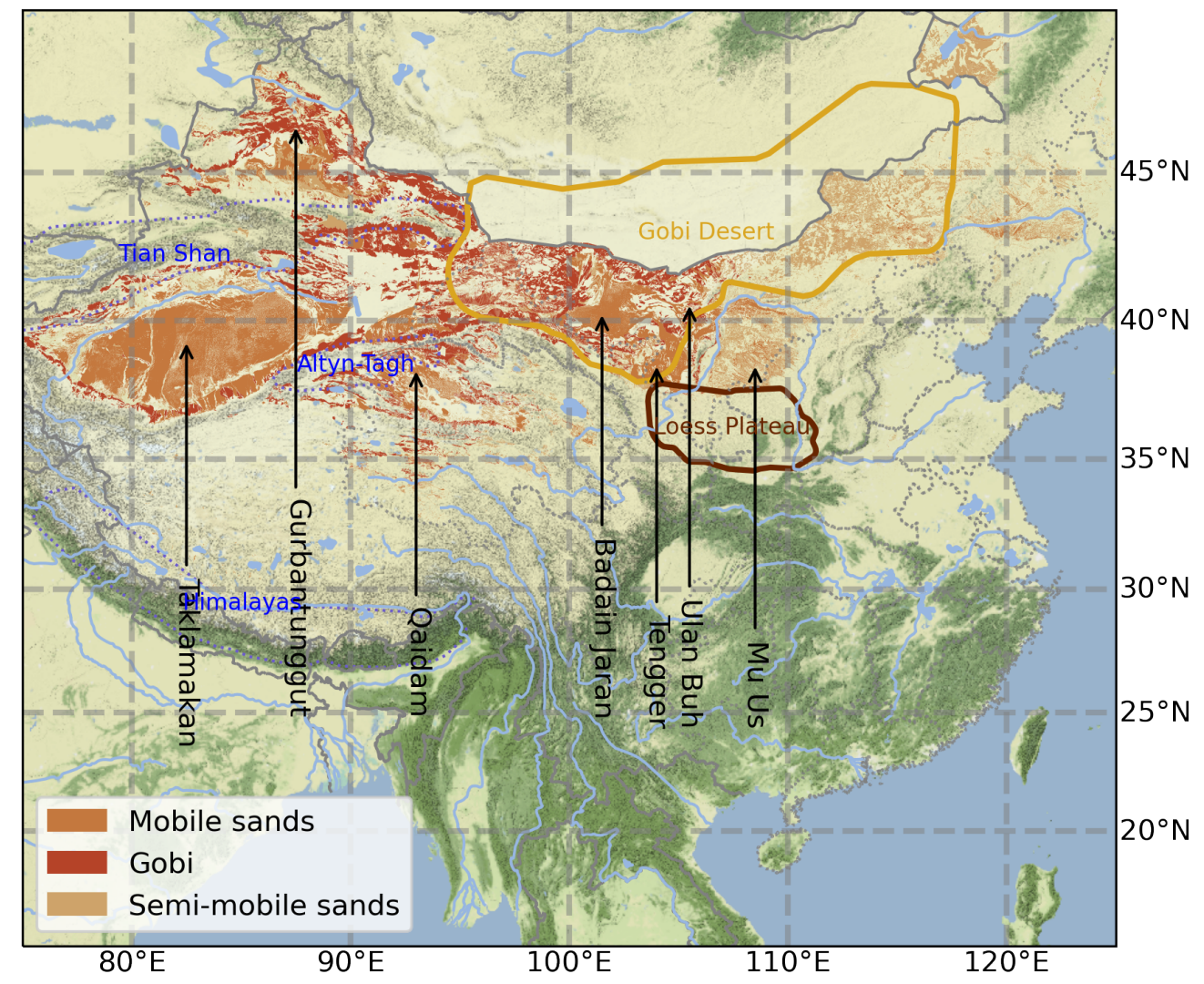

Figure 3.1. The major deserts in East Asia, with the mobile sands, semi-mobile sands and Gobi regions areas indicated, modified from Mao et al. (2013).

with annual precipitation of as low as $20 \mathrm{~mm}$ (Shao and Dong 2006). The extreme dryness makes it impossible for vegetation to set root. As a result, the region has a very small threshold friction velocity of about $4 \mathrm{~m} / \mathrm{s}$ compared to $7 \mathrm{~m} / \mathrm{s}$ for the Gobi desert (Shao 2008), and experiences the highest number of days with blowing sand among the East Asian deserts. However, the desert is well shielded from the weather by tall mountain ranges above $3000 \mathrm{~m}$, such as Tian Shan to the north, Pamir plateau to the west and Kunlun Mountains to the south, on all sides except for the opening at the eastern side of the basin. Therefore severe dust storms form less frequently in Taklamakan that can spread to East Asia (Shao 2008).

There are also several deserts located in close proximity of CLP. Among the larger deserts being the Tegger desert, Ulan Buh desert and Mu Us desert.

\subsection{East Asian dust storms and their formation}

In East Asia about $80 \%$ of the dust events occur in the spring months from March until May, with half of the dust events occurring in April (Sun et al. 2001). The occurrence of dust events is strongly correlated with the surface wind speed (Kurosaki and Mikami 2003). Strong surface wind speeds are typically generated by passing cold fronts and synoptic scale cyclones associated with cold air outbreak (CAOB) (Sun et al. 2001; Takemi and Seino 2005; Zhou and Zhang 2003). Moreover, cold fronts promote strong and deep vertical 


\subsection{INFLUENCE OF REGIONAL AND LARGE-SCALE CLIMATIC FACTORS ON DUST STORMS}

mixing due to the strong surface heat flux in the cold frontal region. The deep mixed layer can carry the dust into the upper troposphere allowing the dust to be transported far downwind (Liu et al. 2003).

Dust storms in Gobi desert and the desert regions northwest of the CLP are usually due to the development of cyclones over Mongolia (Shao and Dong 2006). The dust storm forms within the frontal region of the cyclone to the southeast of the central low pressure (Takemi and Seino 2005). The CAOBs that produces dust events in this region typically follow a northerly path, passing near lake Baikal moving southward across southern Mongolia and China (Sun et al. 2001).

Whereas dust storms in the Gobi and northwestern deserts are a direct consequence of synoptic scale circulation, Taklamakan is less influenced by the large scale circulation due to its shielded location in the Tarim Basin (Takemi and Seino 2005). Rather cold air intrusions caused by the synoptic conditions is the predominate cause of dust storm in Taklamakan. Aoki et al. (2005) identified three primary patterns of dust storm genesis in the Taklamakan desert. The first pattern is characterised by a cold pool located to the north of the Tian Shan creating a strong temperature gradient between the cold pool and the inside of the the basin. The cold air forms a gravity current that intrudes into the basin from the east, producing strong surface winds. The strong winds initiated the dust storm in the eastern end of the basin and then move westward until the whole basin is eventually enveloped. The second pattern is characterised by northerly flow with a trough located on the northern side of the Tian Shan. As the though advances the accompanying cold pool moves over the Tian Shan rather than around, directly into the basin, with similar flow characteristics as the first pattern except for the wind direction. These dust storms occur over a broad area of the desert. In contrast to the first two patterns the third pattern primarily produces dust storm in the western part of the desert. This pattern occur when the $500 \mathrm{hPa}$ trough advances eastward passing over the Parmir plateau bringing along cold air that flows into basin along the western slope.

\subsection{Influence of regional and large-scale climatic factors on dust storms}

Even though dust storms are primarily a spring phenomena, the conditions of the preceding winter have been shown to have a significant influence on the spring dust storm frequency (Gong et al. 2006b; He et al. 2017; Liu et al. 2018). The EAWM dominates the East Asian climate in winter and spring.

The characteristic features of the EAWM are the Siberian High (SH), Aleutian Low (AL), low-level north easterlies, mid-level East Asian trough (EAT), and the high-level East Asian jet stream. Figure 3.2 shows the climatology of the winter and spring circulation. In winter the $\mathrm{SH}$ is distinct. When the $\mathrm{SH}$ exceeded a certain intensity the eastward moving trough over Lake Baikal deepens as it moves toward the EAT located by the coast of japan (Figure 3.2 k). The movement of the trough brings along cold air into East Asia in the process (He et al. 2017). That produces favourable conditions for dust storms as described in the previous sections. A measure of the strength of the EAWM can be defined as the difference in MSLP between the semi permanent AL that forms around the same time as the $\mathrm{SH}$, and the $\mathrm{SH}$ (Yoshiike and Kawamura 2009). 


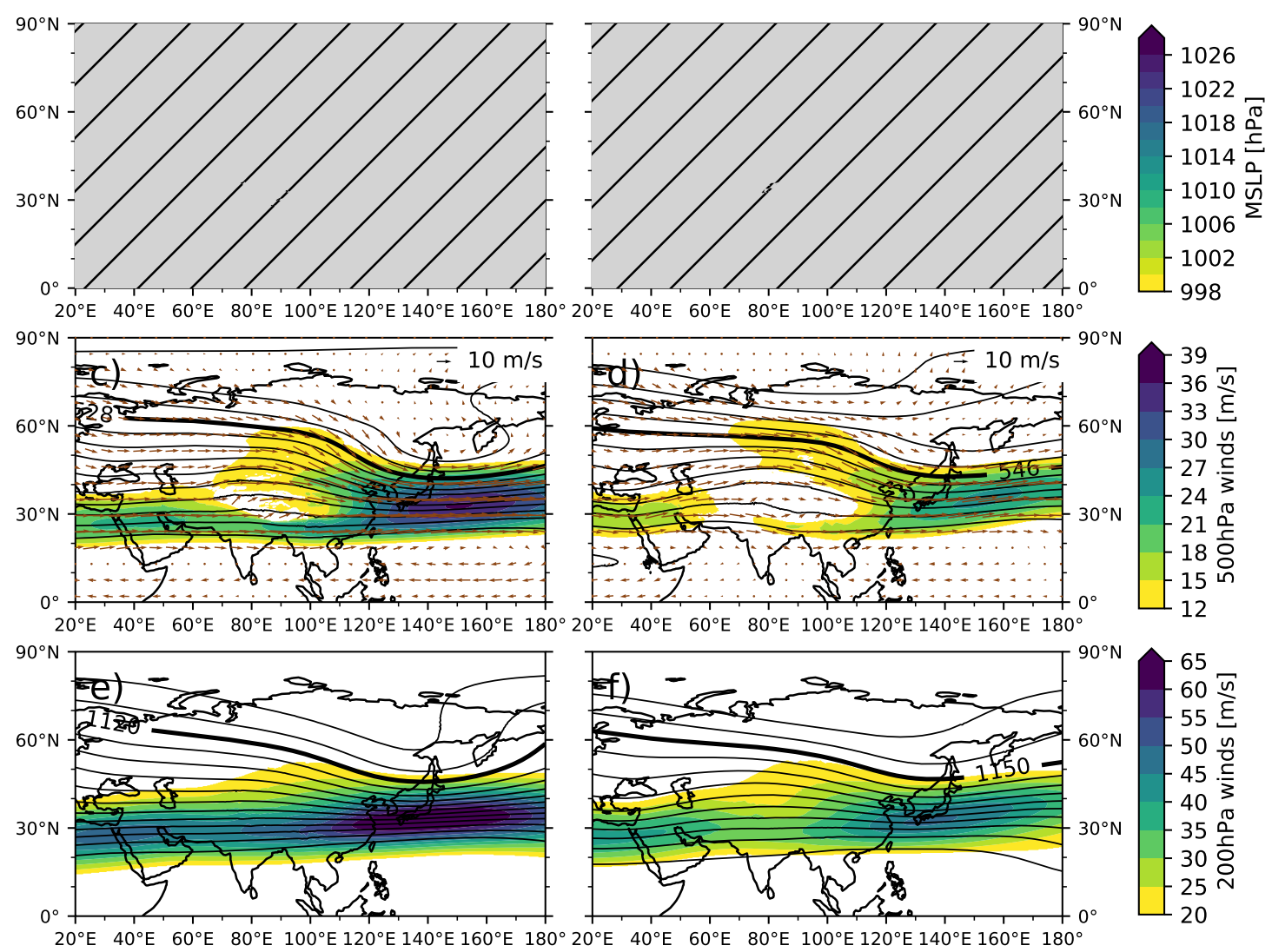

Figure 3.2. The 20 year average of winter (DJF) and spring (MAM) circulation from ERA5. (a) Winter and (b) spring MSLP and 850hPa winds climatology. (c) Winter and (b) spring 500hPa geopotential height and winds. (e) winter and (f) spring 200hPa geopotential height and wind speed.

The EAWM is primarily driven by the temperature contrast between the relatively cold Eurasian continent and warm North Pacific Ocean. The TP also plays an important role in strengthening the EAWM (Tang et al. 2013). The high altitude and excessive snow cover of the TP amplifies the land-sea temperature contrast, and second the topography forces the subtropical westerly jet to follow along both southern and northern margins of the Tibetan Plateau (Tada et al. 2016). It is the northern branch that gives rise to the strenghtend northwesterly of the EAWM.

The EAWM is also influenced by large scale climatic factors, in particular previous studies have shown that the Arctic Oscillation (AO) can have a significant impact on the EAWM (Park et al. 2011; Wu and Wang 2002). Most interesting in this context is the out-of-phase correlation between winter $\mathrm{AO}$ and dust storm frequency reported by privous studies (Gong et al. 2006a; Liu et al. 2018; Mao et al. 2011). The AO is defined as the leading Empirical orthogonal functions (EOF) of the anomalies of $1000 \mathrm{hPa}$ geopotential height poleward of $20^{\circ} \mathrm{N}$ (Thompson and Wallace 1998). In its structure, it resembles the North Atlantic Oscillation (NAO) except being more zonally symmetric as shown in Figure 3.3. A positive phase of the winter $\mathrm{AO}$ is associated with positive winter surface air temperature (SAT) anomalies over high latitude Eurasia, with negative SAT anomalies over Greenland. Cold events are also found to be more frequent over East Asia during negative AO conditions (He et al. 2017). Wu and Wang (2002) examined how the AO influence the 


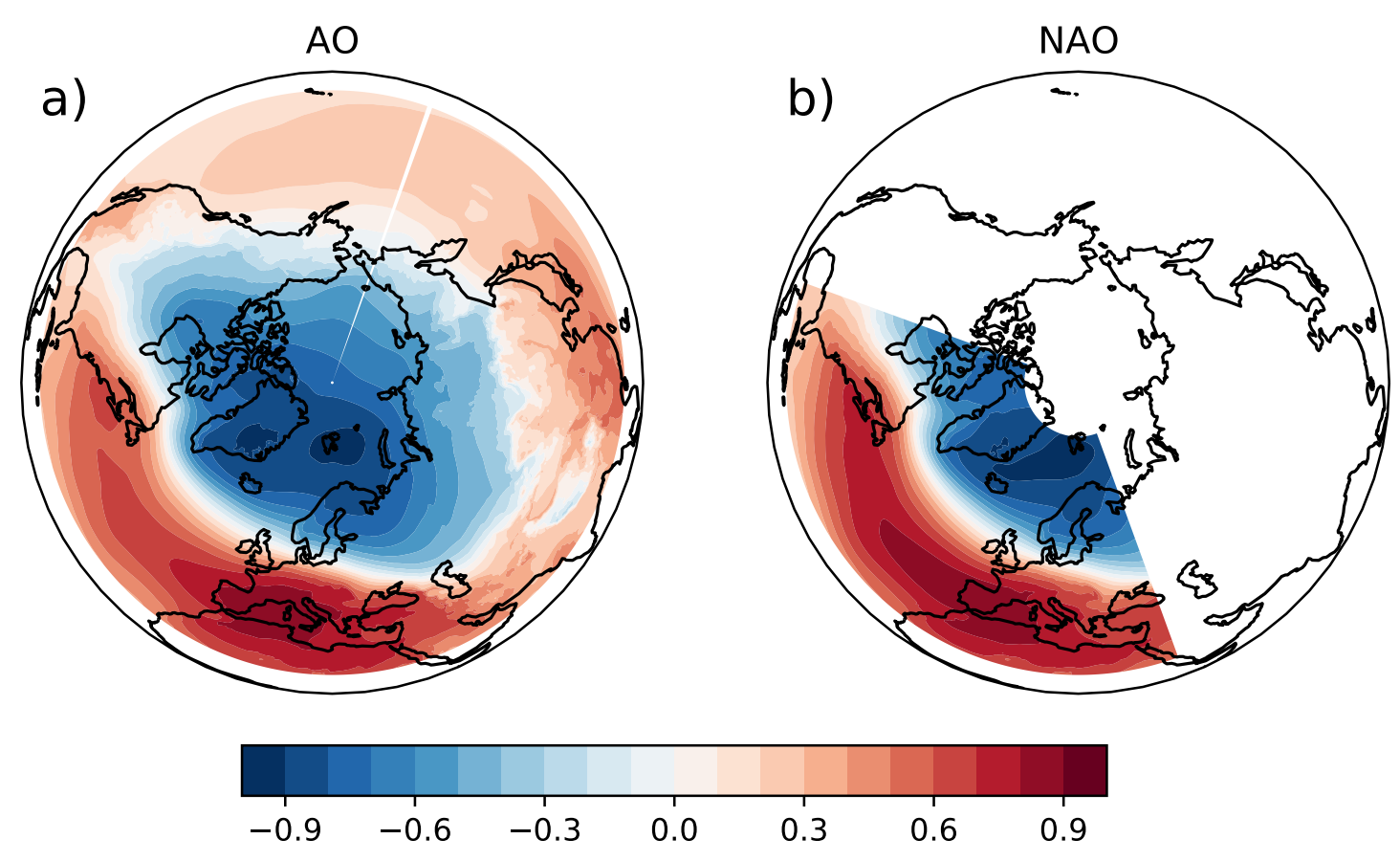

Figure 3.3. The spatial correlation of the leading EOF of $1000 \mathrm{hPa}$ geopotential height (a) representing the AO. (b) spatial correlation of the leading EOF of SLP anomalies over the Atlantic sector, $20^{\circ}-80^{\circ} \mathrm{N}, 90^{\circ} \mathrm{W}-40^{\circ}$, representing the $\mathrm{NAO}$.

EAWM and found that the AO directly influences SAT, MSLP and the mid-level EAT rather than directly impacting the $\mathrm{SH}$.

Figure 3.4 shows winter and spring composite anomalies of strong - weak winter monsoon years. The strenght of the EAWM is calculated according to the MO index, defined as the difference in winter mean sea level pressure (MSLP) between two grid points of $\left(105^{\circ} \mathrm{E}\right.$, $\left.52.5^{\circ} \mathrm{N}\right)$ near Irkutsk and $\left(145^{\circ} \mathrm{E}, 43.75^{\circ} \mathrm{N}\right)$ near Nemuro and the AO. In the negative AO winters there are large positive MSLP anomalies over the arctic region with anti-cyclonic circulation anomalies around the Barent Sea, while in the strong EAWM years the positive pressure anomalies are primarily confined to central Siberia. In the $500 \mathrm{hPa}$ level composite shown in Figure 3.5; the negative geopotential anomalies have a centre over eastern China and the Korean peninsula during strong EAWM years, compared to the negative $\mathrm{AO}$ years where the centre is located over the Mongolian plateau. More importantly, the negative geopotential anomalies persist into the following spring (Figure 3.5 $\mathrm{d})$. Liu et al. (2018) proposed that during negative $\mathrm{AO}$ winters, northeasterly wind anomalies brings cold arctic air into central Siberia cooling the land surface. Further, the anomalous cold surface conditions initiate positive snow-albedo and cloud albedo feedbacks that lasts into the following spring.

In the recent decades, there have been observed a large decrease in the number of dust storm which has been hypothesised to be a consequence of arctic amplification resulting in a weakened temperature gradient (Liu et al. 2020). 

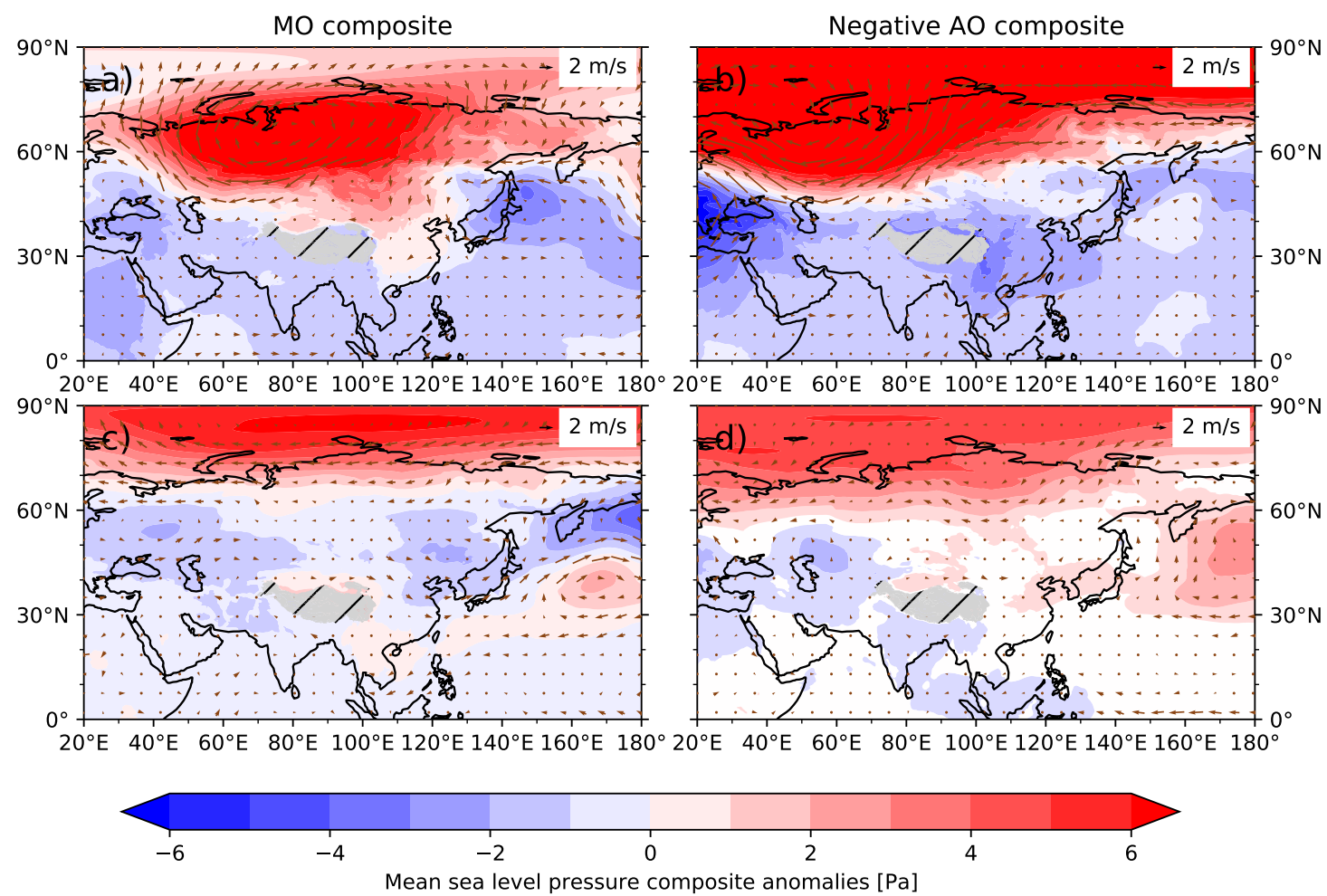

Figure 3.4. Circulation composite anomalies of $850 \mathrm{hPa}$ winds (vectors, unit: $\mathrm{m} / \mathrm{s}$ ) and mean sea level pressure for strong (colored, unit: $\mathrm{Pa}$ ) - weak winter monsoon years and negative - positive winter AO. (a) and (b) is the DJF anomalies and (c) - (d) is MAM anomalies in the following spring

\subsection{The Chinese Loess Plateau as a hotspot for East Asian dust deposition}

CLP is a hotspot of the deposition of East Asian dust. A large portion of the dust emitted from the desert regions in East Asia gets transported and deposited over the CLP during deep geological past. The CLP covers an area of around $450000 \mathrm{~km}^{2}$. In some places the thickness of the loess deposits are excess of 300m e.g. Lanzhou (see Figure 3.6) (An et al. 2014). The main accumulation area extends from ca. $100^{\circ}$ to $115^{\circ} \mathrm{E}$ and $35^{\circ}$ to $45^{\circ} \mathrm{N}$. The Liupan Mountains divide the CLP into the western and eastern parts: in the western part the basal ages of the aeolian dust (loess) deposits are much older, ca 22-25 Ma (Qiang et al. 2011) while those in the east are younger with basal ages of 11-7 Ma. The total volume of deposited dust contained at the CLP is huge, approximately 0.2 million $\mathrm{km}^{3}$, equivalent to the volume of the Scandinavian mountains (Maher 2016).

The aeolian dust record of the Loess Plateau consists of two main sequences, the Quaternary loess-palaeosol and the Neogene Red Clay sequence. The Quaternary sequence consists of alternating glacial-stage loess deposits and interglacial paleosols (Maher 2016). Underlying the Quaternary sequence is the Neogene Red Clay sequence which is of similar aeolian origin and extends the loess record into the Pliocene (2.58-5.3 $\mathrm{Ma}$ ) and Miocene (5.3-23 Ma). In contrast to the Quaternary sequence, the Red Clays are typically strongly reddened and have distinct carbonate nodule rich horizons that have a cyclic pattern. Large proportion of the Red Clay is better pedogenically developed than 


\subsection{THE CHINESE LOESS PLATEAU AS A HOTSPOT FOR EAST ASIAN DUST DEPOSITION}
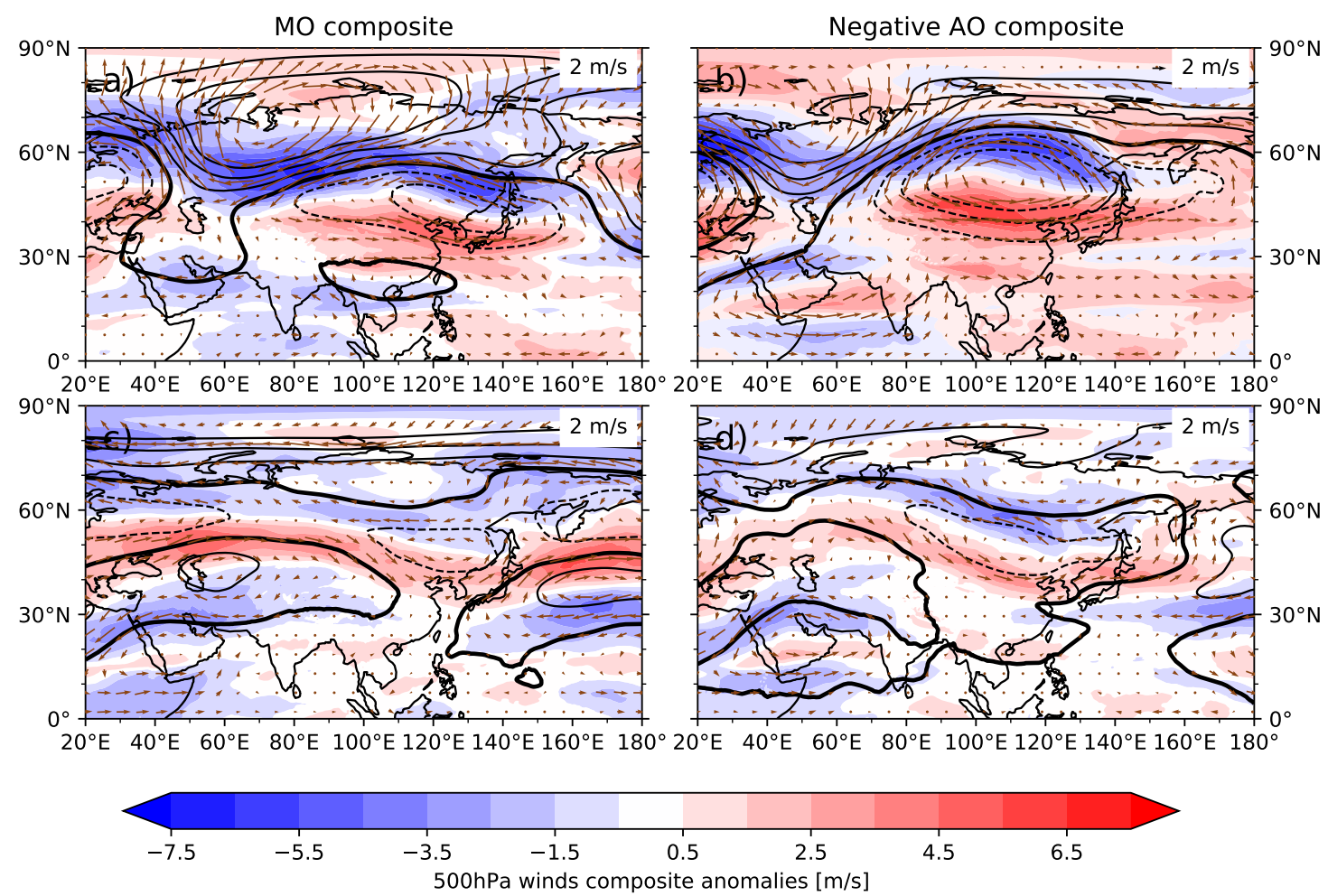

Figure 3.5. Circulation composite anomalies of 500hPa winds strength (colored, unit $\mathrm{m} / \mathrm{s}$ ), wind direction (vectors, unit $\mathrm{m} / \mathrm{s}$ ) and geopotential height (contours, unit dam, distance between contours 2 dam) for strong - weak winter monsoon years and negative - positive winter AO. (a) and $(b)$ is the DJF anomalies and (c) - (d) is MAM anomalies in the following spring. Data from ERA5.

the paleosols within the overlying Quaternary sequence, indicating that the Red Clay was formed under relative humid conditions in contrast to the colder climate during the Quaternary glacial periods (Yang and Ding 2004).

Both sequences are well sorted and mostly composed of silt-sized particles between 3 and $40 \mu \mathrm{m}$ (Maher 2016). The modal grain size varies between 4 and $8 \mu \mathrm{m}$, with the Red Clays being slightly more skewed towards the finer grainsizes (Maher 2016; Sun et al. 2002; Sun et al. 2006). Moreover, the Red Clays typically show a bimodal grain-size distribution with a higher percentage of fine fraction than seen in Quaternary loess (Sun et al. 2002). In terms of the spatial variation across the CLP the mode of the grain size distribution typically becomes coarser along the transect from south east to north west of the plateau (Ding et al. 2000). Moreover the loess mass accumulation rate (MAR) and thickness is the highest in the northern and western part of the plateau (Maher 2016).

The spatial variation in the provenance of the CLP loess has been investigated both for the Red Clay (Shang et al. 2016) and Quaternary sequence (Bird et al. 2015). Using provenance proxies such as zircon U-Pb age, Shang et al. (2016) found that Red Clays from the southern CLP (e.g., Lingtai, Lantian and Luochuan) was primarily sourced from the northern Tibetan Plateau and Taklamakan compared to eastern CLP (Baode) which in addition was likely to be from the Mu Us desert. Using similar techniques, Bird et al. (2015) found that the Quaternary CLP deposits were primarily transported from the northeastern Tibetan Plateau (TP) and Qaidam Basin. They also found distinct spatial variability among 


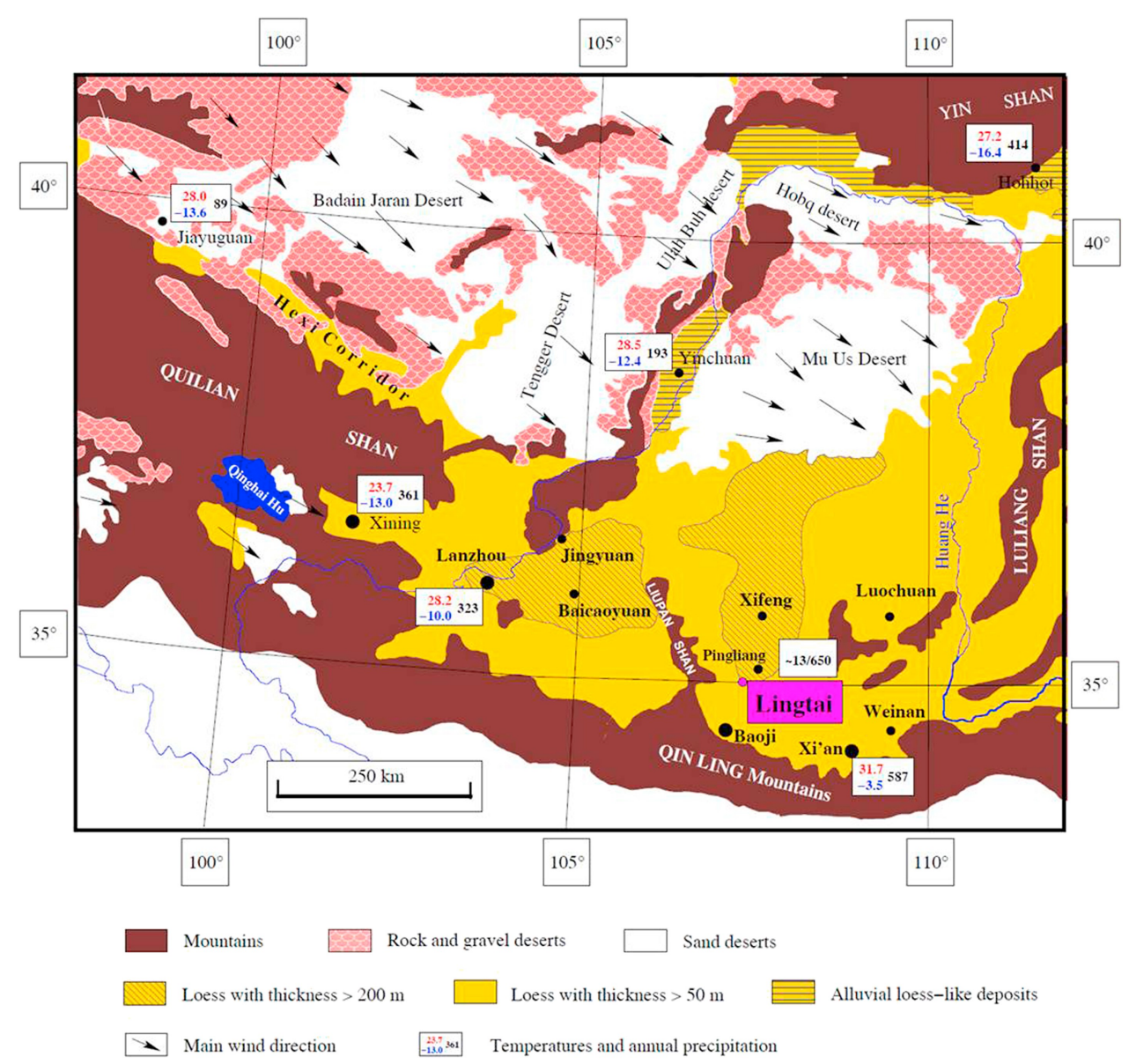

Figure 3.6. Map of the CLP, adopted from Spassov (2002).

the sites with the northeastern CLP receiving a larger contribution from the northern deserts. The challenge of determining the provenance of the loess is that the assumed source should reasonably account for all the features of the loess and not just some of the loess characteristics (Maher 2016).

Sun et al. (2003) investigated the spatial and seasonal variability of modern dust deposition over the CLP along a south north transect across the CLP. The seasonal variability in the MAR of modern dust, showed highest values in spring and lowest values in autumn and winter at all sites along the transect, but the amplitude in seasonal variability of the MAR was greatest at the northern most site. 


\section{Chapter 4}

\section{Models, input data and analysis method}

\subsection{FLEXDUST}

FLEXDUST is an offline global dust emission model developed to be used together with FLEXPART to study long-range dust transport and deposition. FLEXDUST relies on common formulations for dust emissions found in global climate models (Groot Zwaaftink et al.2016). FLEXDUST uses a bulk emission scheme as described in Section 2.2.1. The version of FLEXDUST used is the latest as of July 17th 2021. I modified the FLEXDUST source code slightly to allow the start date, duration and output directory of the simulation to be set dynamically. To avoid having to recompile the code each time I changed the starting date of the simulation.

\subsubsection{Identification of dust sources}

FLEXDUST identifies the possible dust sources as regions with a high bare soil fraction. The bare soil fraction is obtained from the satellite-based Global Land Cover map version 3, by National Mapping Organisations (GLCNMO), with a resolution of 15 arcseconds (Shirahata et al.2017). In addition to bare soil regions, FLEXDUST also considers partly vegetated areas as possible dust sources. The available soil fraction for partly vegetated areas is determined by subtracting the bare soil fraction from the vegetation cover, which is included in the ECWMF meteorological forcing. FLEXDUST considers depressions to be more favourable to dust emissions as sediments are more easily gathered there (Zender et al. 2003). Therefore FLEXDUST applies the erodibility scaling Equation (4.1) according to Ginoux et al. (2001).

$$
S=\left(\frac{z_{\max }-z_{i}}{z_{\max }-z_{\min }}\right)^{5}
$$

Here $z_{i}$ is the local elevation, $z_{\max }$ and $z_{\min }$ is the minimum and maximum elevation in a $10^{\circ} \times 10^{\circ}$ area. The erodibility $S$ is then scaled by the bare soil fraction to get the erodible soil fraction. The erodible soil fraction over East Asia is shown in Figure 4.1. 


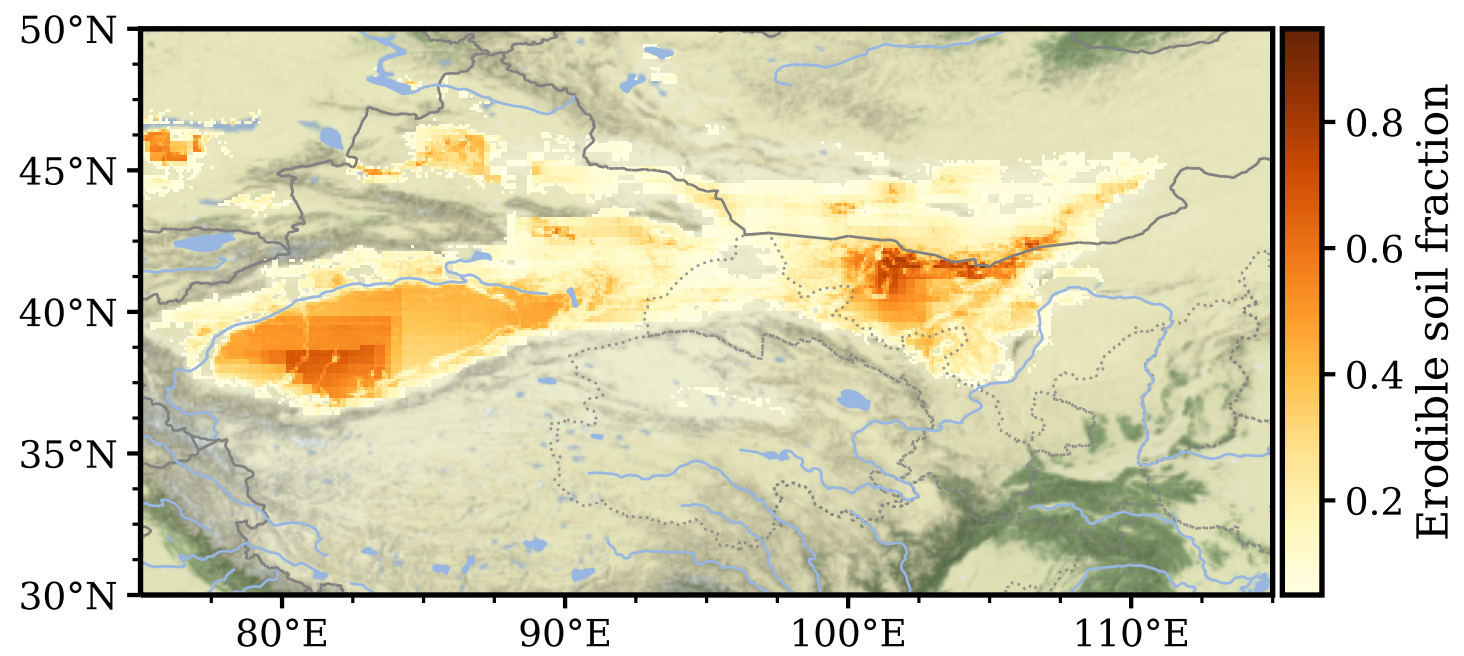

Figure 4.1. The erodible soil fraction from FLEXDUST over East Asia

\subsubsection{Dust mobilisation threshold}

The threshold friction velocity follows the idealised expression of Shao and $\mathrm{Lu}(2000)$ in Equation (2.2), and is determined by the $75 \mu \mathrm{m}$ particles. For regions with clay and silt present, but no sand, $10 \mu \mathrm{m}$ particles are used to determine the threshold friction velocity. The clay and silt fractions can either be obtained from ISRIC $250 \mathrm{~m}$ resolution Soil Grids dataset (Sousa et al. 2020), or using the default Global soil Data Task 2014 dataset. The effect of soil moisture on the threshold friction velocity is parametrized according to Fécan et al. (1998):

$$
\begin{cases}\frac{u_{* t w}}{u_{* t}}=1, & \text { if } w<w^{\prime} \\ \frac{u_{* t w}}{u_{* t}}=\sqrt{1+1.21\left(w-w^{\prime}\right)^{0.68},} & w \geq w^{\prime}\end{cases}
$$

Where $w$ is the volumetric water content of the soil (\%). If the soil moisture exceeds $w^{\prime}$, the capillary forces will start affecting the threshold friction velocity. Here, $w$ ' is given by Equation (4.3) and depends on the clay content $c(\%)$.

$$
w^{\prime}=0.17 c+0.0014 c^{2}
$$

The soil moisture content is retrieved from the ECWMF input fields. Furthermore, if the surface is covered by snow, dust emissions are assumed to be inhibited. Snow cover is available from the ECWMF input fields.

In partly vegetated areas, non-erodible surface elements would increase the surface roughness affecting the dust emissions. In FLEXDUST, the drag partition to non-erodible surface elements for partly vegetated areas are accounted for following the description in Zender et al. (2003), by scaling the mobilisation threshold by $f_{d}$ according to Equation (4.4),

$$
f_{d}=\left[1-\frac{\ln \left(z_{0 m} / z_{0 s}\right)}{0.35 \ln \left(0.1 / z_{0 s}\right)^{0.8}}\right]^{-1}
$$

Here $z_{0 m}$ is the roughness length of momentum transfer, and $z_{0 s}$ is the smooth roughness length which describes the roughness of a bed of potentially erodible particles without any non-erodible elements. Wind tunnel experiments have shown that:

$$
z_{0 s} \approx D / 30
$$


where $D$ is the particle diameter. In FLEXDUST it is assumed globally uniform values of $z_{0 m}=100.0 \mu \mathrm{m}$ and $z_{0 s}=33.3 \mu \mathrm{m}$.

\subsubsection{Dust flux parameterisation}

After the mobilisation threshold is calculated, the dust emission flux is derived following the paremeterisation of the vertical dust flux as described in Marticorena and Bergametti (1995):

$$
F=c \alpha \frac{\rho u_{*}^{3}}{g}\left(1-\frac{u_{* t}^{2}}{u_{*}^{2}}\right)\left(1+\frac{u_{* t}}{u_{*}}\right)
$$

where $u_{*}$ is the friction velocity, $\mathrm{c}$ is a constant scaling factor $\left(4.8 \cdot 10^{-4}\right)$ and $\alpha$ is the sand blasting efficiency:

$$
\alpha=100 \exp \left\{\left(13.4 f_{\text {clay }}-6\right) \ln 10\right\}
$$

Equation (4.7) is only valid for clay fraction $\leq 0.2$, so if the clay fraction exceed 0.2 , it is set to 0.2 (Zender et al. 2003).

The small dust particles $(<20 \mu \mathrm{m})$ has a greater potential to experience long-range transport due to their smaller settling velocities. Since FLEXDUST was developed to study long-range dust transport, the emitted dust is assumed to have a volume size distribution varying between $0.2 \mu \mathrm{m}$ and $18.2 \mu \mathrm{m}$. This size distribution is based on brittle fragmentation theory described in Kok (2011). The log-normal volume size distribution is determined according to Equation (4.8)

$$
\frac{\mathrm{d} V_{d}}{\mathrm{~d} \ln D_{d}}=\frac{D_{d}}{c_{v}}\left[1+\operatorname{erf}\left(\frac{\ln \left(D_{d} / \overline{D_{s}}\right)}{\sqrt{2} \ln \sigma_{s}}\right)\right] \exp \left[-\left(\frac{D_{d}}{\lambda}\right)^{3}\right]
$$

Where $c_{v}=12.62 \mu \mathrm{m}$ is a normalisation constant, $\overline{D_{s}}=3.4 \mu \mathrm{m}$ and $\sigma_{s}=3.0$ is the median diameter and the geometric standard deviation respectively.

\subsection{FLEXPART}

The dust transport and deposition is calculated by the FLEXible PARTicle Dispersion Model (FLEXPART) (Pisso et al. 2019). FLEXPART is an offline LPDM that has been applied to study the transport of a wide range of atmospheric tracers, e.g. mineral dust, black carbon and volcanic ash (Choi et al. 2020; Eckhardt et al. 2008; Groot Zwaaftink et al. 2016). The version of FLEXPART used is 10.4 and includes the improved wet deposition scheme based on cloud information from the ECWMF input fields (Grythe et al. 2017).

FLEXPART calculates trajectories for a large number of computational particles (from here on referred to as particles and not be confused with real dust particles) that move according to the wind-fields resolved in the meteorological forcing with parameterizations of the turbulent motions, subgrid-scale convection, and gravitational settling imposed on the trajectories. Each particle represents a dust-aerosol population with a log-normal mass size distribution with a specified density and mean particle diameter. In addition, ice nucleation efficiency, $I N_{\text {eff }}$, cloud condensation nuclei efficiency $C C N_{\text {eff }}$ and efficiency of below cloud scavenging by rain $C_{\text {rain }}$ and snow $C_{\text {snow }}$, can be assigned to the particle regulating the strength of the wet deposition in the model. 
FLEXPART can be either run forward in time from the source to the receptor or backwards from the receptor to the source. The main difference between forward and backward simulations lies in how the emission strength is constrained. In a forward simulation, the particles are released at the source. The emitted mass which the particles carry is defined before the particle release, directly yielding the concentration and deposition on a regular longitude-latitude grid at each time step. However, in a backward simulation, the particle release happens at the receptor, and the emission strength is unknown. The purpose of the particles in a backward simulation is to probe for the possible source regions and establish the emission sensitivity, i.e. how sensitive the deposition at the receptor would be to a potential source element. For a more in-depth derivation of source receptor relationships within the framework of LPDM see Appendix B. The final output corresponds to a distribution of possible source areas at each time step. The emission sensitivity is constructed such that when multiplied by the emission flux with units $\mathrm{kg} \mathrm{m}^{-3} \mathrm{~s}^{-1}$ would produce a map of how much each source element is contributing to the concentration or deposition at the receptor. In a backward simulation, concentration, wet and dry deposition must be obtained through separate simulations as the particle release is set up differently depending on the configuration.

\subsubsection{Dry deposition}

In FLEXPART, the dry deposition is represented by a dry deposition velocity $v_{d}(z)$, and when multiplied with the concentration at a specified height, yields the deposition flux. FLEXPART includes both a dry deposition scheme for particulate matter as well as gasses and is calculated based on a two-layer resistance model (Stohl et al. 2005).

In backward mode, dry deposition is calculated at the start of the simulation by releasing the particles in a shallow layer close to the ground. This layer corresponds to the layer in which particles in forward mode would be subjected to dry deposition, and is by default is set to $30 \mathrm{~m}$. The "mass" of the particles are then scaled by the deposition velocity and tracked backwards in time as in regular backward simulation (Eckhardt et al. 2017).

\subsubsection{Wet deposition}

The wet deposition scheme in FLEXPART was recently improved in Grythe et al. (2017) to take advantage of the cloud information available from the ECWMF forcing. The wet deposition scheme in FLEXPART consists of two steps. First, the particle's location in relation to the cloud is determined using the 3D specific cloud total water content (CTWC). Then based on the particle's location in relation to the cloud, the particle can either be subjected to nucleation scavenging inside the cloud or impaction scavenging below the cloud. If the particle is above the cloud, no scavenging can occur.

In backward mode, the wet deposition is calculated at the time of the particle release. Since wet deposition can occur throughout the whole atmospheric column, the particles are released over the whole atmospheric column to check if any particles are subjected to wet deposition. FLEXPART then calculates the trajectories for wet deposited particles starting at the height where the particles were scavenged, and the remaining particles are terminated. 


\section{In cloud scavenging}

The in-cloud scavenging scheme in FLEXPART is only activated for particles residing within a precipitating cloud. Precipitation does not necessarily occur over the whole grid cell in the input data. Accordingly, FLEXPART uses an empirical relation to derive the fraction of a gridcell experiencing precipitation; see Stohl et al. (2005) for details. The subgrid precipitating cloud water (PCW) is calculated according to:

$$
P C W=C T W C \frac{F}{C C}
$$

Here $\mathrm{cc}$ is the surface cloud cover, and $\mathrm{F}$ is the precipitating fraction of the gridcell.

The aerosol scavenging coefficient $\Lambda\left(\mathrm{s}^{-1}\right)$ for in cloud scavenging is given by:

$$
\Lambda=F_{n u c}(I / P W C) i c_{r}
$$

Where $F_{n u c}$ is the nucleation efficiency, I is the precipitation intensity, which is derived from the accumulated precipitation during one time interval in the ECWMF input data, and $i c_{r}$ is the cloud water replenishment rate. However, $i c_{r}$ cannot be determined from the ECWMF input data and was determined based on testing in FLEXPART and is considered a tuning parameter in the model.

In reality, $F_{n u c}$ depends on many different parameters such as aerosol size, chemical composition, temperature and cloud phase. A complete parameterization of $F_{n u c}$ in FLEXPART is currently not possible based on the limited information available in the input forcing. Still, FLEXPART can account for the fact that aerosols have different nucleation efficiency depending on whether they serve as cloud condensation nuclei $(\mathrm{CCN})$ or ice nuclei (IN).

\section{Below cloud scavenging}

Dust aerosols residing below the cloud might be scavenged by falling raindrops or snowflakes, called impaction scavenging. In FLEXPART, the probability of an aerosol being scavenged by liquid droplets is parameterised according to Laakso et al. (2003). The removal of aerosols by falling snowflakes is parameterised in FLEXPART according to Kyrö et al. (2009). The efficiency of scavenging by falling rain and snow can be adjusted in the model by changing the $C_{\text {rain }}$ and $C_{\text {snow }}$ parameter.

\subsection{Model input}

\subsection{1 flex_extract}

Both FLEXPART and FLEXDUST depend on external meteorological input data. Flex_extract is a package developed to retrieve and prepare the necessary meteorological input data from the servers of the European Centre for Medium-Range Weather Forecasts (ECWMF) (Tipka et al.2020). flex_extract version was 7.0.4 used to retrieve the necessary input fields from the ERA5 reanalysis at a 3hourly temporal resolution and $0.3^{\circ} \times 0.3^{\circ}$ spatial resolution for over the subdomain of East Asia from March until May for the years 
from 1999 to 2019. The retrieval process can be slow, as, in addition to the large amount of data that needs to be downloaded, the request also has to be processed by the ECWMF servers.

\subsubsection{ERA5}

ERA5 is the latest reanalysis produced by the ECWMF. The ERA5 reanalysis assimilates large amounts of observational data to provide the best estimate of the state of the atmosphere extending back to 1979 (Hersbach et al.2020). Compared to its predecessor ERA-Interim, ERA5 offers a higher spatial resolution of $0.25^{\circ} \times 0.25^{\circ}$, up to hourly temporal resolution, and is based on a more recent version of the Integrated Forecast System (IFS).

\subsection{Model setup}

In this thesis, the dust emission model FLEXDUST and the LPDM FLEXPART was used to simulate the springtime dust deposition between 1999 and 2019 at 7 sites across the CLP.

Groot Zwaaftink et al. (2016) used the same two models to study the transport and deposition of high latitude dust, where they simulated the dust transport from a sourceoriented viewpoint, following the dust from the source to deposition. Here, the dust transport and deposition are simulated from a receptor viewpoint. All the dust deposited at the receptor location is tracked backwards in time to probe for possible sources. The emission field produced by FLEXDUST then constrains the distribution of possible source regions. The flow chart in Figure 4.2 summarises the modelling workflow. The receptor oriented backward approach was chosen over the forward approach due to being more computationally efficient when the number of source elements greatly exceeds the number of receptors. In addition, the backward approach allows for dealing with point receptors naturally (Seibert and Frank 2004). The backward approach also makes it possible to determine exactly the source regions that contribute to deposition at the receptor, namely the sites over CLP.

The simulations have been conducted on the Saga high performance computing cluster operated by the Norwegian high performance computing centre, Sigma2. For storage and postanalysis, the data is transferred to the National Infrastructure for Research Data (NIRD) computing infrastructure.

FLEXPART and FLEXDUST were run at a 3hourly temporal resolution, with $0.1^{\circ} \times 0.1^{\circ}$ output grid and driven by ERA5 meteorological forcing data. As described in Chapter 3 dust events are primarily occurring in spring. Therefore, I only simulated the spring months from March until May. I ran the models over a 20 year period to provide insight on the interannual variation in the dust source, transport and deposition to the CLP.

\subsubsection{FLEXPART}

To make it possible to multiply the emission sensitivity with the dust emission flux, FLEXPART has to be set up such that particle release at each time step is kept separate in the output. Therefore, I specified a new particle release in the RELEASES file for each forward time step. I limited the length of the trajectory to five days by specifying a time 


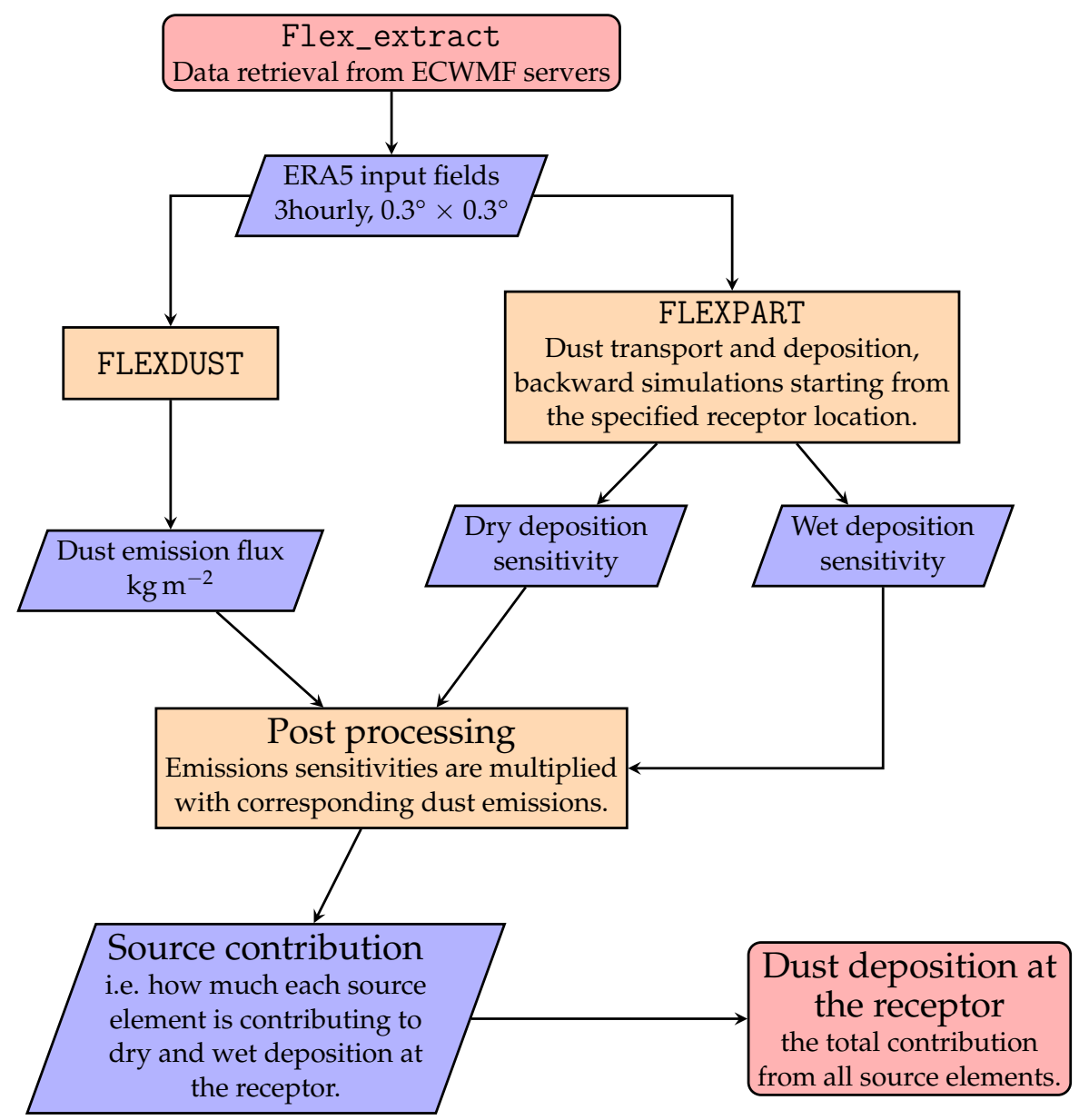

Figure 4.2. Flow chart showing the workflow for the modelling analysis.

limit in the NAGECLASSES file. The FLEXPART output file then contains two temporal dimensions, one time dimension going from the last date backwards to the start date of the simulation and the pointspec dimension representing each release. To allow for all the backward trajectories to complete, I let the last release happen five days after the starting date of the simulation. The particle release is specified at 3rd hourly intervals. The number of particles released in each release is 50000 particles and 200000 particles for dry and wet deposition simulations, respectively. More particles are needed in the wet deposition simulation to achieve statically robust results due to how the particle release is set up. A copy of the exact FLEXPART and FLEXDUST source code used can be accessed at $10.5281 /$ zenodo.5128338.

To provide insight on the spatial variation in the dust source and transport to the CLP, seven sites distributed across the CLP were selected as receptor points in FLEXPART (Figure 4.3), namely: SACOL, Shapotou and Yinchuan in the north-west, Lingtai, Luochuan and Lantian in the south-east and Baode in the north-east. The exact coordinates of the receptor locations are listed in Table A.1.

Moreover, two particle size bins, $1.7 \mu \mathrm{m}-2.5 \mu \mathrm{m}$ representing clay particles and $15 \mu \mathrm{m}-$ $20 \mu \mathrm{m}$ size bin representing silt sized particles were used in the FLEXPART simulations, respectively. The two particle size bins do not only differ in size, but they also have different assumptions on the $C C N_{e f f}$. The parameters for the two particle species are 


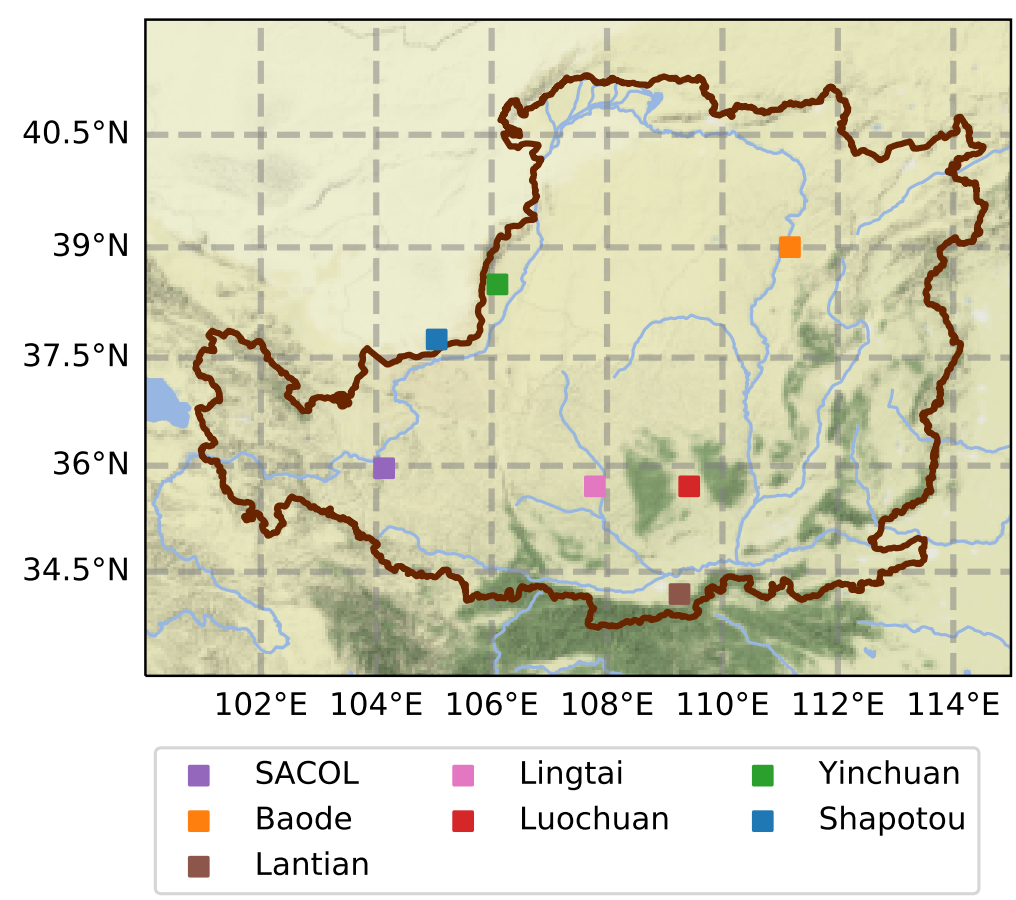

Figure 4.3. Map of the receptor points, specified in the FLEXPART simulations

listed in Table 4.1. I included only two size bins as a trade-off to allow running multiple years and keep the computational demand reasonable.

Table 4.1. FLEXPART species parameters for "clay" and "silt" particle size bin

\begin{tabular}{lll}
\hline & Clay & Silt \\
\hline PCRAIN_AERO & 1.00 & 1.00 \\
PCSNOW_AERO & 1.00 & 1.00 \\
, PCC_AERO & $0.45($ Groot Zwaaftink et al. 2016) & 0.90 (Groot Zwaaftink et al. 2016) \\
PIN_AERO & $0.10($ Groot Zwaaftink et al. 2016) & $0.10($ Groot Zwaaftink et al. 2016) \\
PDENSITY & $2500.0 \mathrm{~kg} \mathrm{~m}^{-3}$ & $2500.0 \mathrm{~kg} \mathrm{~m}^{-3}$ \\
PDQUER & $2.057 \times 10^{-6} \mathrm{~m}$ & $17.32 \times 10^{-6} \mathrm{~m}$ \\
PDSIGMA & 1.21 & 1.15 \\
\hline
\end{tabular}

Given that all the FLEXPART simulations are independent of each other, it is easy to take advantage of the parallel computing capabilities of Saga. By splitting the simulation into several independent FLEXPART simulations, each covering one month, the simulation could be run across multiple CPUs simultaneously. All in all, this added up to a total of 1680 individual FLEXPART simulations. To help set up the FLEXPART simulations, a python scrip $1^{1}$ was developed.

\footnotetext{
${ }^{1}$ https://github.com/Ovewh/FLEXPART-script
} 


\subsubsection{FLEXDUST}

Compared to FLEXPART, FLEXDUST is much less demanding to run. The FLEXDUST simulation was split into sub simulations covering one spring, and the whole simulation took a few hours to complete on the supercomputer. The soil texture dataset used was the ISRIC 250m Soil grids dataset. The ISRIC dataset was proven based on model sensitivity experiments to represent the East Asian dust sources better than the default soil texture dataset used in FLEXDUST.

\subsubsection{Model validation}

There are very few published observations of dust deposition fluxes that separate both dry and wet deposition over East Asia and have a sufficient temporal resolution to evaluate the performance of FLEXPART/FLEXDUST. Osada et al. (2014) published an observation data set of monthly dry and wet deposition fluxes from 6 locations by the coast of Japan, covering the time period from November 2008 until December 2010. They used a 4-stage filtration approach to separate the deposited dust into four size bins $>20 \mu \mathrm{m}$, $20 \mu \mathrm{m}-10 \mu \mathrm{m}, 10 \mu \mathrm{m}-5 \mu \mathrm{m}$ and $5 \mu \mathrm{m}-1 \mu \mathrm{m}$. The four particle size bins were simulated separately in FLEXPART and assumed to follow the same size distribution as the main model experiment. The Hedo, Fukuoka, Tottori and Toyama sites were selected as receptor points for FLEXPART simulations in this study.

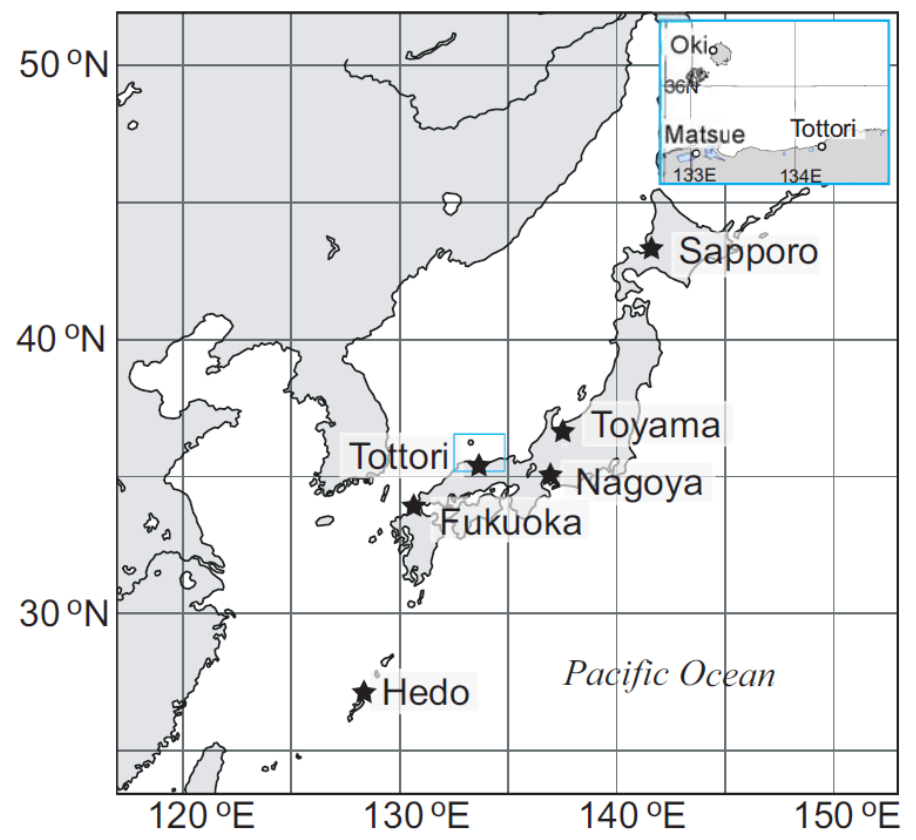

Figure 4.4. Map of the locations where dust deposition was sampled (Osada et al. 2014)

\subsubsection{Model sensitivity experiments}

To better evaluate the sensitivity of the model results to the uncertainties in the input data and model parameters. Four sensitivity experiments were conducted to investigate the 
impact of (1) different meterological forcing data, (2) varying particle density, (3) choice of soil texture data and (4) below cloud scavenging. All the sensitivity experiments were done for 2019 except experiment (1), which was done for 2015. Except for the parameters listed in Section 4.4.4, all other parameters are equal to the main model experiment described previously. The control run, which the sensitivity simulations are compared to is the main model experiment.

Table 4.2. The model sensitivity experiments performed in this study

\begin{tabular}{lllll}
\hline Sensitivity experiment & Soil map & Forcing & Below cloud scavenging & Particle density \\
\hline Model forcing & ISRIC & ERA-Interim & Yes & $2500 \mathrm{~kg} \mathrm{~cm}^{-3}$ \\
Particle density & ISRIC & ERA5 & Yes & $2200 \mathrm{~kg} \mathrm{~cm}^{-3}-2800 \mathrm{~kg} \mathrm{~cm}^{-3}$ \\
Soil texture & Default & ERA5 & Yes & $2500 \mathrm{~kg} \mathrm{~cm}^{-3}$ \\
Cloud scavenging & ISRIC & ERA5 & No & $2500 \mathrm{~kg} \mathrm{~cm}^{-3}$ \\
\hline
\end{tabular}

\subsection{Analysis tools}

The analysis and postprocessing of the model output was achieved using a handful of Python libraries. More details on the specific software used and developed to facilitate the analysis are provided in Appendix D.

\subsubsection{Post-processing of model output}

The FLEXDUST emission flux has to be matched with the corresponding emission sensitivity from FLEXPART to calculate the source contribution and deposition at the receptor. However, there is currently no software available that can match output from a backward simulation with an emission inventory. Therefore, Python code was developed to combine the FLEXPART and FLEXDUST output automatically. FLEXPART output data was reshaped to a format that would easily match with FLEXDUST.

After the FLEXPART and FLEXDUST outputs have been combined, the final step is to scale the source contribution by the fraction of the size distribution corresponding to the specific size bin listed in Table 4.3. The assumed size distribution in Table 4.3 is the same size distribution used in FLEXDUST to generate RELEASE files for forward FLEXPART simulation and follow the log-normal distribution of Equation (4.8),

\section{Snakemake workflow}

To manage the considerable amount of data produced by FLEXPART, a snakemake workflow was implemented. Snakemake is a workflow management system (Mölder et al. 2021) that can keep track of all dependencies and steps required to generate a specific result. This means that snakemake would notice changes made to a file at the beginning of the workflow and regenerate all the results depending on that file. Snakemake also keeps track of which steps of the analysis have been completed, so if anything happens while the analysis is running, it does not have to start from the beginning. Snakemake works by defining a sequence of rules that takes predefined input files based on a specified filename pattern. Based on this filename pattern snakemake knows the sequence of rules 
Table 4.3. Assumed size distribution of emitted dust in FLEXPDUST

\begin{tabular}{ll}
\hline bin width $(\mu \mathrm{m})$ & fraction \\
\hline $0.02-0.1$ & 0.0030 \\
$0.1-0.5$ & 0.0163 \\
$0.5-1.0$ & 0.0327 \\
$1.0-1.7$ & 0.0556 \\
$1.7-2.5$ & 0.0820 \\
$2.5-5.0$ & 0.1605 \\
$5.0-7.5$ & 0.2209 \\
$7.5-10$ & 0.2425 \\
$10-15$ & 0.1516 \\
$15-20$ & 0.0349
\end{tabular}

that generates the desired output file. Figure 4.5 show an example of how this sequence of rules might look like.

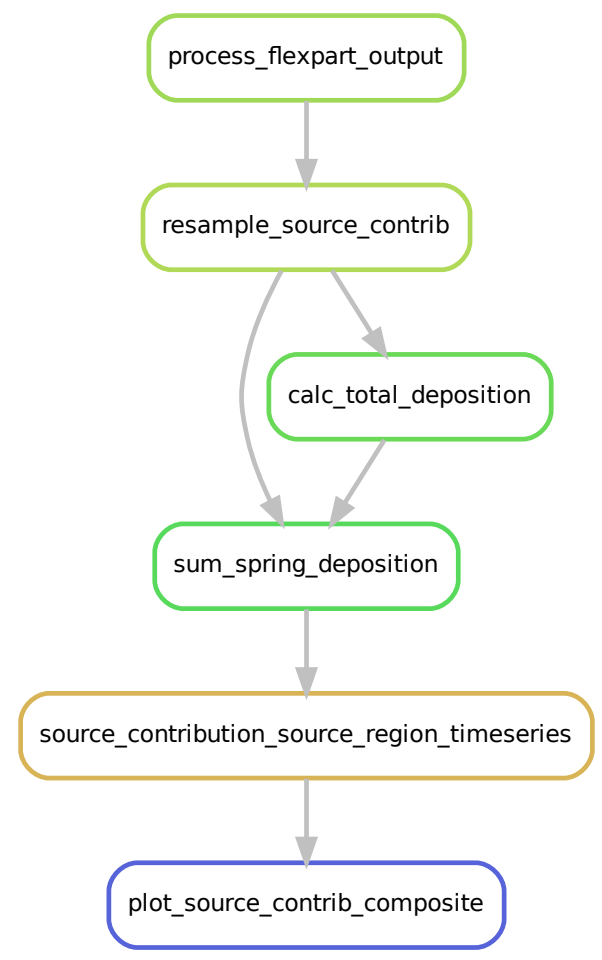

Figure 4.5. Example rulegraph for generating Figure 5.22 and Figure 5.23

\subsubsection{FLEXPART trajectory analysis}

In addition to emission sensitivity, FLEXPART can also output information about the particle trajectories. Including calculating the centroid trajectory and cluster trajectories of the particle cloud. Unfortunately, the clusters produced by FLEXPART are not very informative, as the clustering routine only considers the position of the particles at the output time and does not consider which cluster it was previously assigned to. However, 
the centroid trajectory can still provide insight into the dust transport paths. The original idea was to take the centroid trajectories of every particle release and then cluster the centroid trajectories to obtain a set of trajectories representing the main dust transport pathways. This procedure is described in more detail in Appendix C. However, this did not work out for two reasons, (1) it was challenging to define a suitable distance metric, and (2) the centroid trajectories are an average of both dust loading and non-dust loading trajectories, thus smooths out the dust transport paths. Therefore, making a clever selection and averaging of the trajectories proved to be more informative.

The current trajectory analysis was done by first filtering out the non-dust centroid trajectories based on whether dust was deposited at the receptor at the time of arrival. Then all the dust loading trajectories were given a weight based on their dust loading and averaged to make one weighted average centroid trajectory. This averaged centroid dust loading trajectory was then applied to diagnose the averaged paths of dust transport to the receptors.

\subsubsection{Statistical methods}

\section{Pearson's correlation}

Pearson's correlation was used to examine the potential connection of climatic factors with the interannual variability of the dust cycle over the CLP. The interannual correlations were calculated between spring dust emissions, wet and dry deposition simulated by FLEXDUST and FLEXPART and several climatic variables characterizing different aspects of large-scale circulation. The following climate indices were used: AO, NAO, the southnorth temperature gradient across East Asia (refered to as he EATG), EAWMI, SH and MO. The definition of each of the indices is listed in Table 4.4. The indices were calculated based on monthly ERA5 data for both winter and spring to investigate the influence of winter conditions on the spring EADC. The decadal trends were removed from the time series before correlation analysis to avoid any influence of low-frequency variations.

\section{Composite analysis}

Composite analysis is a useful method for identifying climatic features that are difficult to observe in its totally. A composite analysis involves collecting several cases of a given situation, e.g. years with strong deposition, and creating an average representation of meteorological conditions in that given situation, e.g. surface winds during strong deposition years. The change can then be enlarged further by subtracting the weak composite from the strong composite to show the composite anomalies. In the composite analysis, each year is ranked based on the spring deposition rate, and then the four strongest and weakest years are composited. It should be noted that the frequency of extreme years varied greatly among the sites over this relatively short period. Therefore, it did not make sense to use a more objective criteria for selecting the strong and weak deposition years, e.g. standard deviation. 
Table 4.4. Definition of the climatic indices used in the correlation analysis.

\begin{tabular}{|c|c|}
\hline Indices & Definition \\
\hline $\begin{array}{c}\text { Arctic Oscillation (AO) } \\
\text { (Thompson and Wallace } \\
\text { 1998) }\end{array}$ & $\begin{array}{l}\text { Leading EOF of the } 1000 \mathrm{hPa} \text { geopotential height anomalies poleward of } \\
\qquad 20^{\circ} \mathrm{N}\end{array}$ \\
\hline $\begin{array}{c}\text { East Asian Winter } \\
\text { Monsoon index (EAWMI) } \\
\text { (Jhun and Lee 2004) }\end{array}$ & $\begin{array}{l}\text { Difference in area averaged } 300 \mathrm{hPa} \text { zonal winds } \\
U_{300}\left(27.5^{\circ}-37.5^{\circ} \mathrm{N}, 110^{\circ}-170^{\circ} \mathrm{E}\right)-U_{300}\left(50^{\circ}-60^{\circ} \mathrm{N}, 80-140^{\circ} \mathrm{E}\right)\end{array}$ \\
\hline $\begin{array}{c}\text { Monsoon index (MO) } \\
\text { (Sakai and Kawamura } \\
2009 \text { ) }\end{array}$ & $\begin{array}{l}\text { Difference in mean sea level pressure (MSLP) between two grid points } \\
\left(105^{\circ} \mathrm{E}, 52.5^{\circ} \mathrm{N}\right) \text { near Irkutsk and }\left(145^{\circ} \mathrm{E}, 43.75^{\circ} \mathrm{N}\right) \text { near Nemuro. }\end{array}$ \\
\hline $\begin{array}{l}\text { Siberian High index (SHI) } \\
\text { (Wang and Chen 2010) }\end{array}$ & Area averaged $\operatorname{MSLP}\left(40^{\circ}-65^{\circ} \mathrm{N}, 80^{\circ}-120^{\circ} \mathrm{E}\right)$ \\
\hline $\begin{array}{l}\text { North Atlantic Oscillation } \\
\text { (NAO) }\end{array}$ & Leading EOF of MSLP anomalies of the cutout $\left(40^{\circ}-90^{\circ} \mathrm{N}, 20^{\circ}-80^{\circ} \mathrm{E}\right)$ \\
\hline $\begin{array}{l}\text { East Asian temperature } \\
\text { gradient (EATG) (Liu et al. } \\
\text { 2020) }\end{array}$ & $\begin{array}{c}\text { Gradient in zonally averaged temperature between } 30^{\circ}-120^{\circ} \mathrm{E} \text {, and taken } \\
\text { the averaged gradient between } 40^{\circ} \text { and } 50^{\circ} \mathrm{N}\end{array}$ \\
\hline $\begin{array}{c}\text { Asian polar vortex } \\
\text { intensity index (APVI) (Yu } \\
\text { and Sun } 2021)\end{array}$ & Area averaged geopotential height anomalies over $45^{\circ}-90^{\circ} \mathrm{N}, 60^{\circ}-150^{\circ} \mathrm{E}$ \\
\hline
\end{tabular}

\section{Empirical orthogonal function}

Empirical orthogonal functions (EOF) analysis is often used in climate studies to identify the regions with the largest variability and study how they change with time. Given a space-time field EOF analysis finds a set of orthogonal (independent) spatial patterns along associated with a time series of Principal components (PCs) (Hannachi et al. 2007). The EOF analysis finds a new set of variables that capture most of the observed variance from the data through linear combinations of the original variables. However, due to sampling issues, the eigenvalues of PCs might be mixed. North et al. (1982) provides a rule of thumb for determining whether the eigenvalues are distinct. North et al. (1982) states that if the neighbouring PCs lays within the typical error of the respective PCs $\lambda$, the two EOFs might be mixed in their signal, thus not representing true patterns. The AO is an example of a climatic feature that was first described based on an EOF analysis (Thompson and Wallace 1998). Here the EOF analysis was done using eofs python package (Dawson 2016).

were 


\section{Chapter 5}

\section{Results}

In this chapter, the results from the FLEXPART and FLEXDUST model simulations are presented. The results from the model sensitivity experiments and validation are presented first in Section 5.1 and Section 5.2. The rest of this chapter will show the results of the 20-year FLEXPART/FLEXDUST simulation of springtime deposition over the CLP. In Section 5.3 the climatology of the dust cycle over the CLP is investigated. Then the inter-annual variations in the dust cycle over the CLP and its relation to the large scale circulation are examined in Section 5.4.

\subsection{Model sensitivity to input data and parameters}

\subsubsection{Forcing data}
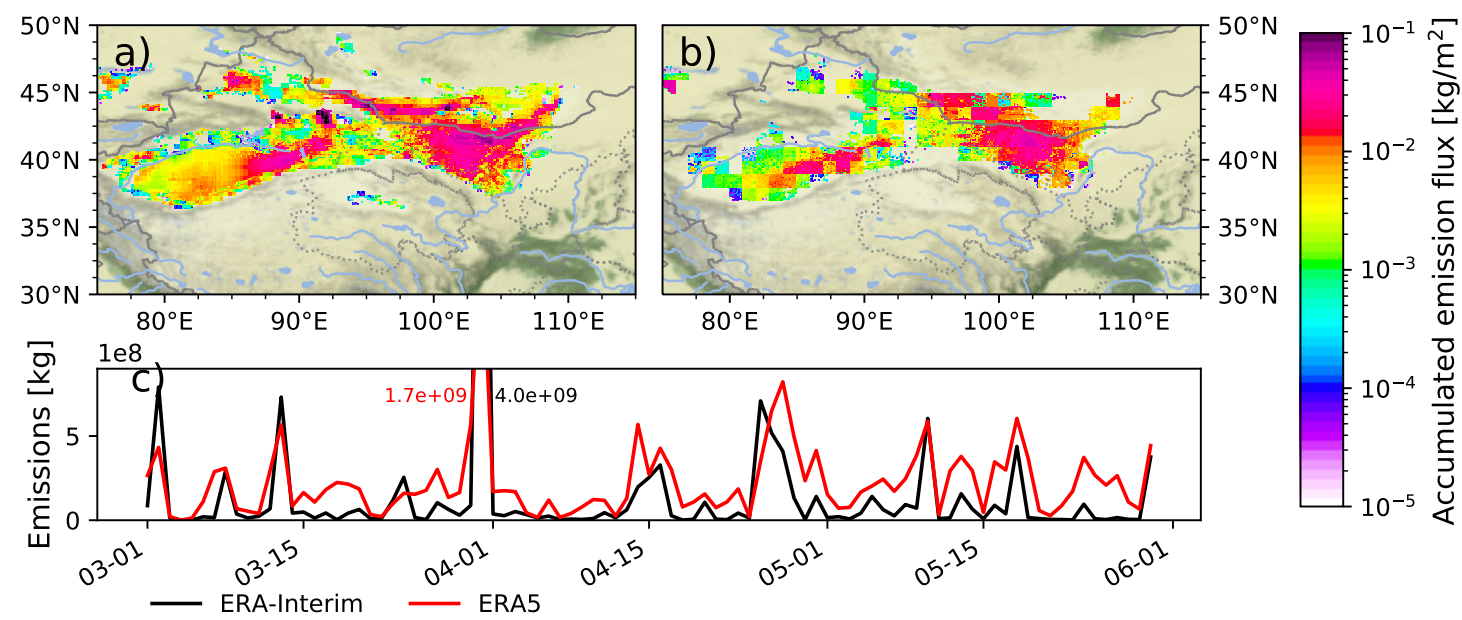

Figure 5.1. Accumulated emission flux $\left(\mathrm{kg} \mathrm{m}^{-2}\right)$ simulated by FLEXDUST for the spring of 2015. (a) ERA5 $0.3^{\circ}$ resolution and (b) ERA-Interim $1^{\circ}$ resolution. (c) The time series of daily accumulated emissions ERA-interim (red) and ERA-5 (black)

Figure 5.1 shows the dust emission flux simulated by FLEXDUST with (a) ERA5 and (b) ERA-Interim. The impact of the coarser resolution of ERA-Interim is noticeable. 
Modelled dust emissions over the Taklamakan are particularly sensitive to the spatial resolution of the forcing. Another feature missing in the ERA-Interim simulation is the boundary between Mongolia and the deserts northwest of the CLP. There are also major differences in the temporal evolution of simulated dust emissions (Figure 5.1k) both in the magnitude and frequency. The ERA-Interim simulation also exhibits unrealistic sharp boundaries between the high and low emission regions, while in ERA5 this transition is more continuous. In the ERA-Interim simulation, the most intense dust events show higher dust emissions compared to ERA5. However, for the weaker dust events, the opposite is true.
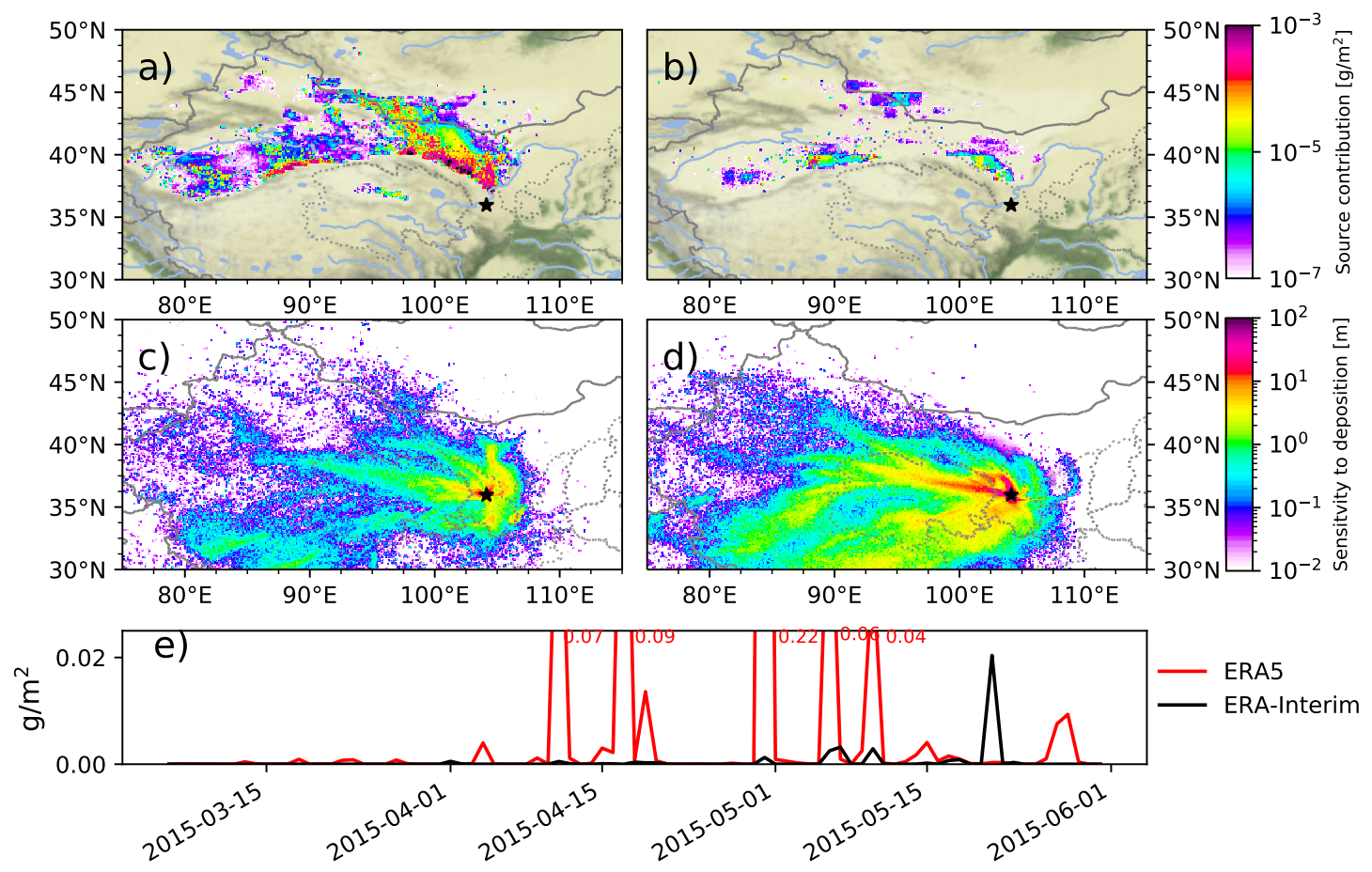

Figure 5.2. Accumulated source contribution and emission sensitivity for ERA5 (a),(c) and ERA-interim (b),(d) for total deposition of "silt" during the spring of 2015. (e) time series of daily accumulated deposition flux for ERA5 (red) and ERA-Interim (black).

The source contribution of total deposition as shown in Figure 5.2 is even more sensitive to input forcing. Because the source contribution depends on all the components of the dust cycle, the differences in the forcing are felt at each step of the modelled dust cycle, amplifying the differences between the two simulation.

\subsubsection{Soil texture data}

The dust emission scheme used in FLEXDUST assume that the sandblasting efficiency Equation (4.7) increases exponentially with $f_{\text {clay }}$ for $f_{\text {clay }} \leq 0.2$. Consequently the simulated dust emission might be sensitive to the soil texture data set used. During the process of performing these sensitivity experiments, I discovered that the original soil texture dataset had a very small clay fraction over the Taklamakan (Figure 5.3a). This resulted in FLEXDUST barely simulating any emissions from the Taklamakan desert (Figure 5.4a). 


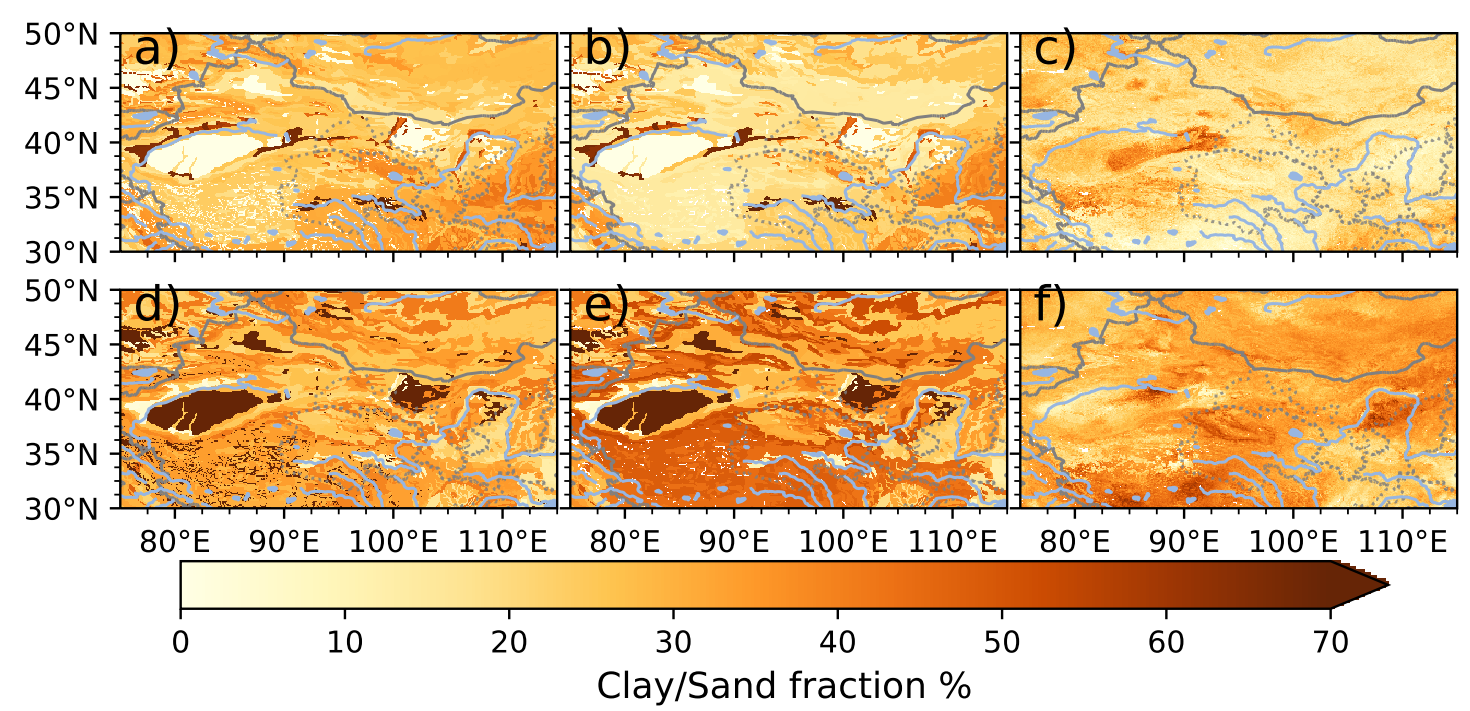

Figure 5.3. Clay and sand fraction maps from 3 different data sources: default clay (a), CLM clay (b), ISRIC clay (c), default sand (d), CLM sand (e) and ISRIC sand (f)

This bias was addressed by implementing new sand and clay maps in FLEXDUST based on the SoilGrids database developed by ISRIC (Sousa et al. 2020). The SoilGrids soil maps use state-of-the-art machine learning methods to map the spatial distribution of soil properties across the globe, providing a map of soil properties at 250 metres spatial resolution. As shown in Figure 5.3 ISRIC clay and sand fractions have a higher clay fraction over Taklamakan compared to the default soil maps. The accumulated modelled emissions for 2019 are shown in Figure 5.4. (a) using the default soil maps and (b) with new ISRIC maps. The difference between the two is noticeable, with the new ISRIC maps, Taklamakan as well as Badain Jaran Desert are now represented as a major dust source.

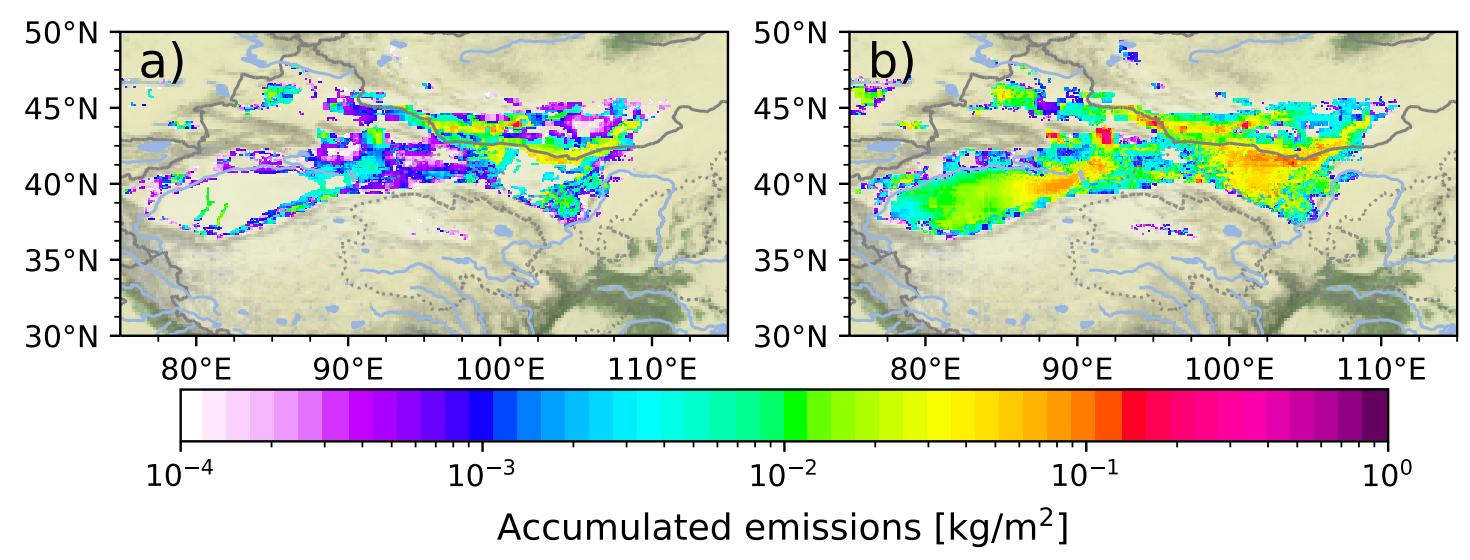

Figure 5.4. Accumulated simulated dust emissions for 2019, default soil maps (a), and ISRIC soil maps (b). 


\subsubsection{Particle density}

The density of a dust particle varies depending on the mineralogical composition. To assess how the density of the dust particle affects the long-range transport and the amount of deposited material, FLEXPART simulations with varying particle density from $2200 \mathrm{~kg} \mathrm{~cm}^{-3}$ to $2800 \mathrm{~kg} \mathrm{~cm}^{-3}$ were conducted from the SACOL site. In Figure 5.5 and Figure 5.6 the rate of dry and wet deposition are plotted for different densities and a least-squares fit is done to the data. The deposition rate increases approximately linearly with increasing particle density. The density has a bigger impact on the deposition rate of the coarse particles (Figure 5.5p, Figure 5.6), where the rate of deposition of the heaviest particle is almost twice that of the lightest particle. The fine particles only show about a $2 \%$ difference between the lightest and heaviest particles in the dry deposition rate. The wet deposition is more sensitive to the particle density than the dry deposition for both the fine and coarse particles.
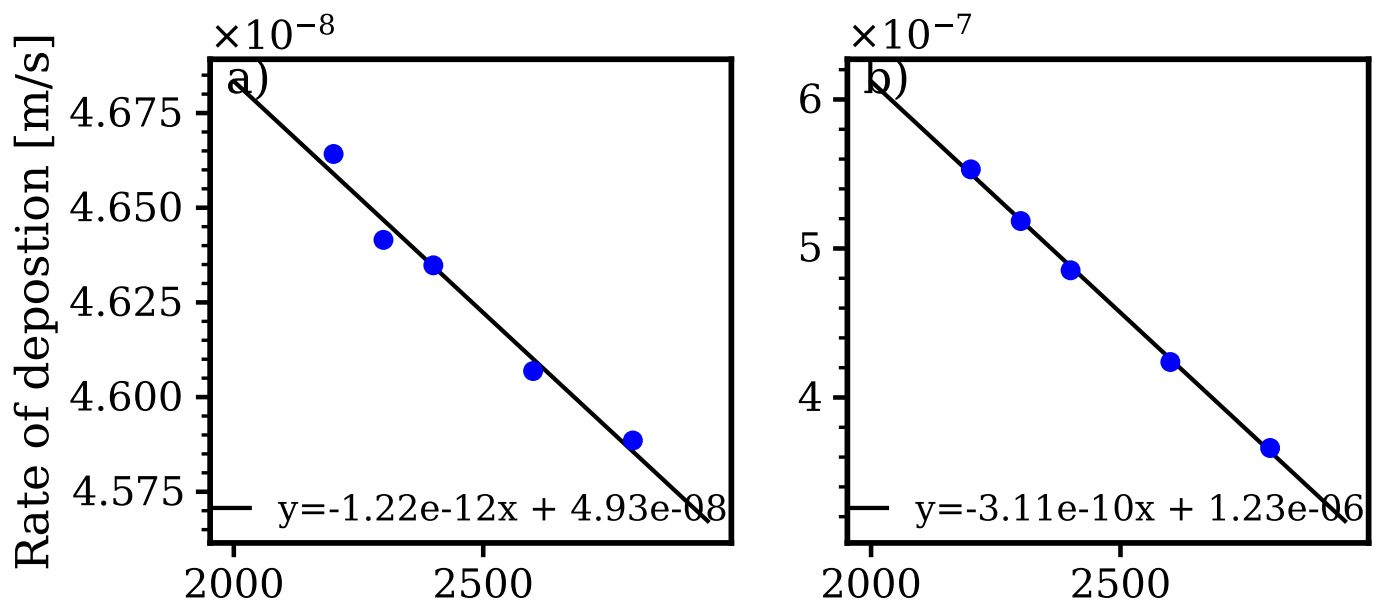

Figure 5.5. Dry deposition rate at the SACOL site as a function of dust particle density, (a) clay and (b) silt

\subsubsection{Below cloud scavenging}

To examine the effect of below cloud scavenging in FLEXPART, FLEXPART was run with below cloud scavenging turned off. Figure 5.7 shows the difference between having the below cloud scavenging scheme turned on and off. There is a higher contribution from the proximal regions with the below cloud scavenging turned on, as to be expected since below cloud scavenging should be most efficient close to the source region.

\subsection{Model evaluation against observation}

Figure 5.8 shows the time series of observed and modelled monthly dry deposition fluxes from January 2009 until December 2010 for the four sites at the coast of Japan, as described in Section 4.4.3. Evident is FLEXPART ability to reproduce the spatial variation between 

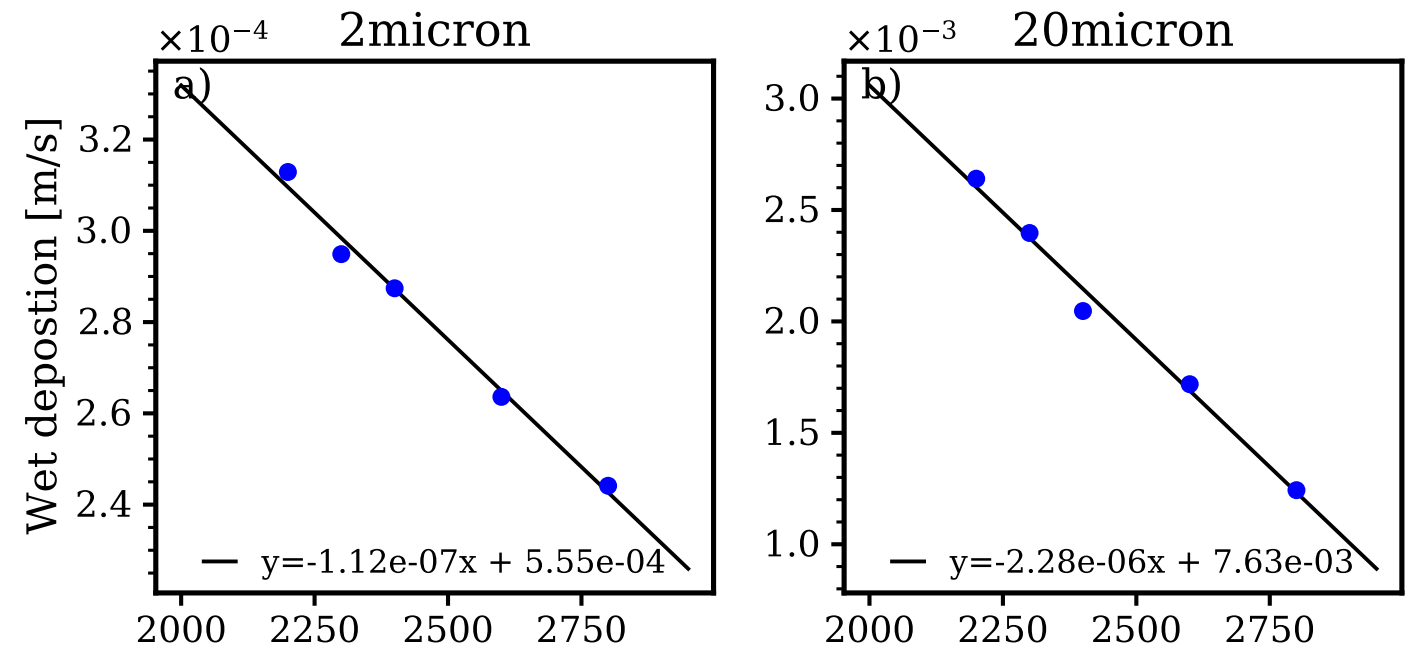

Figure 5.6. The wet deposition rate at the SACOL site as a function of dust particle density, (a) clay and (b) silt

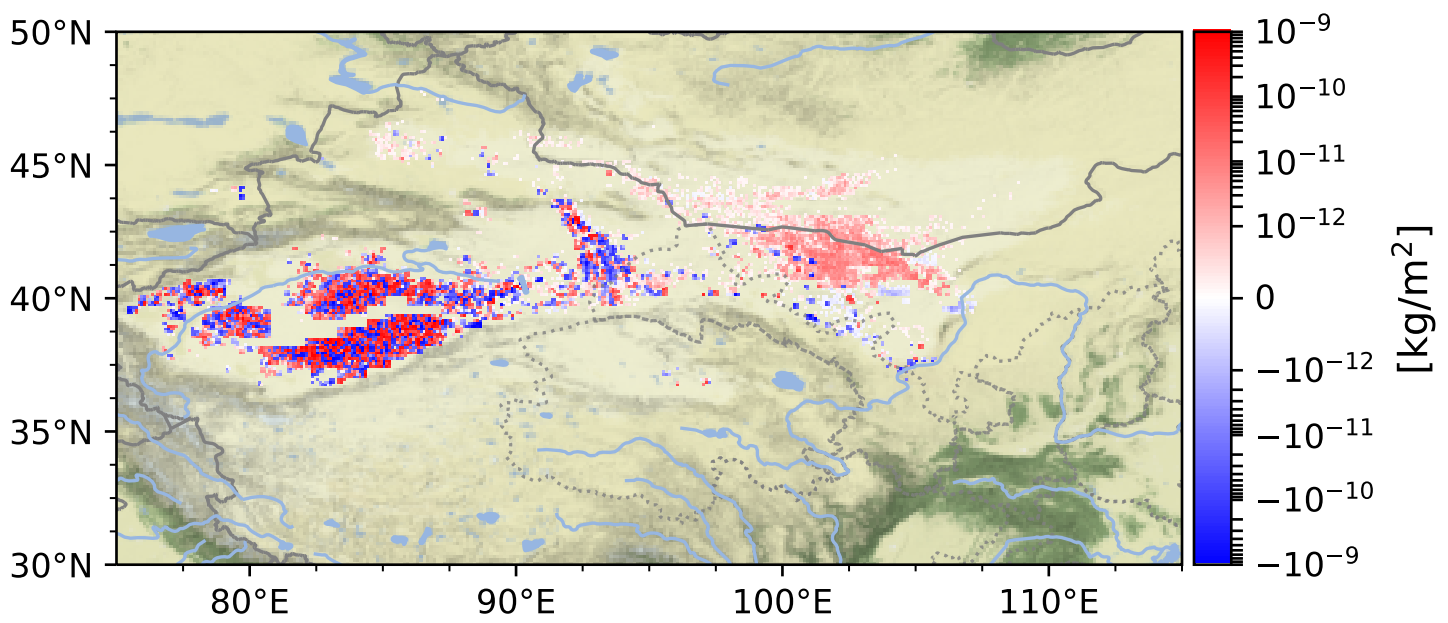

Figure 5.7. The difference in the source contribution to the wet deposition at Baode during spring 2019. With below cloud scavenging turned on minus below cloud scavenging turned off. 
the sites, with Fukuoka and Toyama experiencing the strongest deposition. The dry deposition rate is strongest in spring and weakest in summer in both the observations and model. The interannual variation between the two years is well captured in the model, with stronger deposition during 2010 compared to 2009. The model is able to account for over half of variability in measured dry deposition flux with an average correlation coefficient of 0.52 .
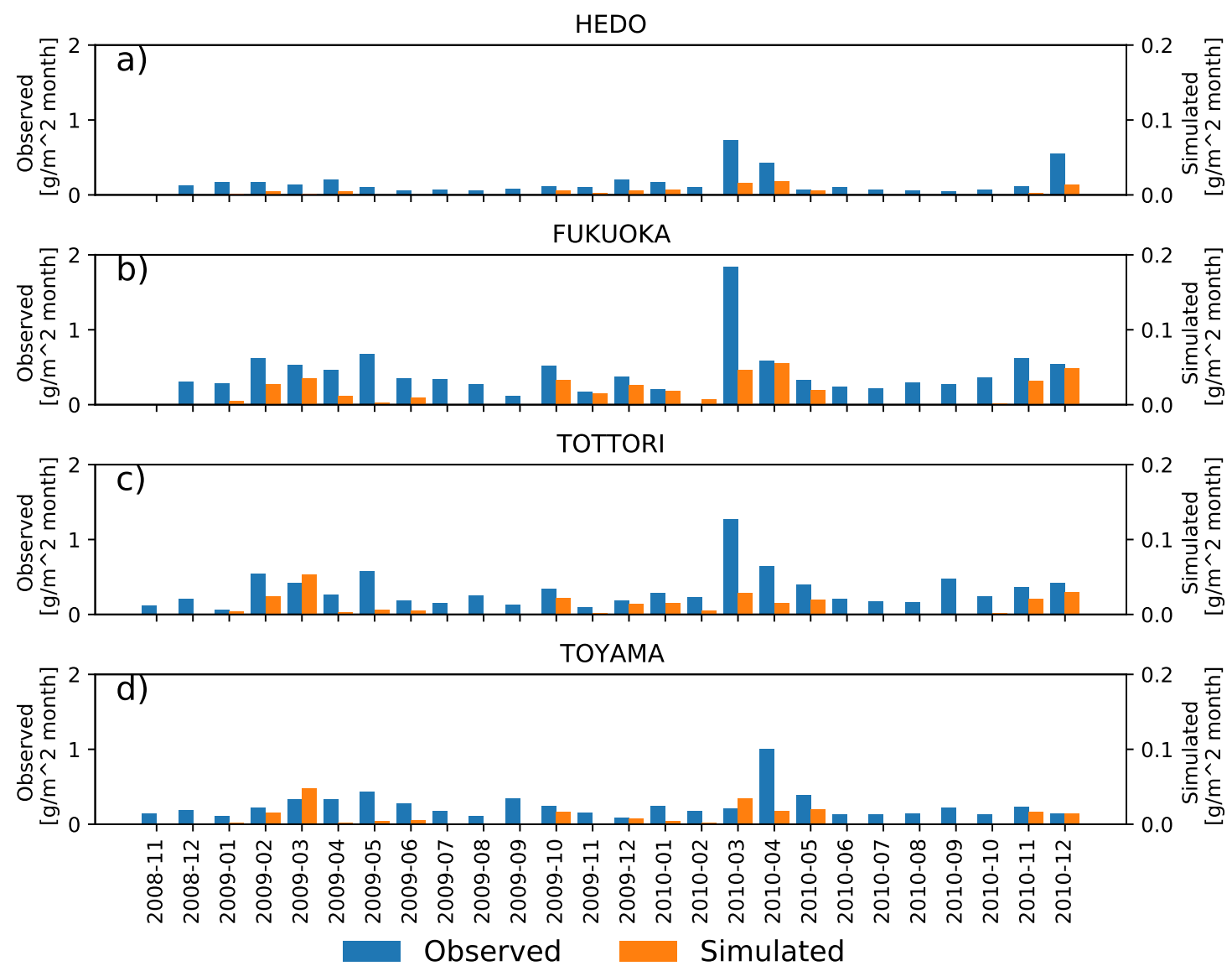

Figure 5.8. Dry deposition flux (orange) simulated at 4 locations by the coast of Japan. The measurements (blue) monthly deposition flux are described by Osada et al. (2014)

For wet deposition, the agreement between the model and observation is worse (Figure 5.9). With the highest correlation coefficient between observed and modelled wet deposition being 0.17 for the Tottori site. Still, the spatial difference between the sites is retained and the difference in total deposition between the two years. However, when looking at the individual months, the agreement between the model and observations is low. Especially odd is the extreme wet deposition in July of 2009 at the Fukuoka and Toyama site simulated by FLEXPART. 


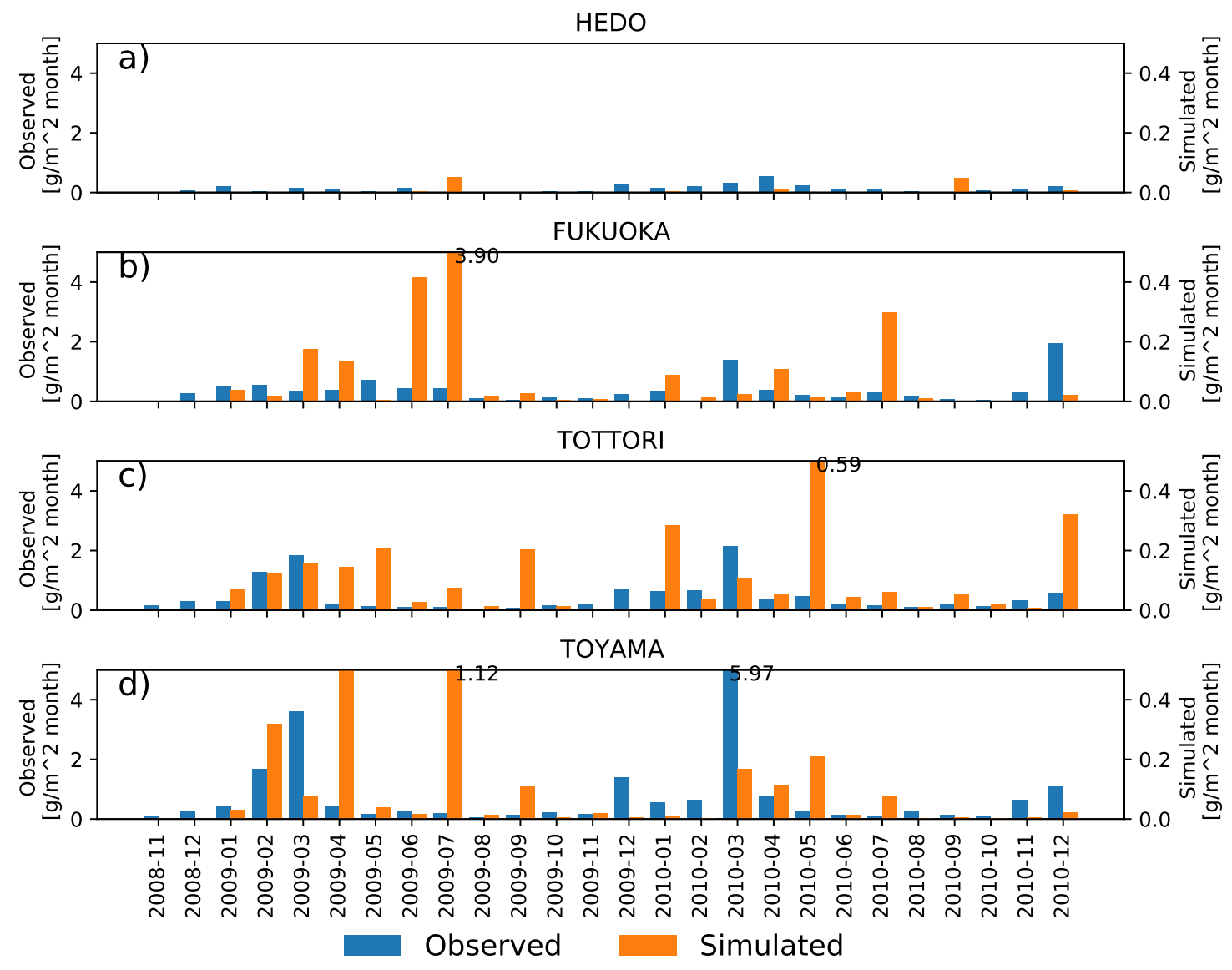

Figure 5.9. Wet deposition flux (orange) simulated at 4 locations off the coast of Japan. The measurements (blue) of monthly deposition flux are described by Osada et al. (2014)

\subsection{Climatology of the East Asian dust cycle}

\subsubsection{Emissions}

The spatial distribution of the multiyear mean simulated dust emissions is shown in Figure 5.10. The source regions are divided into five regions as shown in Figure 5.10. namely; Taklamakan, Junggar Basin, Qaidam Basin, Mongolia and the deserts northwest of the CLP. Of these five regions, the largest dust producers according to the FLEXDUST simulation are the deserts northwest of the CLP, Taklamakan and Mongolia (Table 5.1). In total, FLEXDUST estimates approximately $11 \mathrm{Mt} /$ spring. The source distribution show increasing emissions between $110{ }^{\circ} \mathrm{E}-95^{\circ} \mathrm{E}$, and with increasing emissions again at the entrance of the Tarim basin that decreases towards the western end of the basin (Figure 5.10).

\subsubsection{Transport}

The averaged path the dust is transported along can tell a lot about the typical weather the dust encounters en route. Therefore, multi-year mean dust loading transport trajectories for all the receptor sites were calculated. Figure 5.11a and b show the mean dry 
Table 5.1. The mean springtime emissions for the three largest source regions

\begin{tabular}{lll}
\hline & Emissions (Mt) & Percentage (\%) \\
\hline Taklamakan & 1.96 & 19 \\
North west CLP & 3.33 & 31 \\
Mongolia & 1.54 & 14 \\
Remaining regions & 3.99 & 36 \\
Total & 10.83 & 100 \\
\hline
\end{tabular}

deposition dust loading trajectories for the clay and silt particles, respectively, with their accompanying vertical profiles shown in Figure 5.11k and d. Similarly, wet deposition dust loading trajectories are shown in Figure 5.11 $\mathrm{e}-\mathrm{h}$.

The dry deposited dust is transported along a similar northwesterly trajectory for both clay and silt particles. The exception is SACOL, where the trajectory of coarse particles is turned more westward. The air masses carrying the silt particles move faster compared to clay particles. The vertical profile of the averaged trajectories shows that the altitude of the dry deposited dust approximately increase linearly with time along the backward trajectory. The height of the fine dust particles increases more slowly with time backward and are primarily transported through the lower troposphere compared to the coarse particles that have to be transported through the upper troposphere to reach the receptor location from the most distant sources.

Compared to the dry deposited dust, the wet deposited dust follows a more westward trajectory. The spread between the wet deposition trajectories is larger than the dry deposition trajectories, indicating that the source of the wet deposited dust is more sitedependent. The vertical profile of the wet deposition shows lifting starting approximately 12 hours before arriving at the receptor. Precipitation over the CLP during spring is usually caused by convection initiated by frontal activity. Figure $5.11 \mathrm{~g}$-h then shows the average time window between the wet deposition event and the start of the frontal lifting. Moreover, this also approximates how long before deposition the dust would have to be entrained into the atmosphere, assuming that the dust must be entrained before entering the frontal region. Compared to the mean trajectory of dry deposition, wet deposited dusts usually have higher trajectories mainly at mid and upper troposphere.

\subsubsection{Deposition}

The advantage of using FLEXPART and FLEXDUST for modelling dust deposition is that it makes it possible to directly quantify how much each source region contributes to the deposition at the receptor. Figure 5.12 and Figure 5.13 show the spring averaged source contribution of total deposition of the clay and silt particles, respectively. The main source of the dust deposited at all receptor locations is the deserts northwest of the CLP. The western sites, Shapotou, Yinchuan, Sacol and Lingtai, have a stronger contribution from Taklamakan than the eastern sites. Figure 5.12 h and Figure 5.13h show that the primary mode of deposition for all the sites is wet deposition. The wet deposition is even more dominating for the coarse particles. Couterintuitively, the areas with the largest contribution to the deposition of coarse dust are located further away from the receptor than the fine dust. 


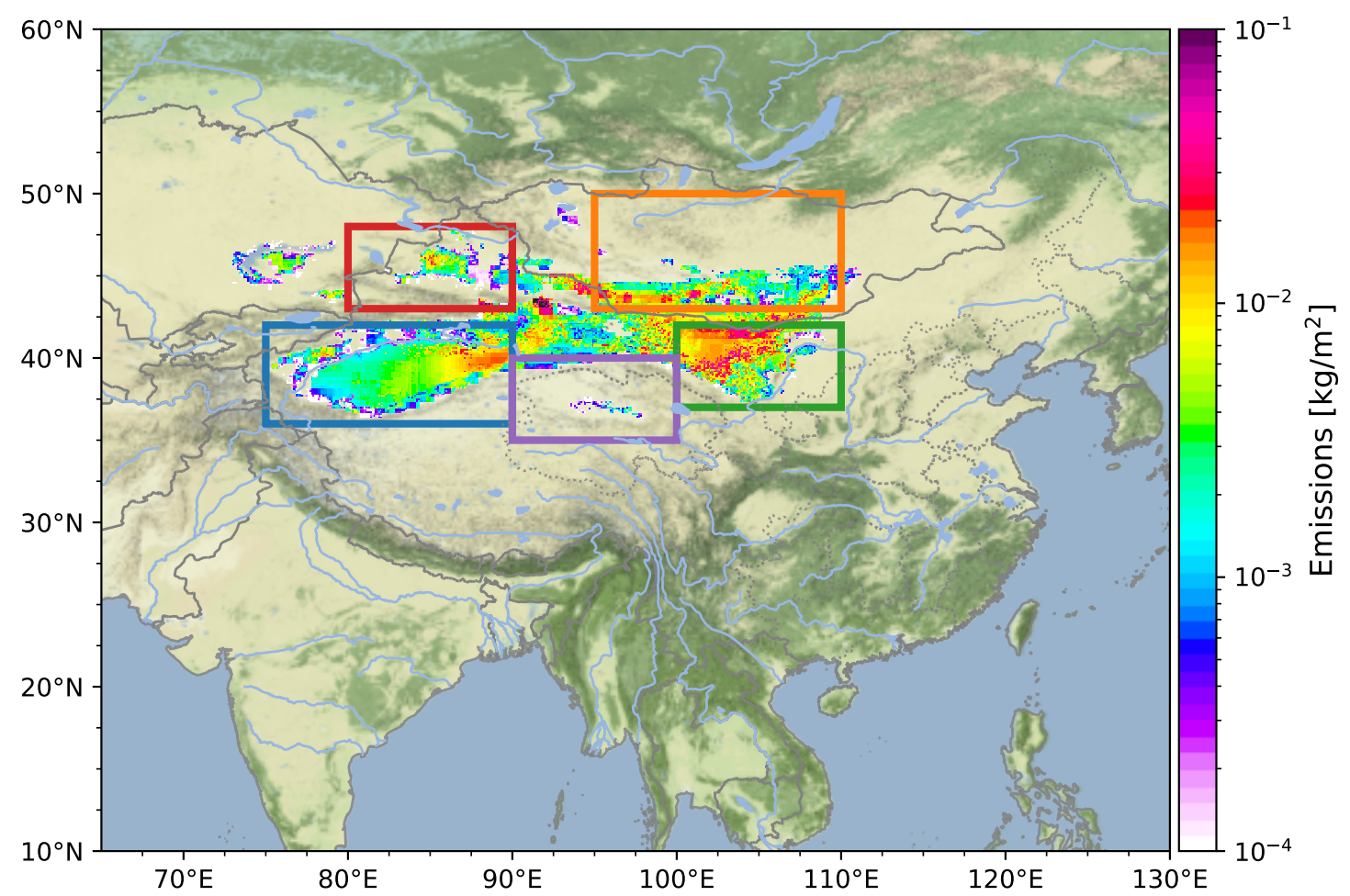

Figure 5.10. Map of spring averaged dust emission flux simulated by FLEXDUST. The major source regions are indicated, Junggar Basin (Red), Taklamakan (Blue), Qaidam Basin (Purple), northwest CLP (Green), Mongolia (Orange)

\subsection{Interannual variability of the East Asian dust cycle}

\subsubsection{Emissions}

The time series of springtime emissions for the 3 main source regions are shown in Figure 5.14. Over this 20-year period, there is no evident long-term trend in the springtime dust emissions. The three years with the strongest overall dust emissions are identified as 2001, 2010 and 2018. For 2001 and 2010, the northwest CLP region stands for the main increase in emissions. Whereas for 2018, Taklamakan and the smaller source regions are mainly responsible for the increased emission. Years with strong emissions from the northwest CLP generally coincide with enhanced emissions from Mongolia but not always with enhanced emissions from Taklamakan, e.g. 2013.

Empirical orthogonal functions (EOF) analysis based on yearly de-trended spring emissions was done to identify spatiotemporal characteristics in dust emissions from the East Asian deserts. The eigenvalues and their standard error are shown in Figure A.1. thus according to the North et al. (1982) rule of thumb, EOF1 and EOF2 are retained.

Figure 5.15a and $\mathrm{b}$ shows the spatial pattern of EOF1 and EOF2, which account for $54 \%$ and $12 \%$ of the total variance in annual springtime emissions, respectively. The leading EOF represents increased emissions across all the source regions. As expected, the years with a large positive principal component (PC) correspond to strong emission years (Figure 5.15k). The second EOF shows a dipole pattern between emissions in Mongolia and Taklamakan. The signal of the second EOF is also visible from the time series where the positive EOF2 

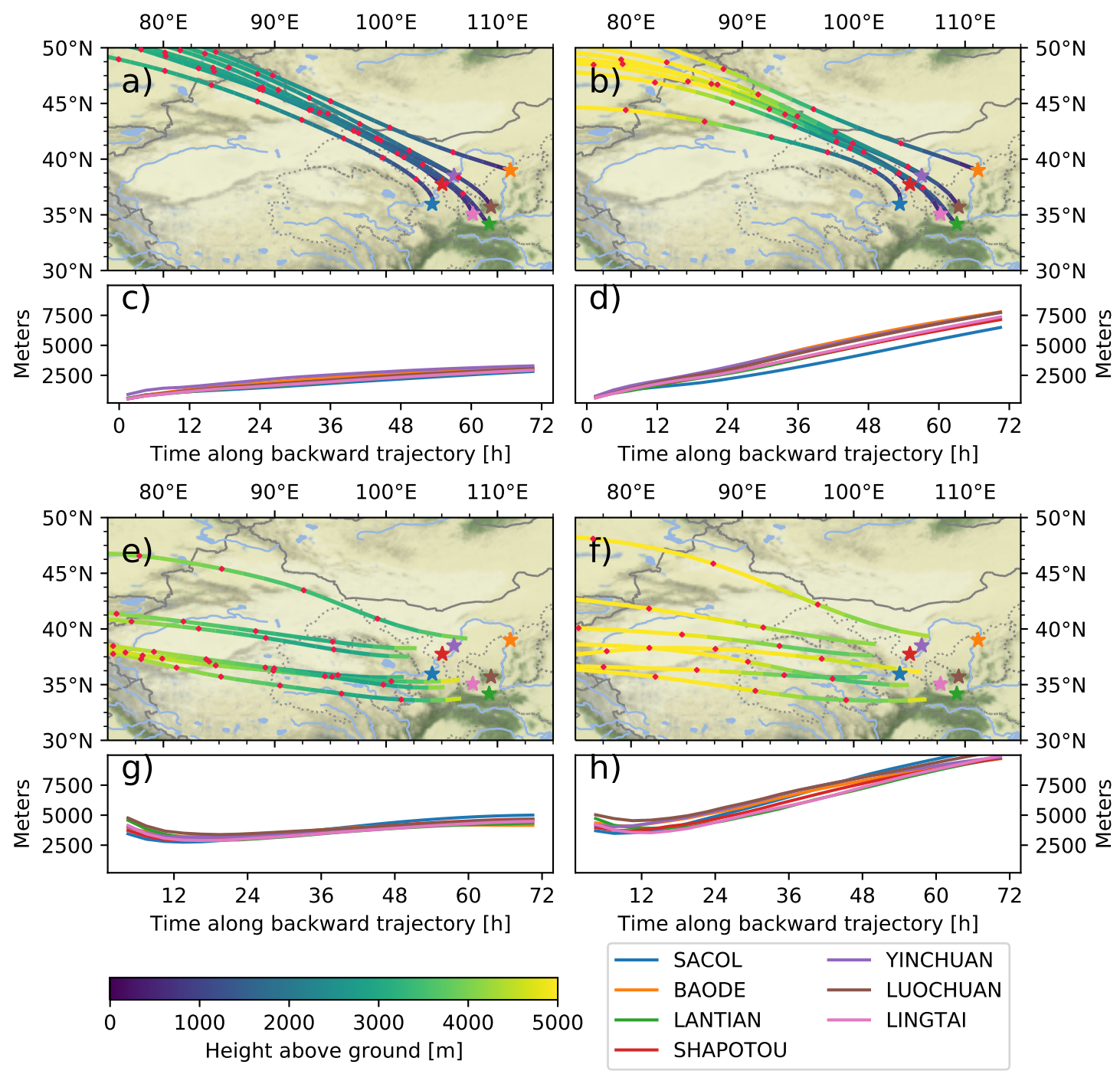

Figure 5.11. The weighted average of centroid dust loading trajectories for all the receptor locations during springtime from 1999-2019. (a) and (b) is the dry deposition dust loading trajectories for "clay" and "silt", respectively, $(c)$ and $(d)$ is their accompanying vertical path. (e)-(h) as (a)-(d) just for wet deposition dust loading trajectories. The red points are spaced at 12 hours apart, indicating the speed of the dust transporting airmasses 

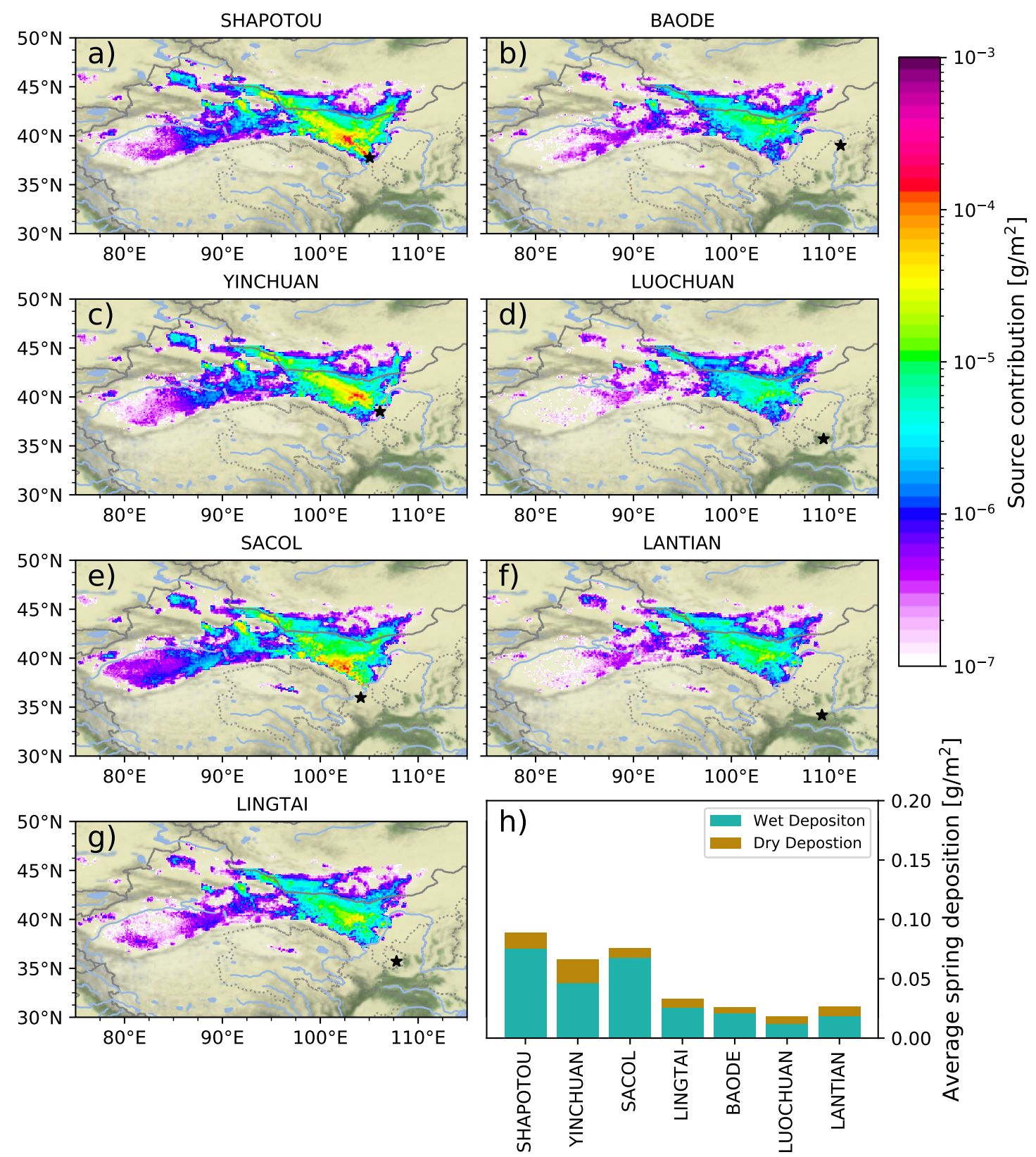

Figure 5.12. Yearly averaged spring source contribution "clay" dust size bin for the seven sites across the CLP (a-g). (h) shows the averaged spring deposition of each site for both wet-and dry deposition 

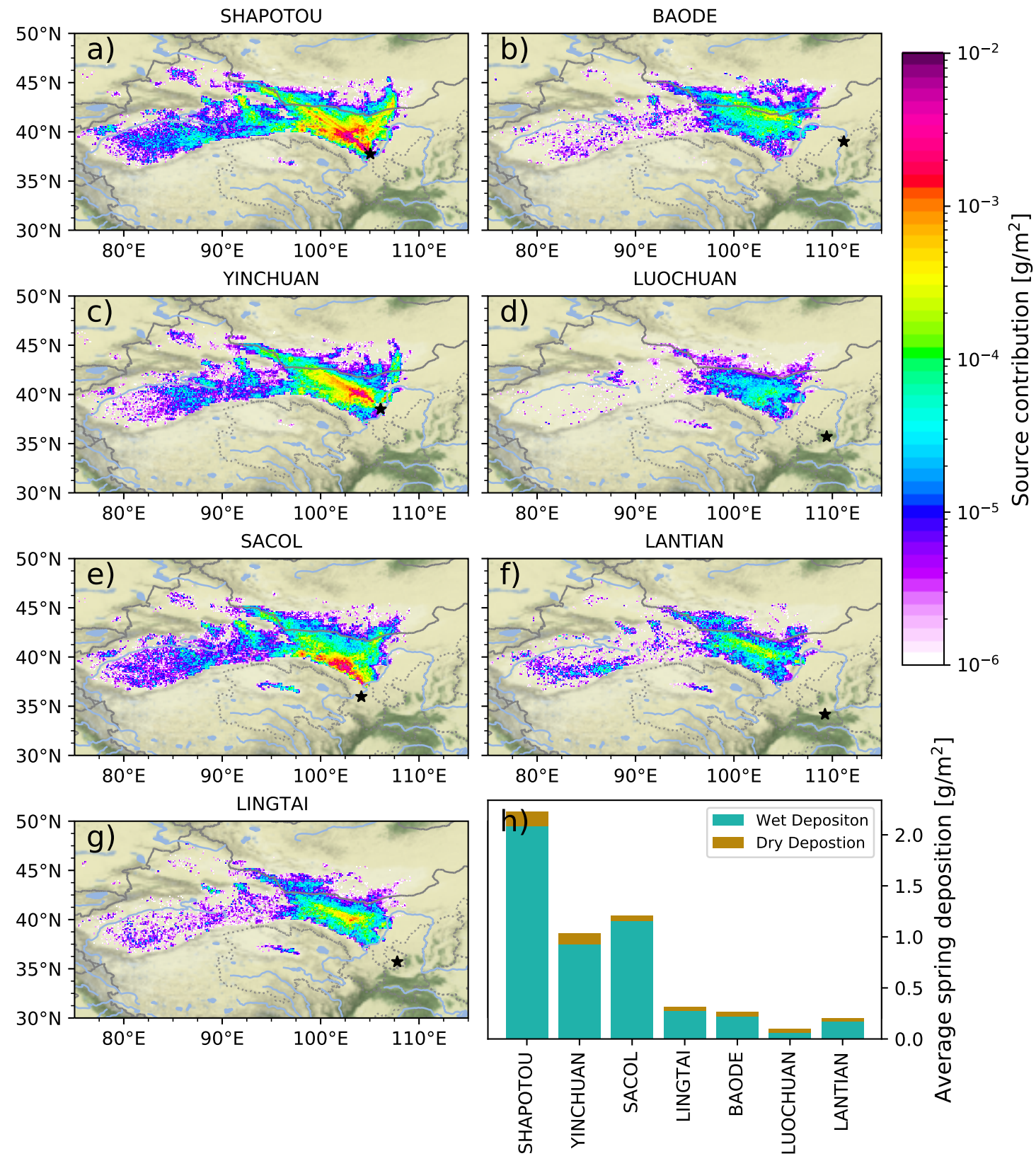

Figure 5.13. Yearly averaged March-May source contribution "silt" size bin for the seven sites across the CLP (a-g). Panel h) shows the averaged spring deposition of each site for both wet-and dry deposition 


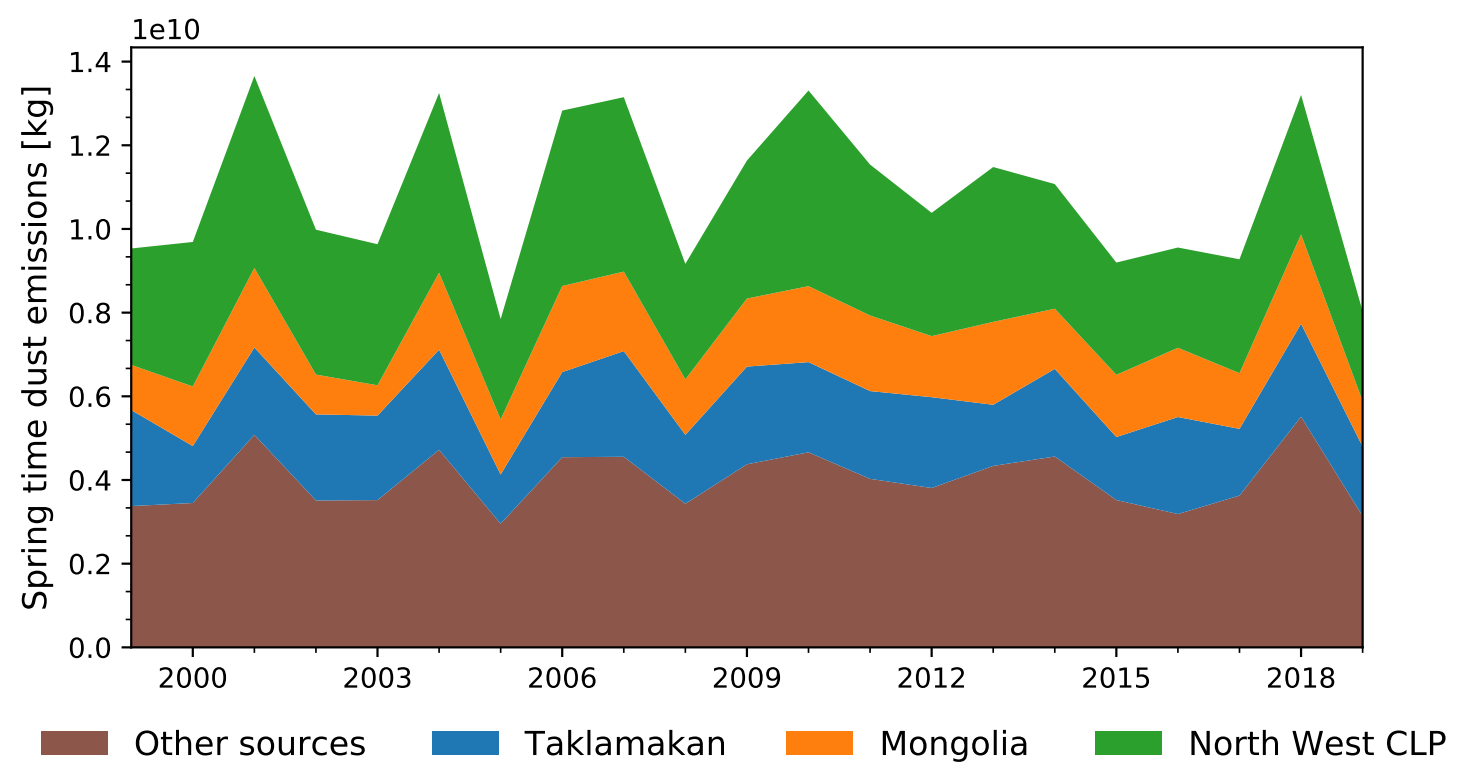

Figure 5.14. Time series of total springtime dust emissions from 1999-2019. The total emission is partitioned into the contribution from the Taklamakan (Blue), North West CLP (Green) and Mongolia (Orange)

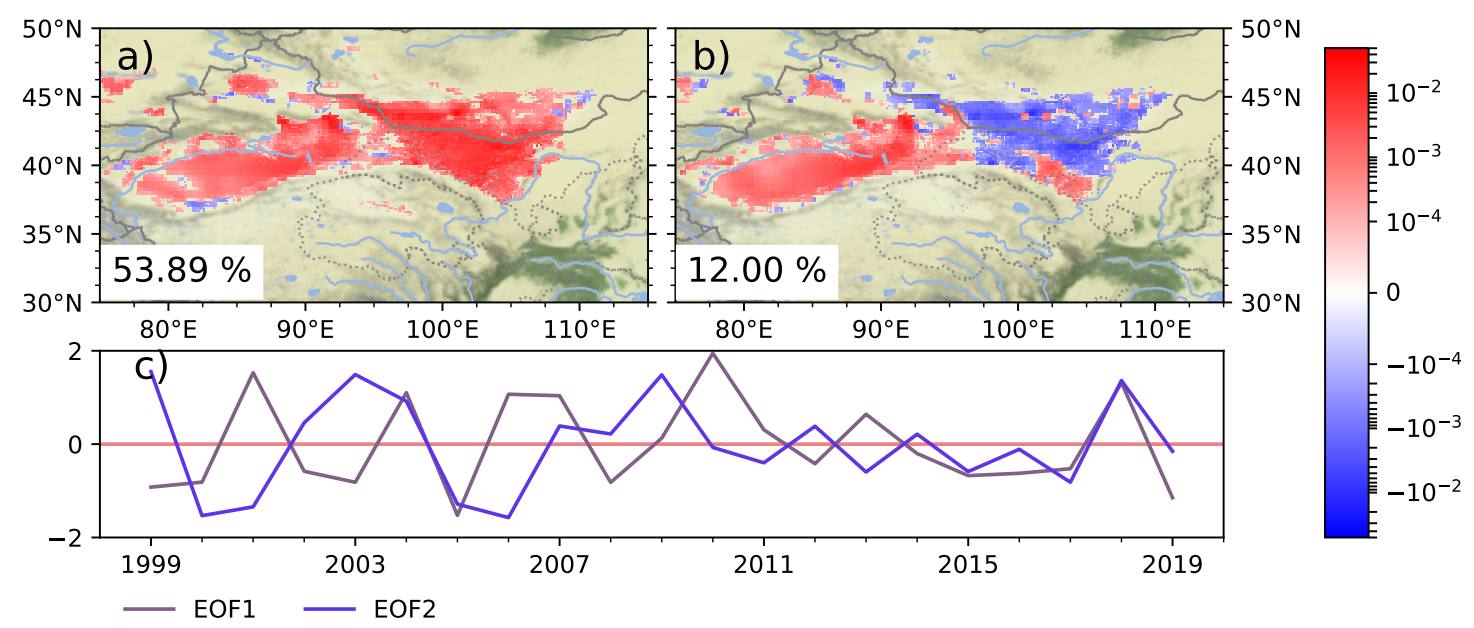

Figure 5.15. The spatial pattern of the leading EOF (a) and second EOF (b). (c) the time series of the normalized principal component of the first (purple) and second (blue) EOFs. 
years correspond to a disproportional increase in emissions from Taklamakan compared to emissions from Mongolia and vice versa.

Composite analysis of the preceding winter circulation for strong positive minus strong negative EOF years was done to understand better the circulation anomalies associated with the spatial pattern identified by the EOF analysis. In positive EOF1 years, the composite anomalies indicate a negative AO-like pattern, with positive MSLP anomalies over the Arctic region.

The composite anomalies for the second EOF show a strong negative pressure anomaly to the northeast of the $\mathrm{SH}$ and a positive pressure anomaly around the location of the AL. The MAM composite (Figure 5.17) shows how the circulation anomalies evolve into

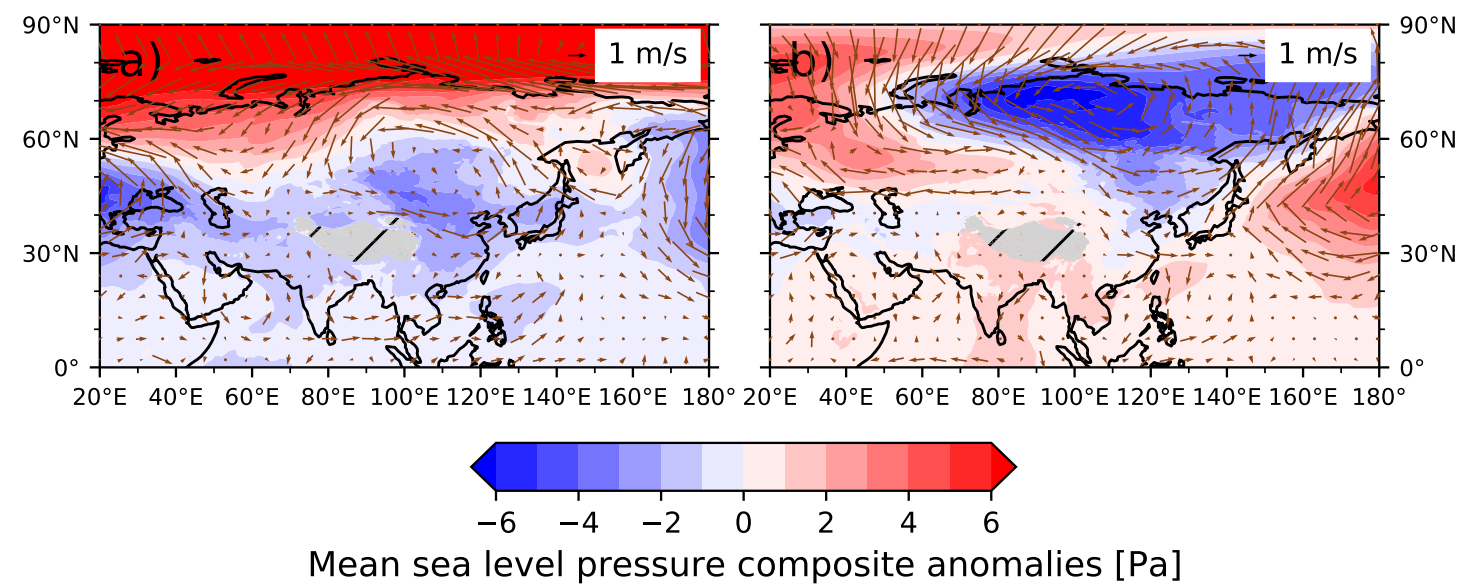

Figure 5.16. DJF composite anomalies of MSLP and 850hPa winds the strong positive minus strong negative EOF1 (a) and EOF2 (b) years

spring. The spring composite difference of EOF1 indicates a weakened AL and SH. While EOF2 spring composite also shows positive MSLP anomalies over the ocean the centre is now located over Southeast China. Moreover, the EOF2 composite shows a positive AO-like pattern with negative MSLP anomalies over the arctic. Over the Taklamakan there is now a negative pressure anomaly over Taklamakan, causing easterly wind anomalies in the Tarim Basin.

\subsubsection{Transport}

Examining the differences in transport between strong and weak deposition years can provide insight on how the dust transport to the CLP is different in periods with high and low MAR. Figure 5.18 and Figure 5.19 shows the dry deposition dust loading trajectories for the clay and silt particle size bin in weak and strong deposition years, respectively. The standard deviation during strong and weak years is shaded red and blue, respectively, and the purple region is where the two overlap. During strong deposition years, the spread of the trajectories is generally narrower and more condensed to a northwesterly direction, suggesting a more organised dust transport path and source areas in strong deposition periods. Moreover, the dust during strong dry deposition years is transported more swiftly than in weak deposition years. The more efficient dust transport in strong deposition years is consistent with the dust being transported at higher altitudes as shown in Figure 5.19h and more intense winds. 


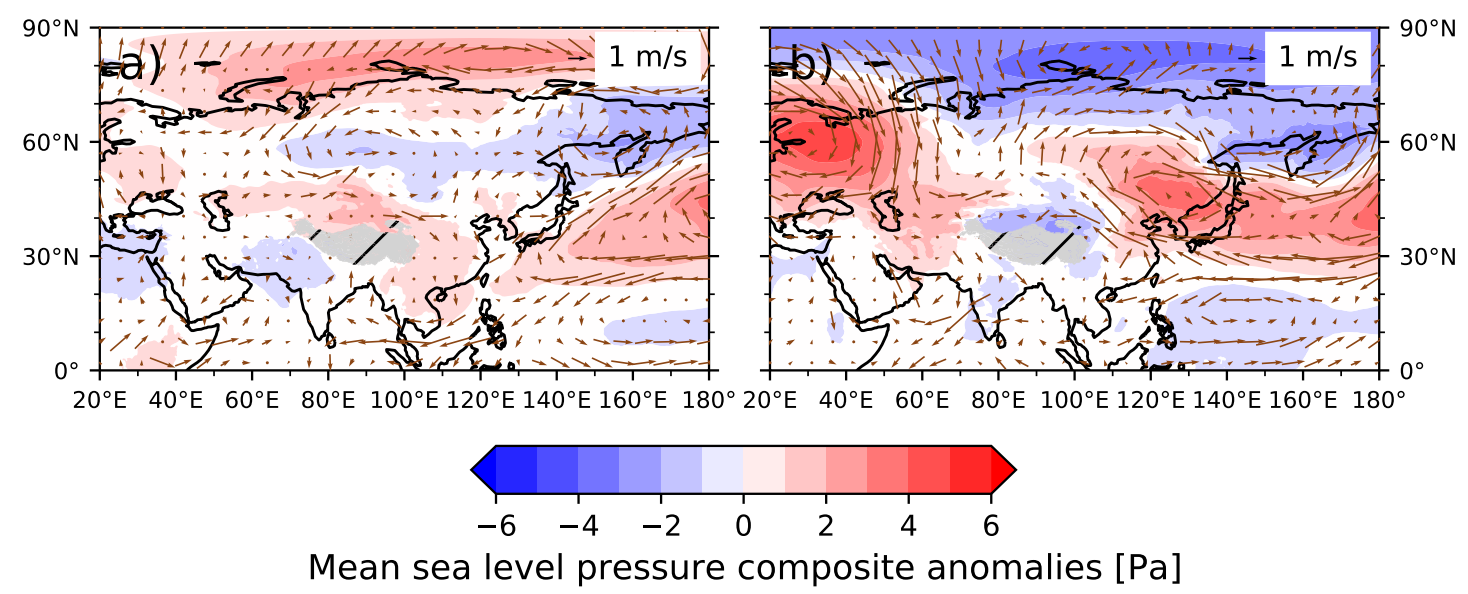

Figure 5.17. MAM composite anomalies of MSLP and 850hPa winds the strong positive minus strong negative EOF1 (a) and EOF2 (b) years

The prerequisite conditions involved in wet deposition occur more randomly and are thus not as strongly influenced by changes in the mean winds. Therefore it is hard to make a general statement about the transport of wet deposited dust. Beyond that, the dust is transported more swiftly in strong deposition years compared to weak deposition years. As with the multiyear averaged wet deposition trajectories, the differences in dust transport trajectories between weak and strong wet deposition years are mostly site-dependent.

\subsubsection{Source contribution}

From the mineralogy of the loess deposits, it is possible to differentiate the provenance of deposited dust in periods of high and low MAR. Similarly, this can be examined with FLEXPART by comparing the source contribution during strong and weak deposition years. Figure 5.22 shows the normalised source contribution for the clay particle size bin. The model result suggests that strong deposition years have a more concentrated source contribution. By comparison, in weak deposition years, the source regions are more randomly distributed. The exception is SACOL (Figure 5.22 e), which during strong deposition years has increased contribution from the entire region northwest of the CLP.

Figure 5.23 is as the previous figure just for the silt particle size bin and tells much of the same message. However, Lantian, which showed reduced deposition from Taklamakan during strong deposition years for clay-sized particles, shows increased contribution from Taklamakan during strong silt deposition years.

\subsubsection{Covariations between deposition and large-scale circulation patterns}

Correlation analysis between deposition at each site and several regional and large-scale climate indices was done to detect the potential influence of regional and large-scale circulation changes on the MAR over the CLP. The circulation indices are calculated based on seasonally averaged ERA5 reanalysis. The full analysis is shown in Figure 5.24, and the significant correlations are displayed. It is found that the winter $\mathrm{AO}$ and $\mathrm{NAO}$ show 

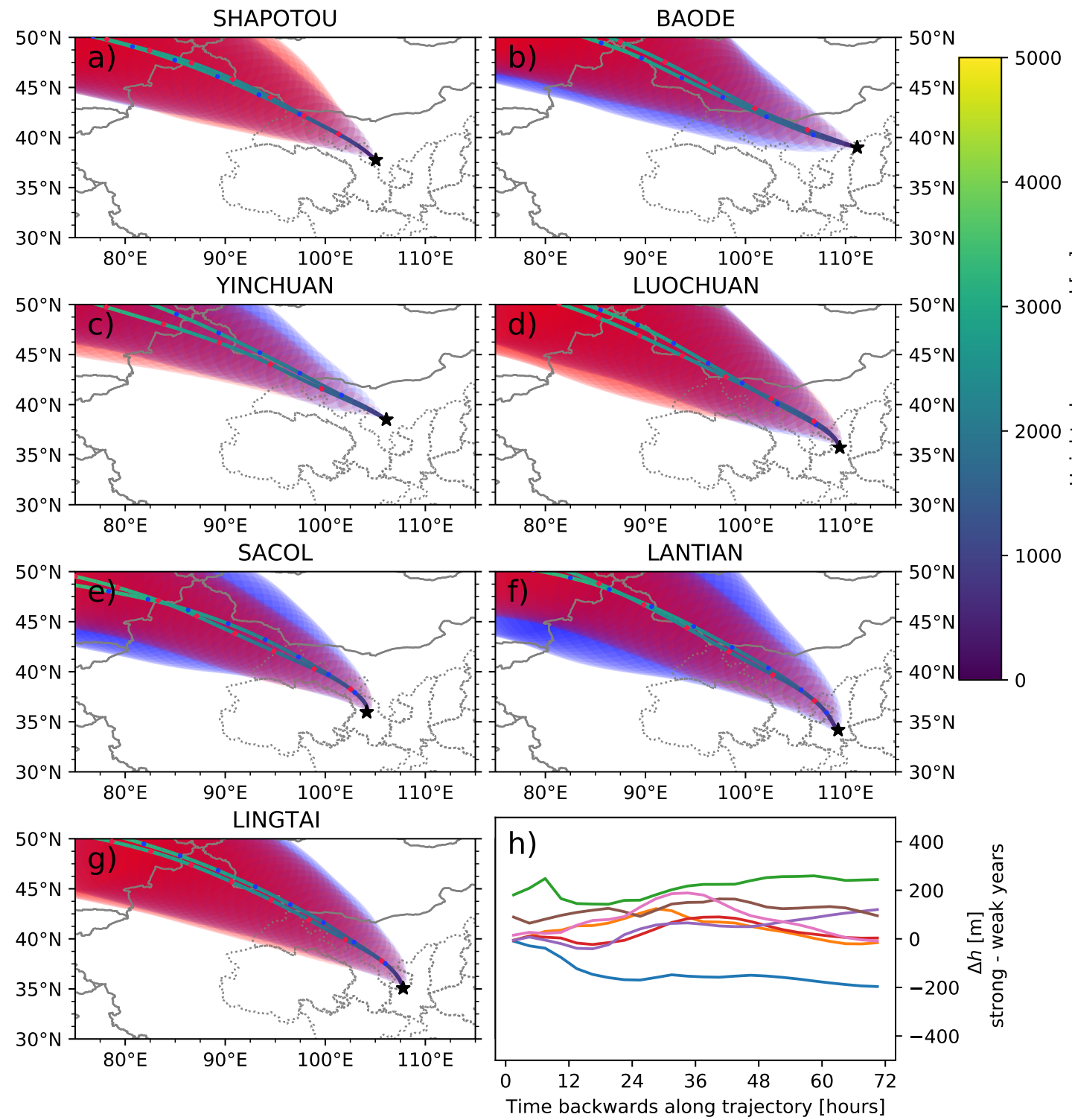

$\begin{array}{lll}- \text { SHAPOTOU } & - \text { YINCHUAN } & - \text { SACOL } \\ \text { BAODE } & - \text { LUOCHUAN } & - \text { LANTIAN }\end{array}$

Figure 5.18. The weighted average of dry deposited clay dust loading trajectories for strong (red diamonds) and weak deposition (blue circles) years for every location. The standard deviation of the trajectories during the weak deposition and strong deposition years is represented by the blue and red shading. (h) show the difference in the height of the dust transporting air masses during strong and weak deposition years. 


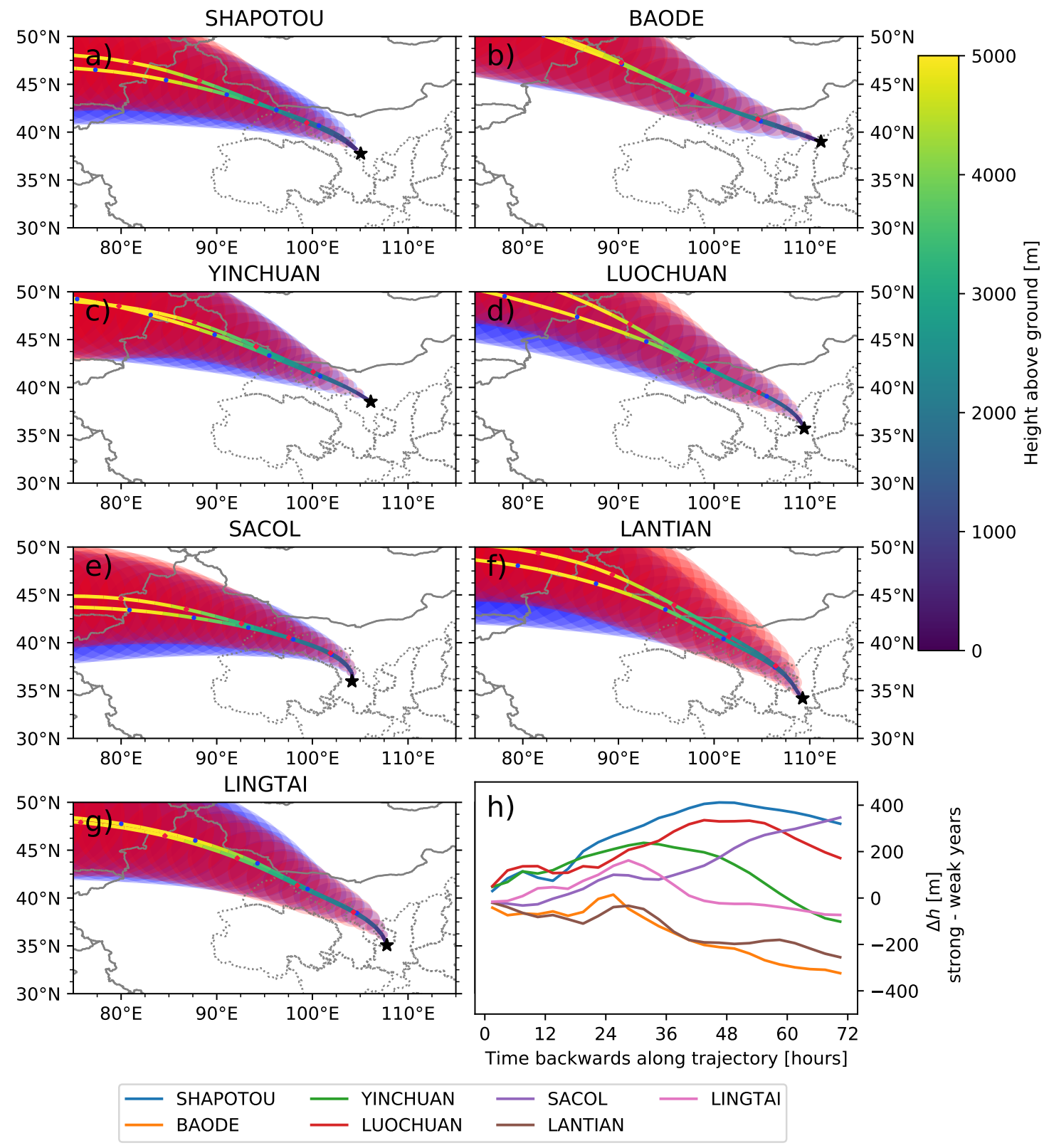

Figure 5.19. The weighted average of dry deposited silt dust loading trajectories for strong (red diamonds) and weak deposition (blue circles) years for every location. The standard deviation of the trajectories during the weak deposition and strong deposition years is represented by blue and red shading. ( $h$ ) show the difference in the height of the dust transporting air masses between strong and weak deposition years. 

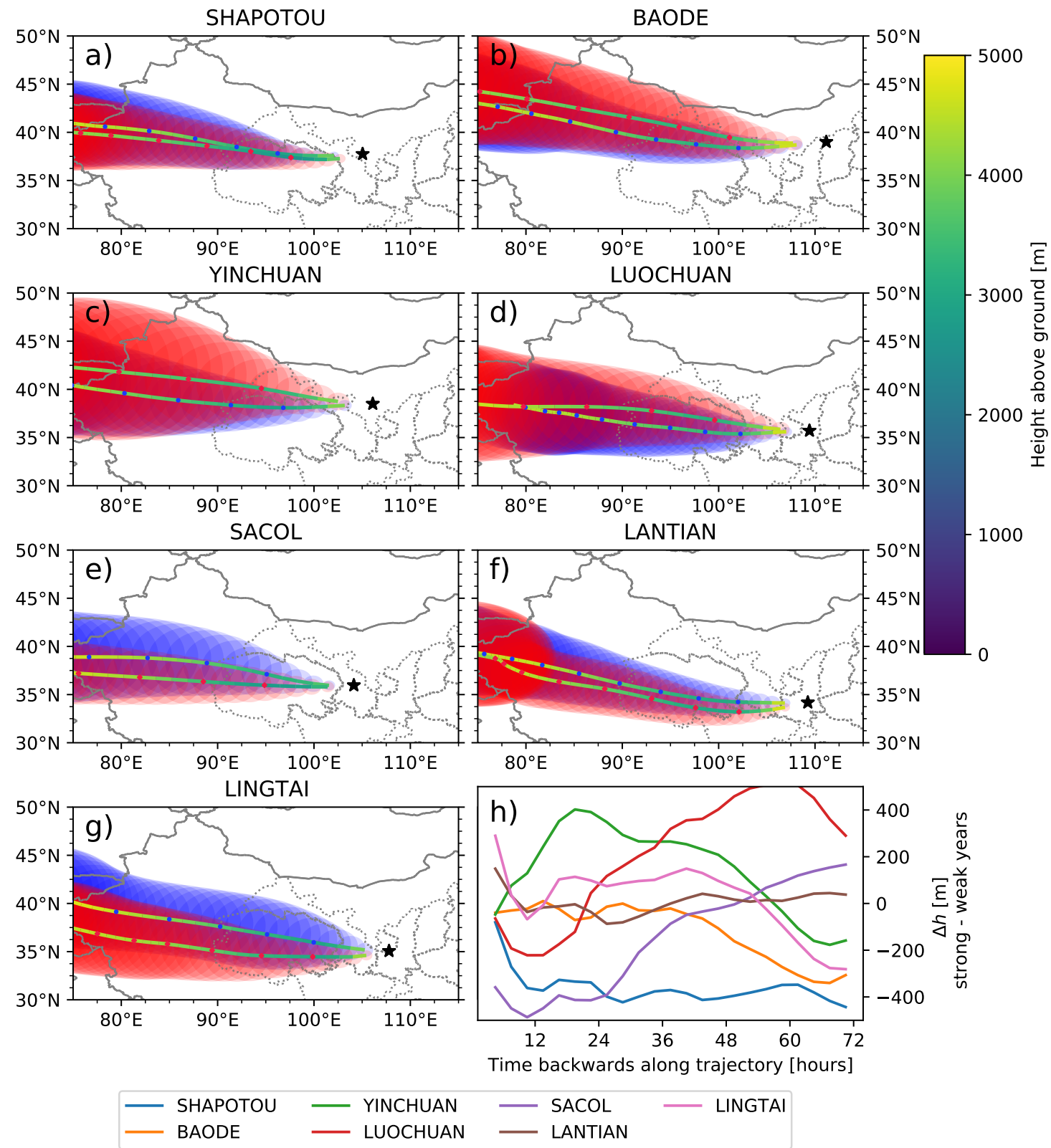

Figure 5.20. The weighted average of wet deposited clay dust loading trajectories for strong (red diamonds) and weak deposition (blue circles) years for every location. The standard deviation of the trajectories during the weak deposition and strong deposition years is represented by blue and red shading. (h) show the difference in the height of the dust transporting air masses between strong and weak deposition years. 

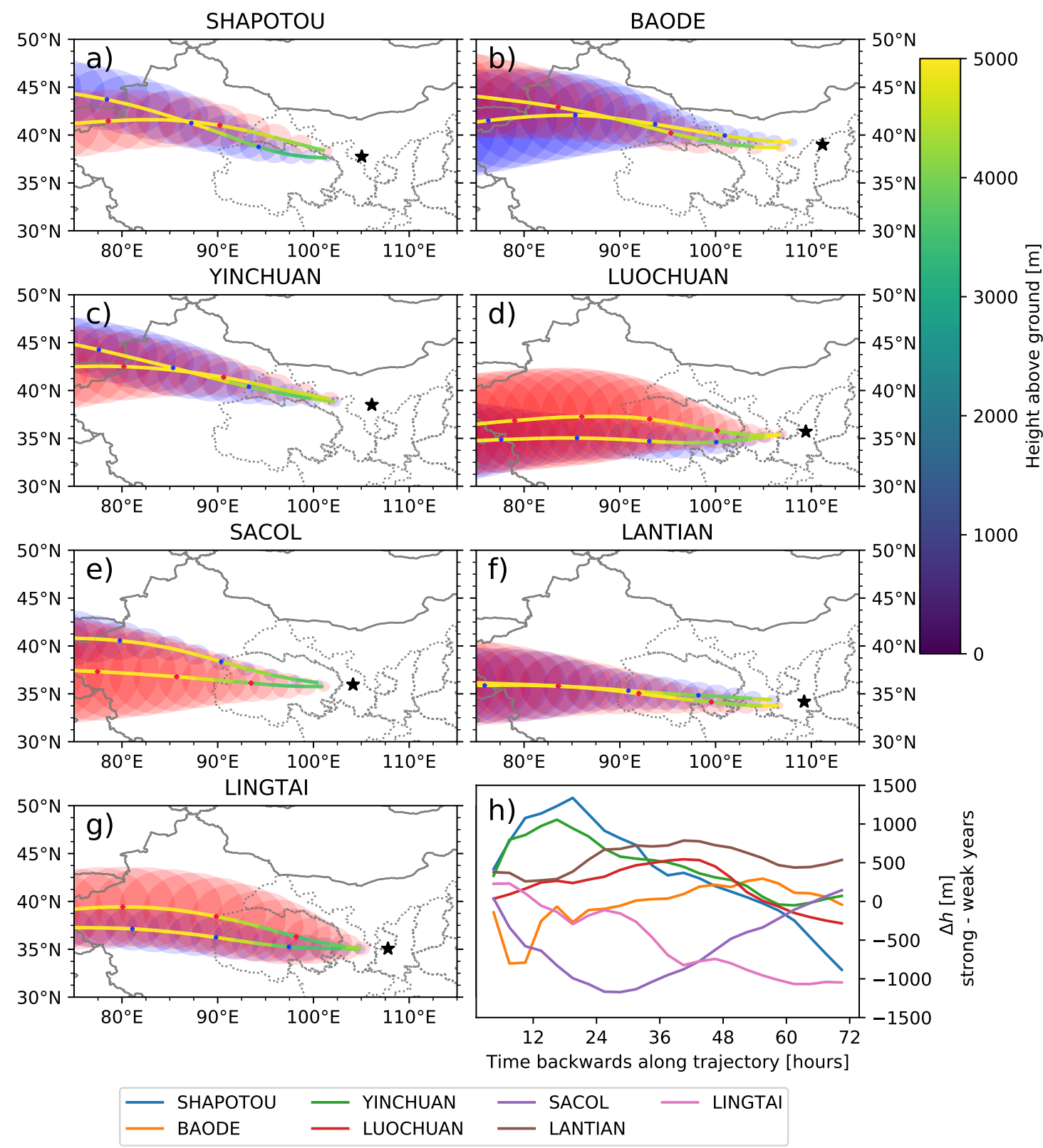

Figure 5.21. The weighted average of wet deposited silt dust loading trajectories for (red diamonds) and weak deposition (blue circles) years for every location. The standard deviation of the trajectories during the weak deposition and strong deposition years is represented by blue and red shading. (h) show the difference in the height of the dust transporting air masses between strong and weak deposition years. 

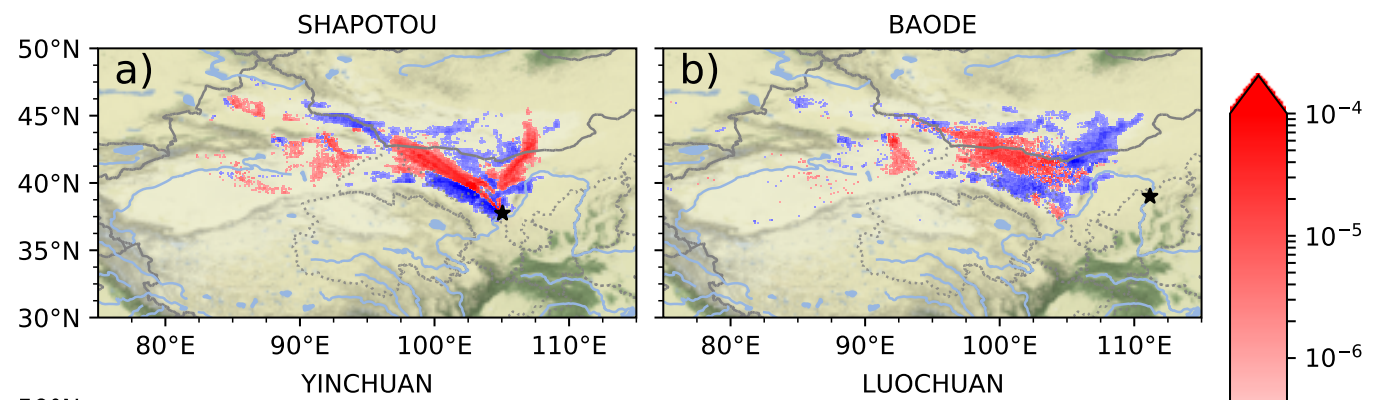

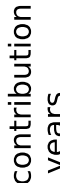
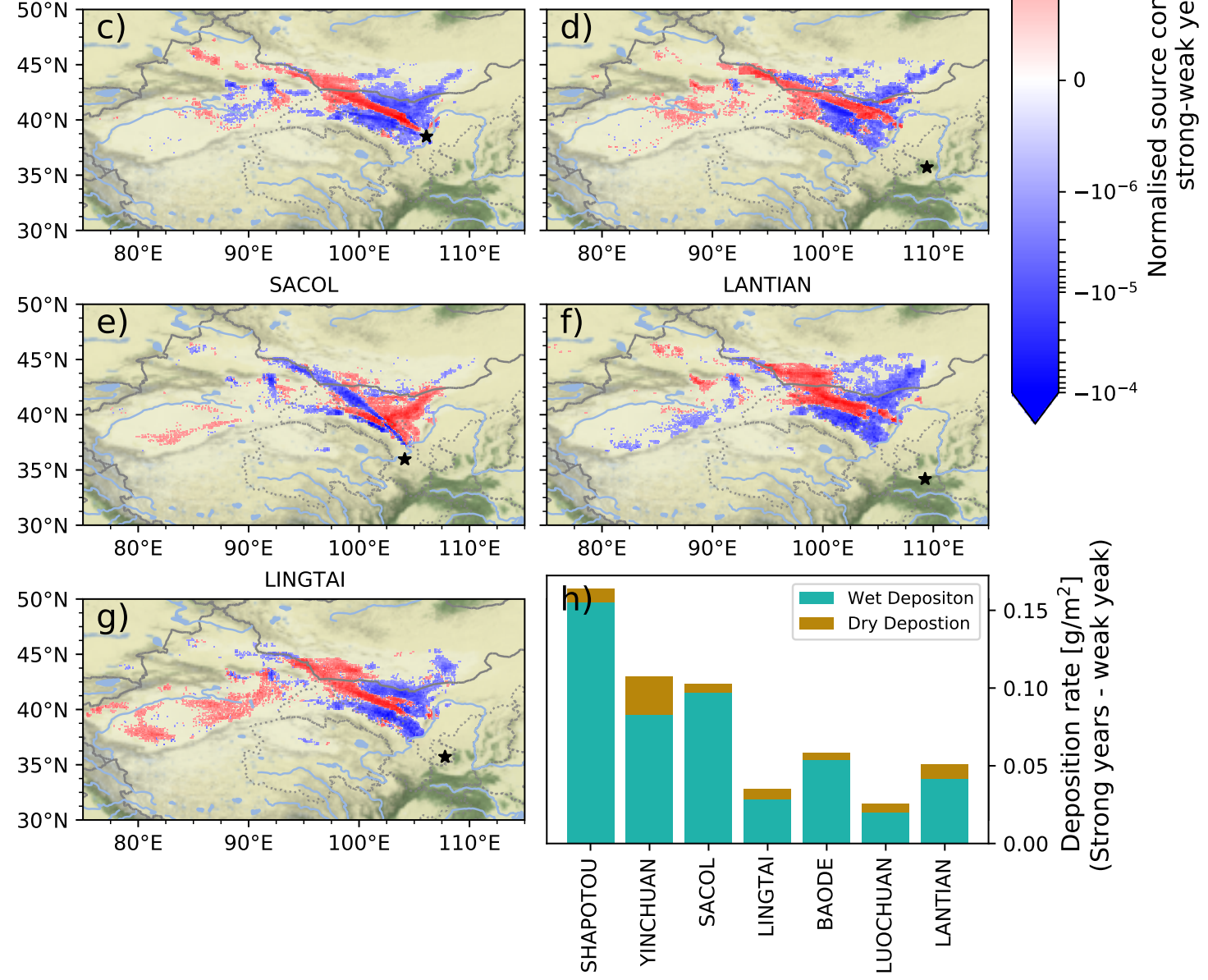

Figure 5.22. Normalised source contribution composite anomalies of "clay" particle size bin for all locations, strong - weak deposition years. 

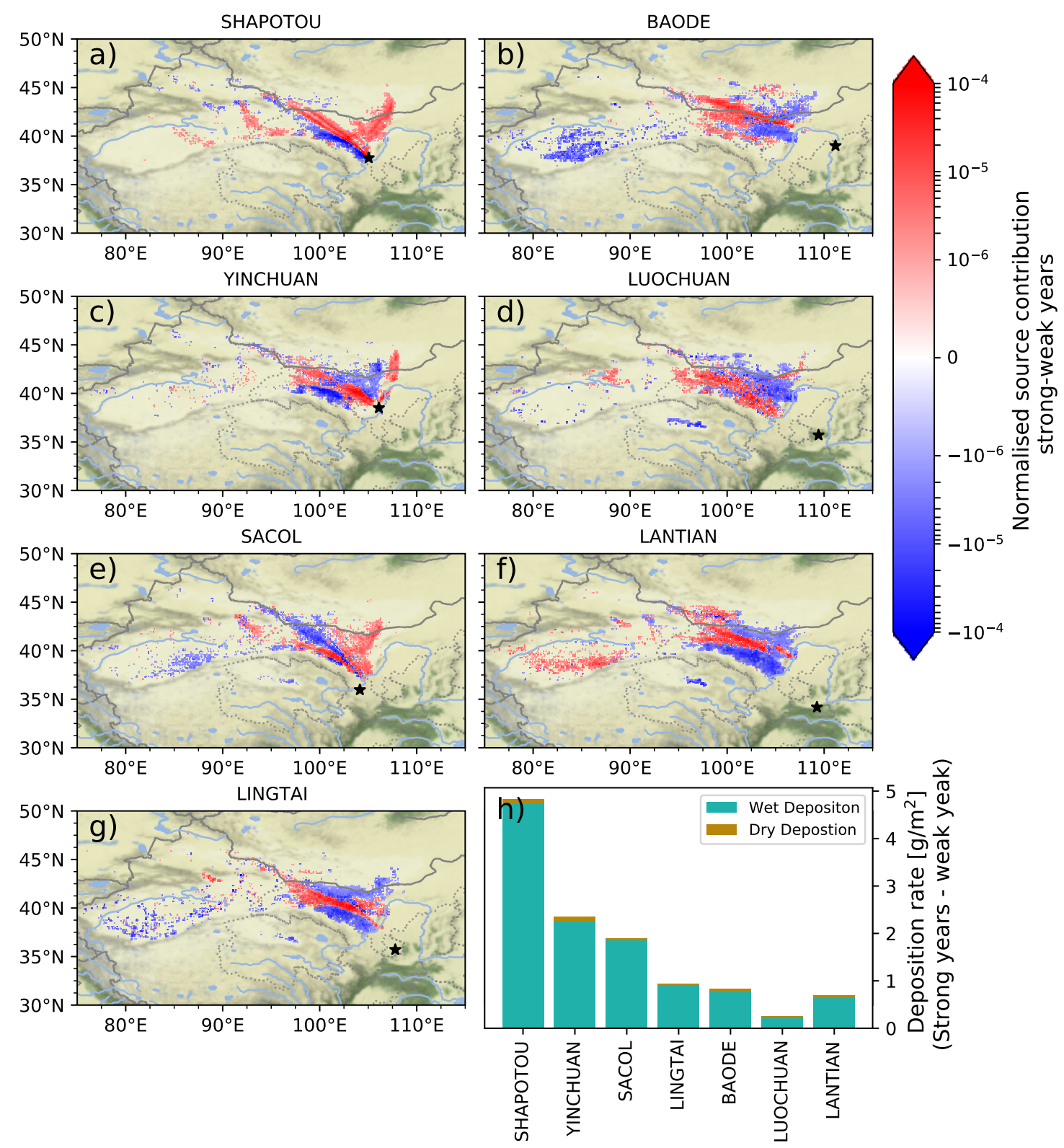

Figure 5.23. Normalised source contribution composite anomalies of "silt" particle size bin for all locations, strong - weak deposition years. 
the strongest correlation with dust deposition of all the indices considered in this analysis. There are only weak non-significant correlations between the EAWM and dust deposition to CLP.

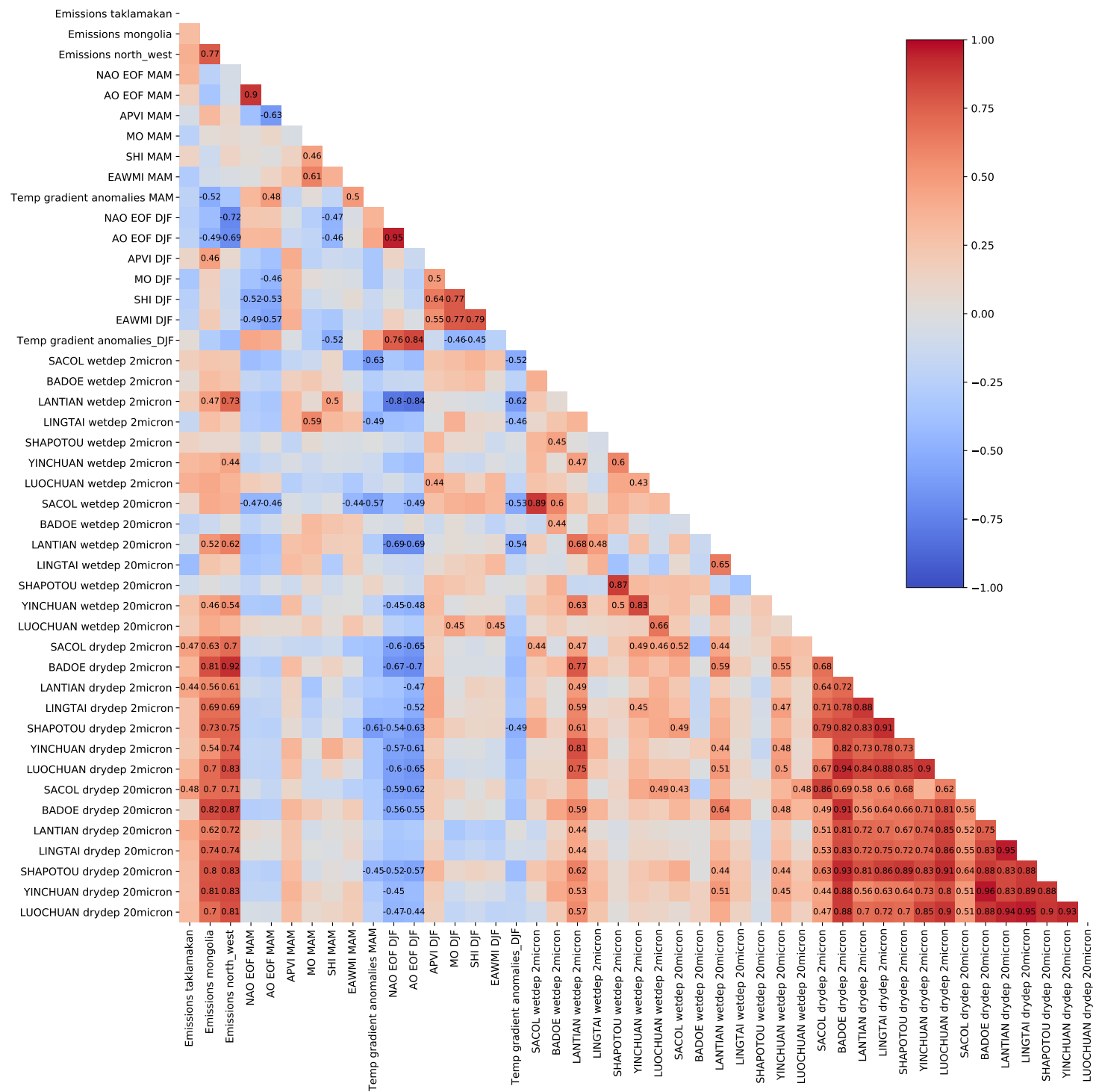

Figure 5.24. Interannual correlations between deposition and each site and local and large-scale climate indices. The significant correlations are indicated

A correlation analysis between deposition and emissions was also included to examine the covariability between the emission strength in the different source regions and deposition at the receptor locations over the CLP. The dry deposition is strongly correlated with emissions in Mongolia and the northwest CLP for almost all sites. However, only Lantian and SACOL show a significant correlation between emissions from Taklamakan and dry deposition. Moreover, wet deposition is generally not significantly correlated with emissions, except Lantian which shows a significant positive correlation between emissions from Mongolia and northwestern sources. For the same reason, wet deposition at Lantian exhibits a strong correlation with dry deposition at the other sites for both clay and silt particles. 


\subsubsection{Winter circulation and spring deposition}

The correlation analysis showed significant negative correlations between winter $\mathrm{AO}$ and dust deposition at several receptor locations. To further examine the influence of the wintertime circulation on springtime deposition, composite anomalies of strong minus weak deposition years for DJF $850 \mathrm{hPa}$ winds and MSLP were calculated Figure 5.25 and Figure 5.26). The results show positive MSLP anomalies over the arctic for Lantian, SACOL, Yinchuan and Luochuan, similar to the negative AO composite anomalies in Figure 3.4p. The exception to the negative-AO pattern is Baode and silt particles at Lingtai. Baode seems to be more influenced by pressure changes over the north Pacific ocean. However, since the wet deposition at Baode is not significantly correlated with any of the winter circulation indices, therefore it is hard to quantify the influence of the preceding winter circulation on the springtime deposition. The negative pressure anomalies over the ocean are particularly pronounced in the composite for clay particles (Figure 5.25p), the feature is less pronounced in the the composite for silt particles (Figure 5.26b).

The circulation differences between the strong and weak deposition years are less pronounced in spring compared to winter, as shown in Figure 5.27 and Figure 5.28, In general, the spring composites show increased northwesterly $850 \mathrm{hPa}$ wind anomalies around the receptor locations in the strong deposition years. The spring MSLP composite anomalies do not show a clear negative AO-like pattern as in the winter composites (Figure 5.24). The differences in spring seem to be more dependent on the location and particle size in our simulations. Still, there are some shared features between the sites. For instance, Shapotou and Yinchuan have weaker anomalies suggesting a more similar circulation between weak and strong deposition years compared to the other sites. Moreover, SACOL, Luochuan and Lantian all show positive MSLP anomalies over the Arctic and northeast Pacific in spring during the strong deposition years. However, solely based on the lowlevel circulation changes, it is hard to establish a connection between the spring and winter circulation.

To further investigate whether the linkage between the winter circulation and dust deposition is also apparent in the mid to high troposphere. Composite anomalies of $500 \mathrm{hPa}$ geopotential height and wind as previously done with the low-level circulation changes were calculated (Figures 5.29 to 5.32). The results show a prominent negative $500 \mathrm{hPa}$ geopotential height anomaly present during the winter of strong deposition years for all the receptor locations, especially for the clay particles. The strength and location of the geopotential height anomaly, however depend on the site. The strengthened mid-tropospheric westerly induced by the negative geopotential anomaly, located at the south of the anomaly, coincide well with the location of each site, suggesting a strong involvement of locally enhanced mid-tropospheric westerly wind in dust transport and deposition to the sites over the CLP. The geopotential and westerly wind anomaly is substantially more pronounced for the sites that are closely linked to the AO. The two receptors that showed the highest correlation with the winter AO, Lantian and SACOL (see Figure 5.24), the wintertime geopotential height anomaly and associated enhancement of westerly wind persist into the following spring. 

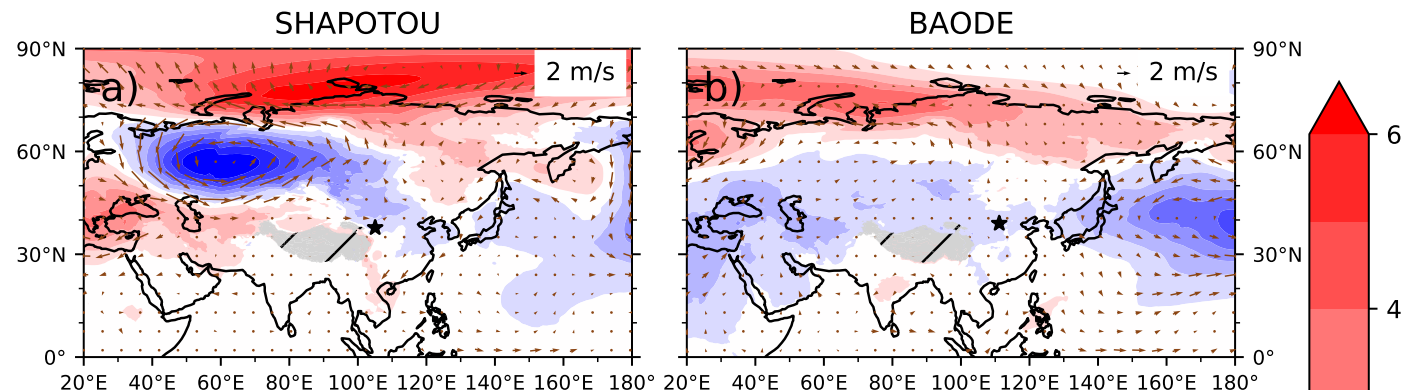

YINCHUAN
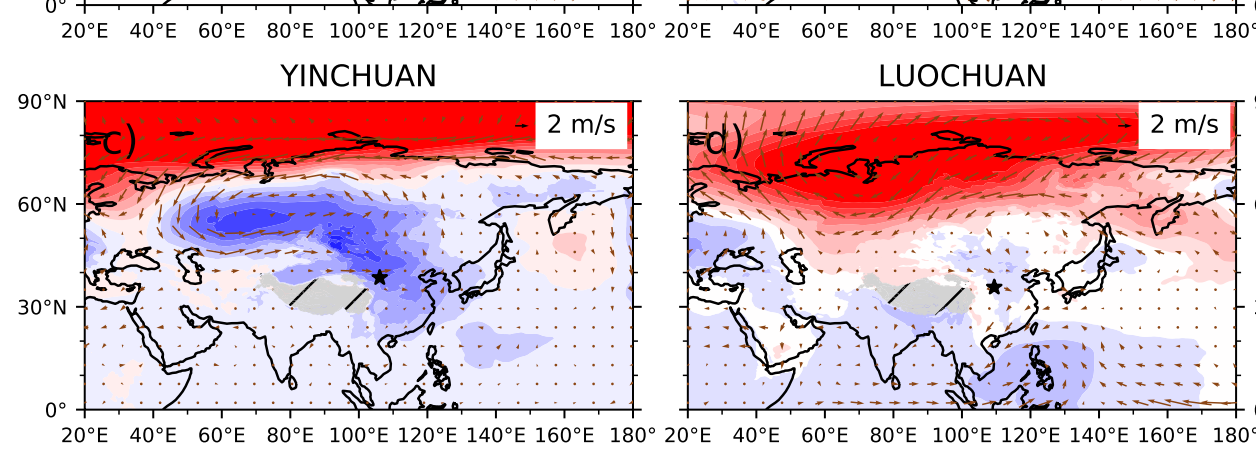

LUOCHUAN

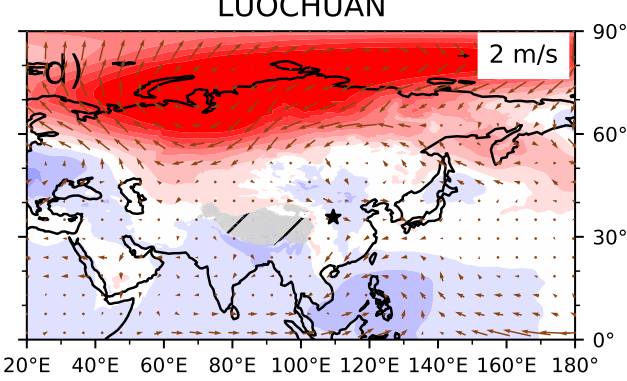

SACOL

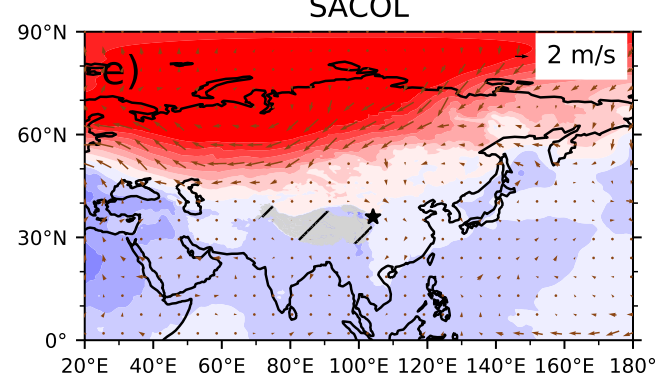

LANTIAN

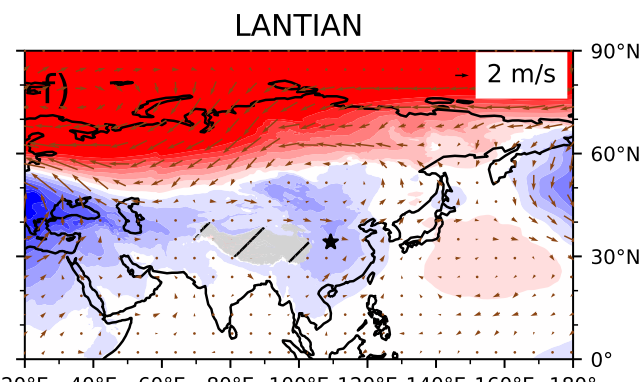
LINGTAI
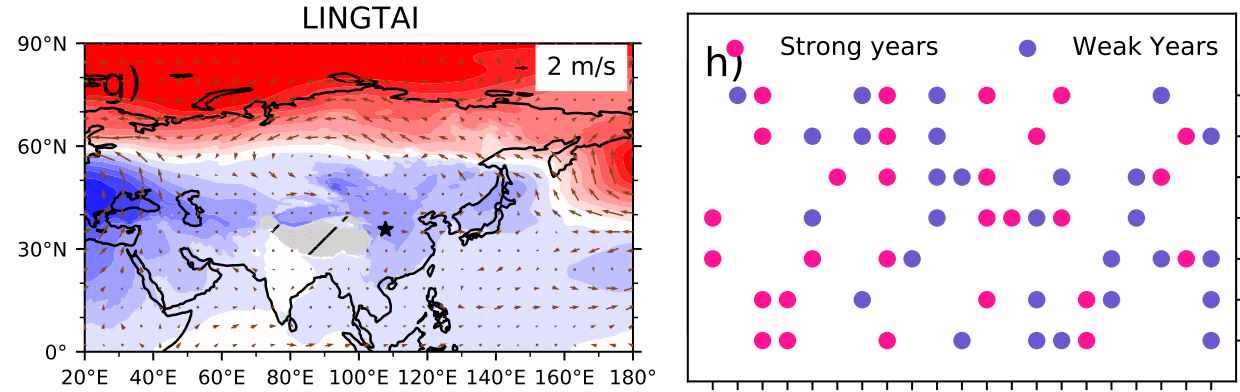

LANTIAN

LUOCHUAN

BAODE

LINGTAI

SACOL

YINCHUAN

- SHAPOTOU

Pon

Figure 5.25. Composite difference anomalies of mean sea level pressure and 850hPa strong minus weak deposition years of the "clay" size bin in winter (DJF) for all the locations (a-g). (h) indicates which years are strong and which years are weak. 

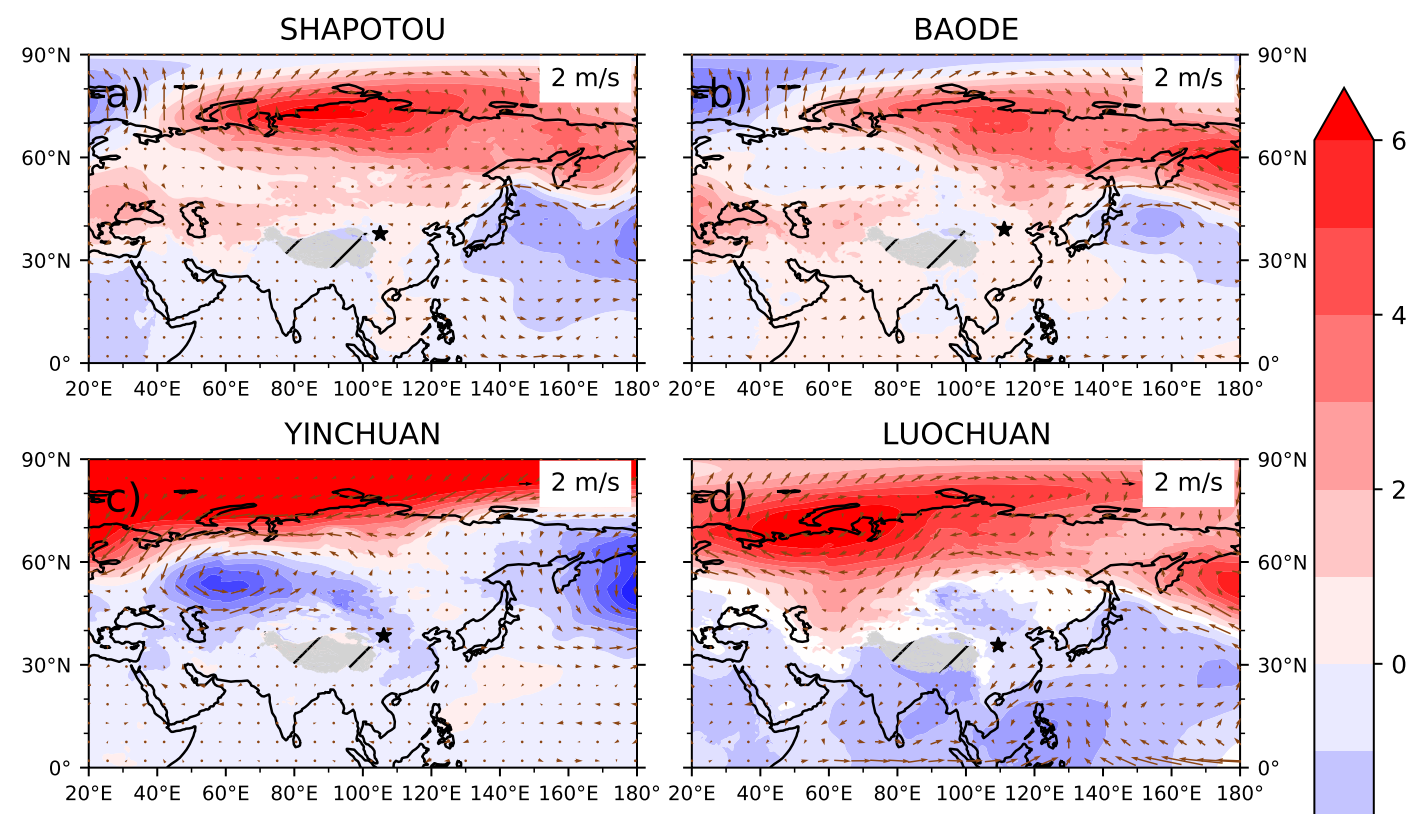

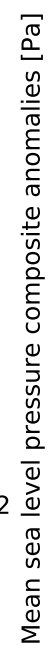
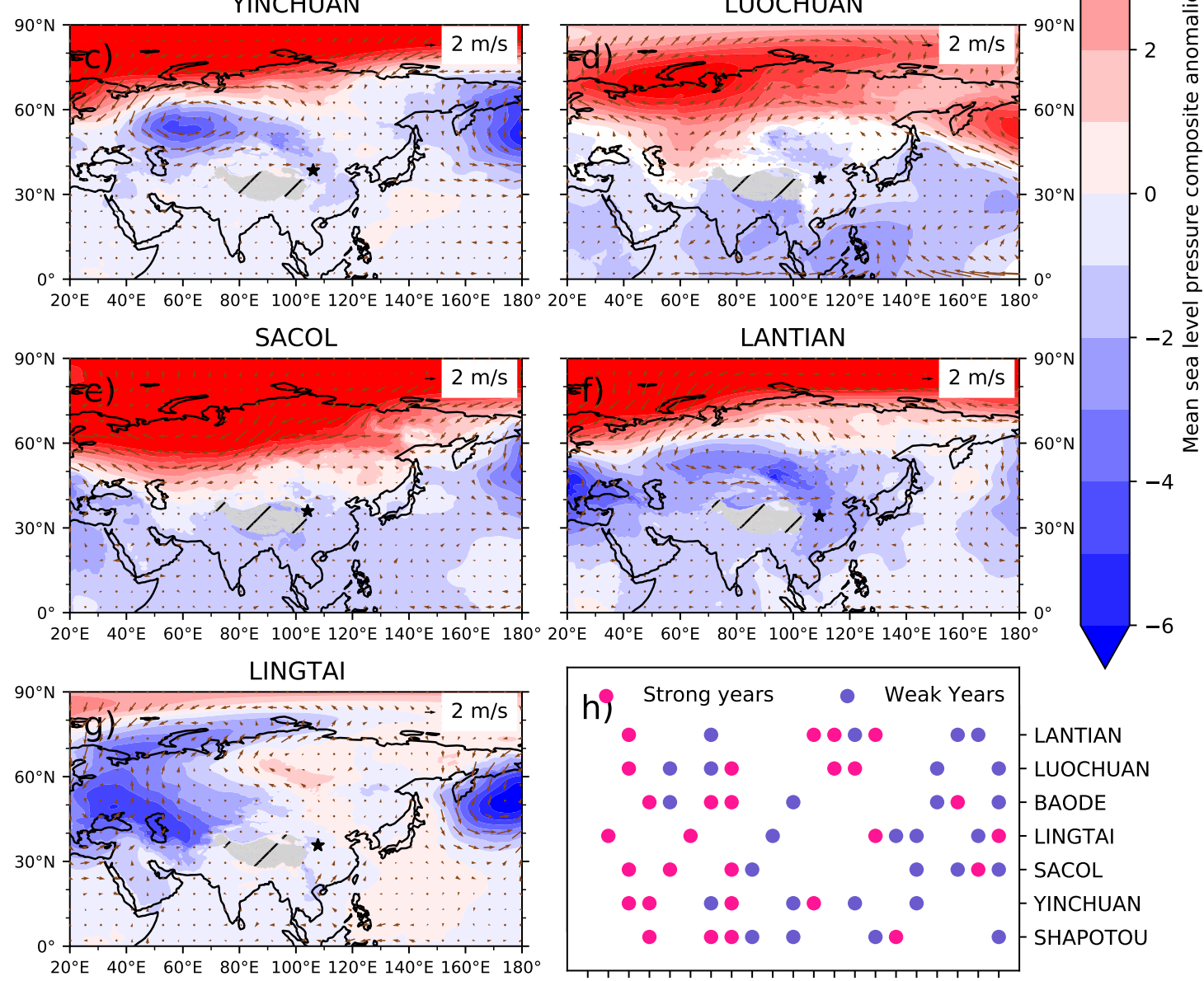

Pon

Figure 5.26. Composite difference anomalies of mean sea level pressure and 850hPa strong minus weak deposition years of the "silt" size bin in winter (DJF) for all the locations (a-g). (h) indicates which years are strong and which years are weak. 

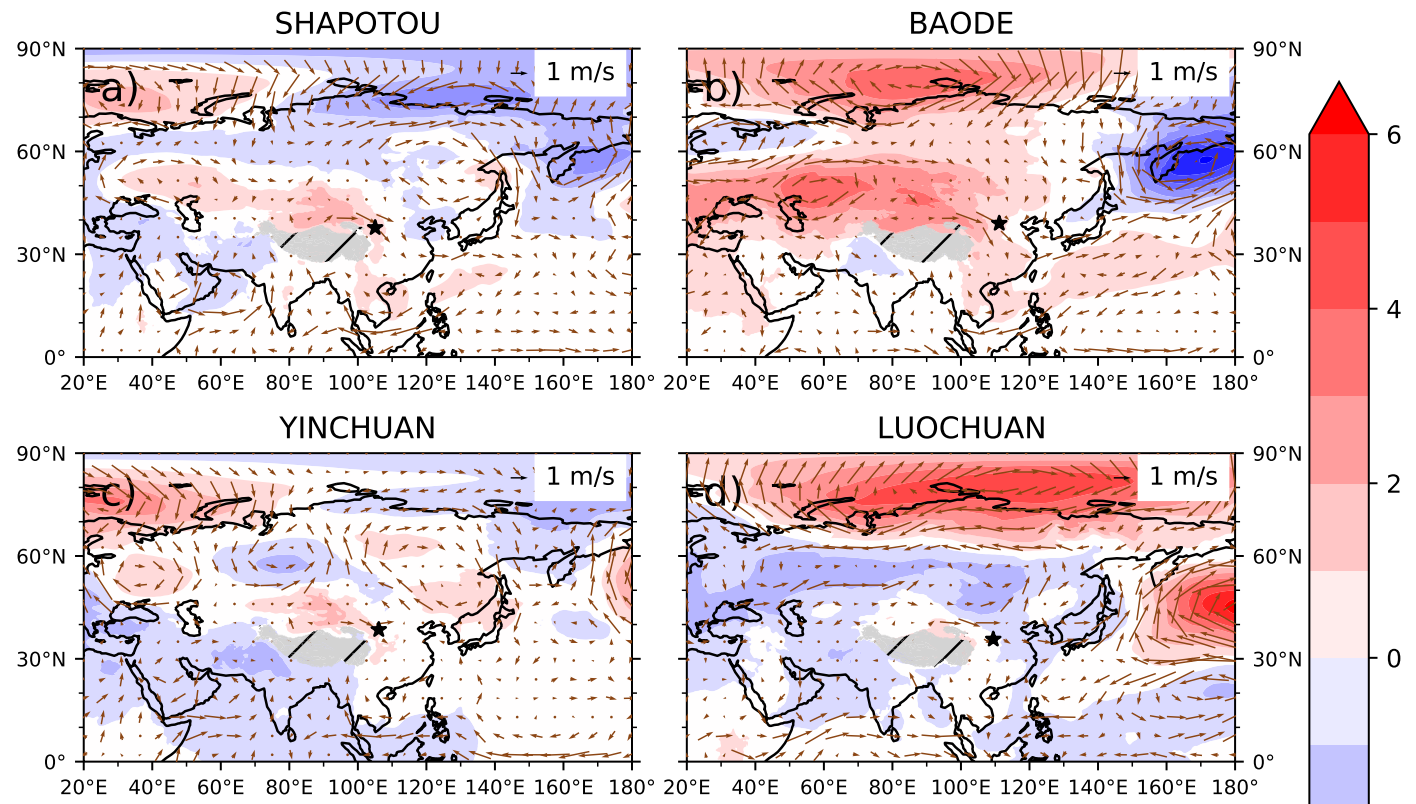

SACOL

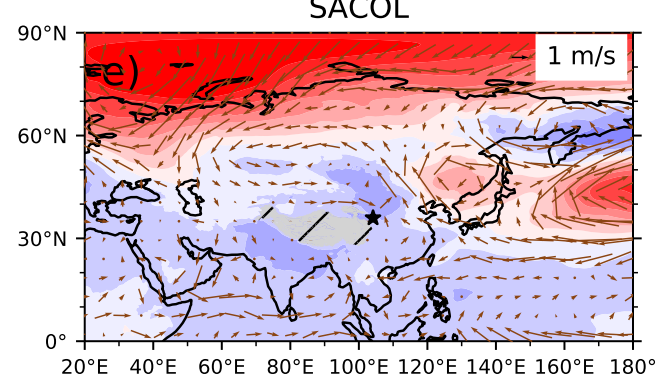

LANTIAN
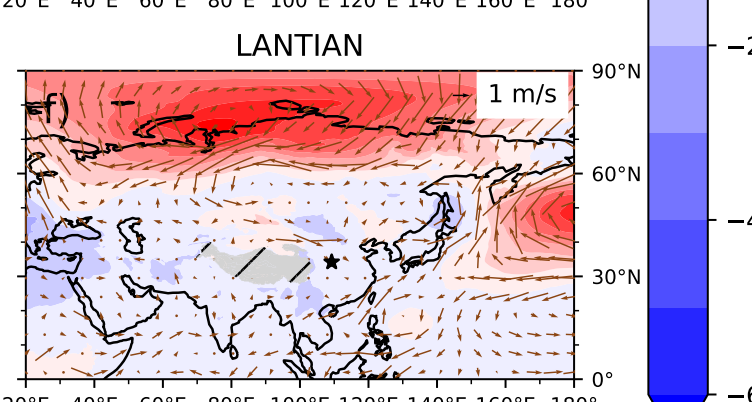

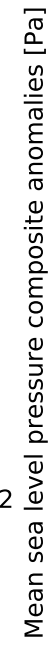
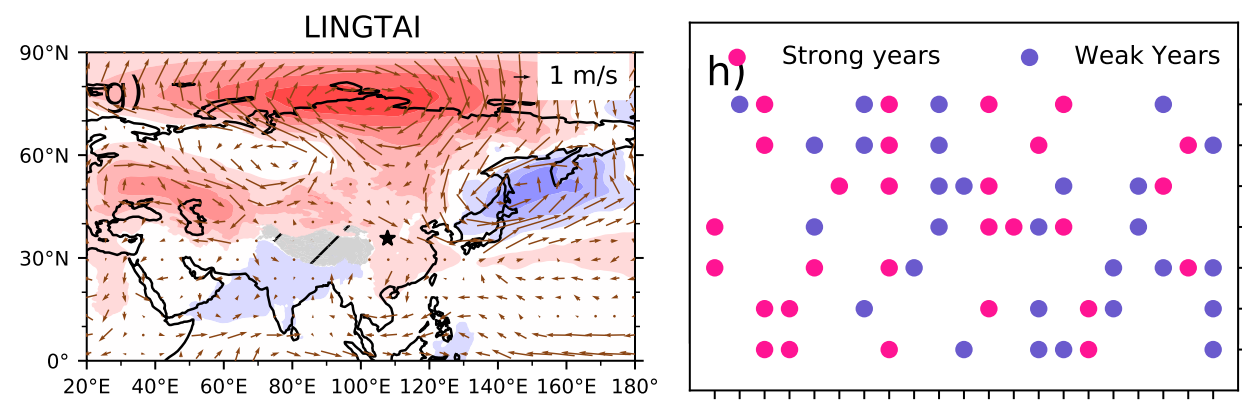

LANTIAN

LUOCHUAN

BAODE

LINGTAI

SACOL

YINCHUAN

SHAPOTOU

\%

Figure 5.27. Composite difference anomalies of mean sea level pressure and 850hPa strong minus weak deposition years of the "clay" size bin in spring (MAM) for all the locations (a-g). (h) indicates which years are strong and which years are weak. 

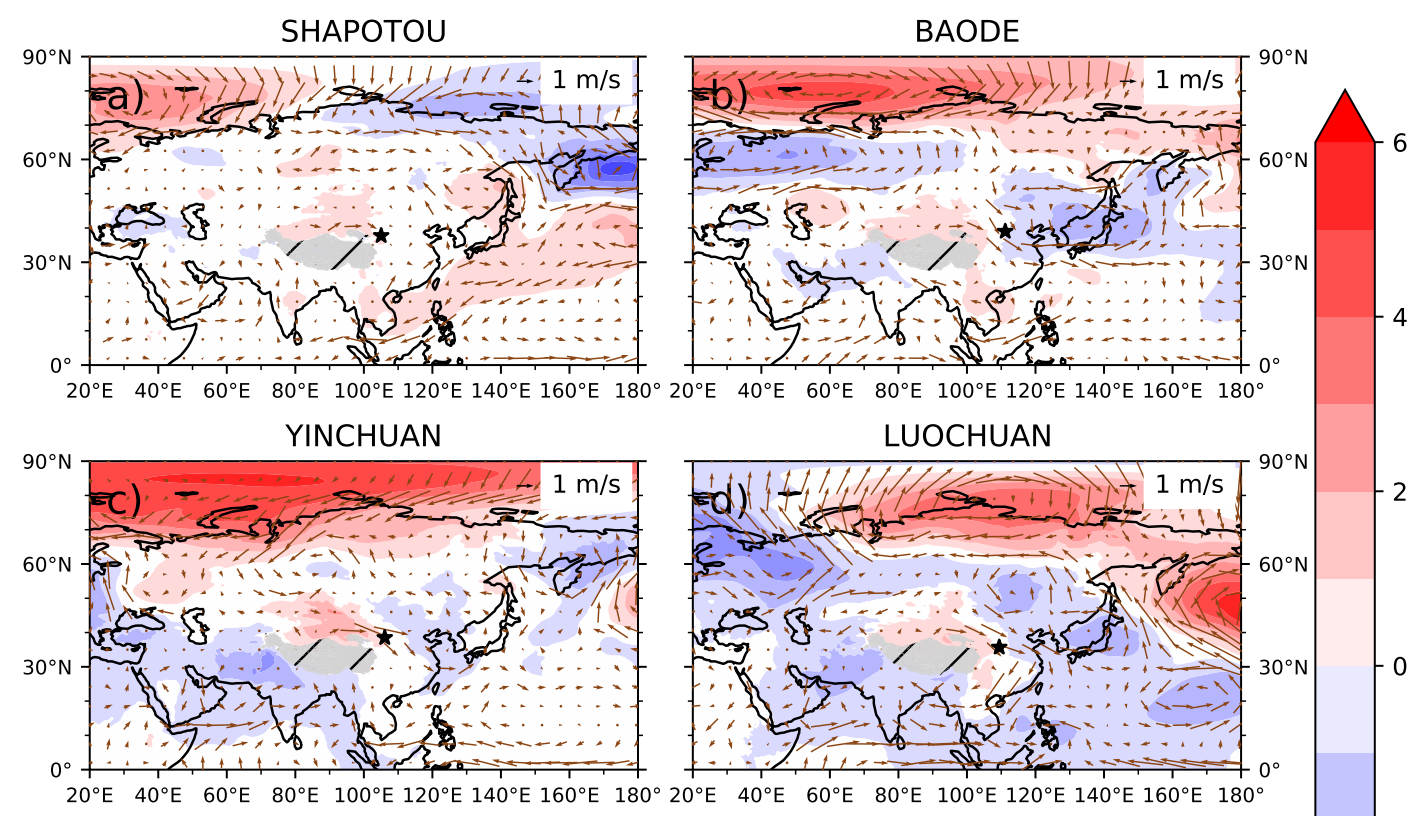

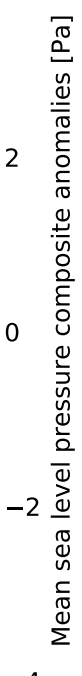
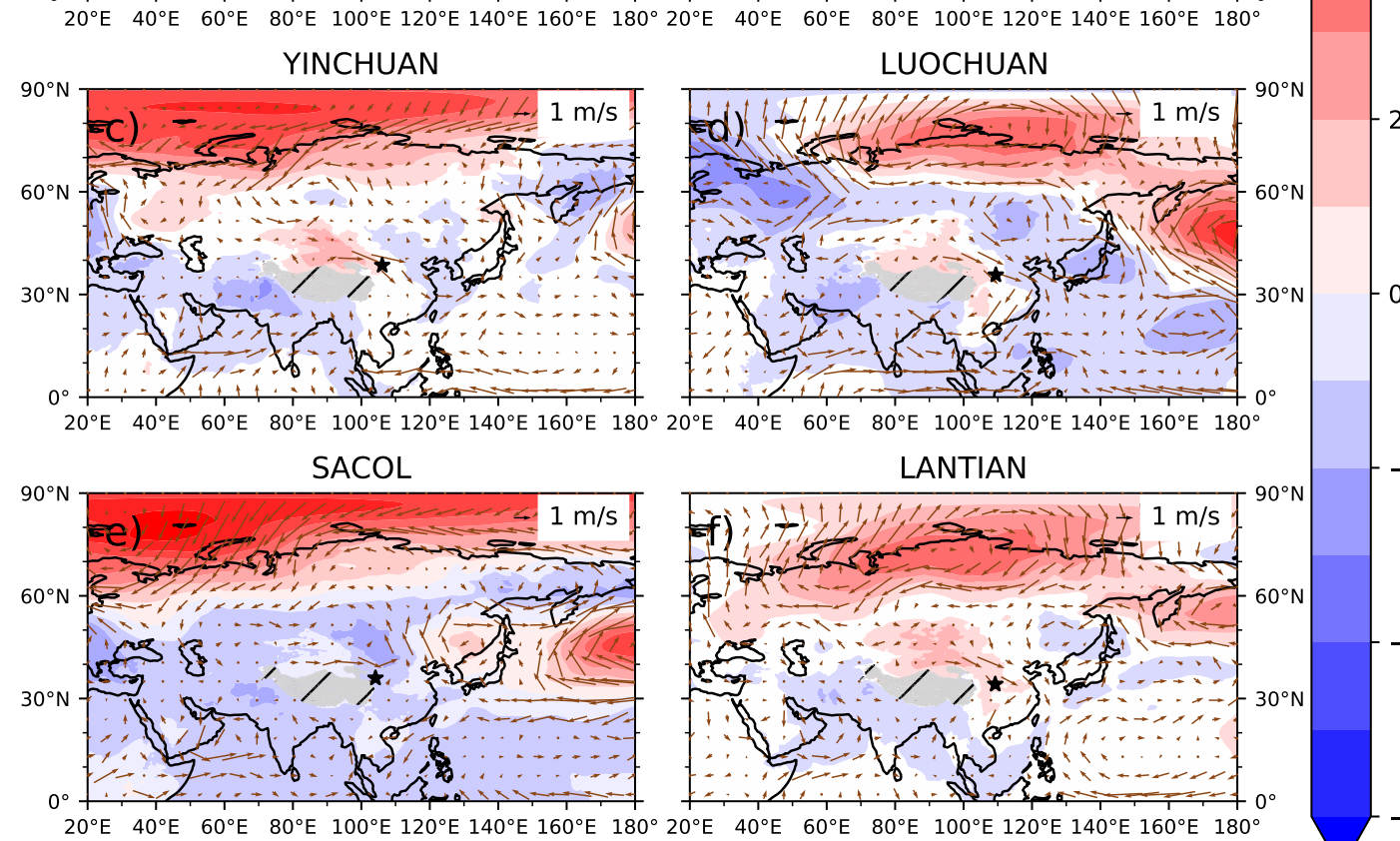
LINGTAI
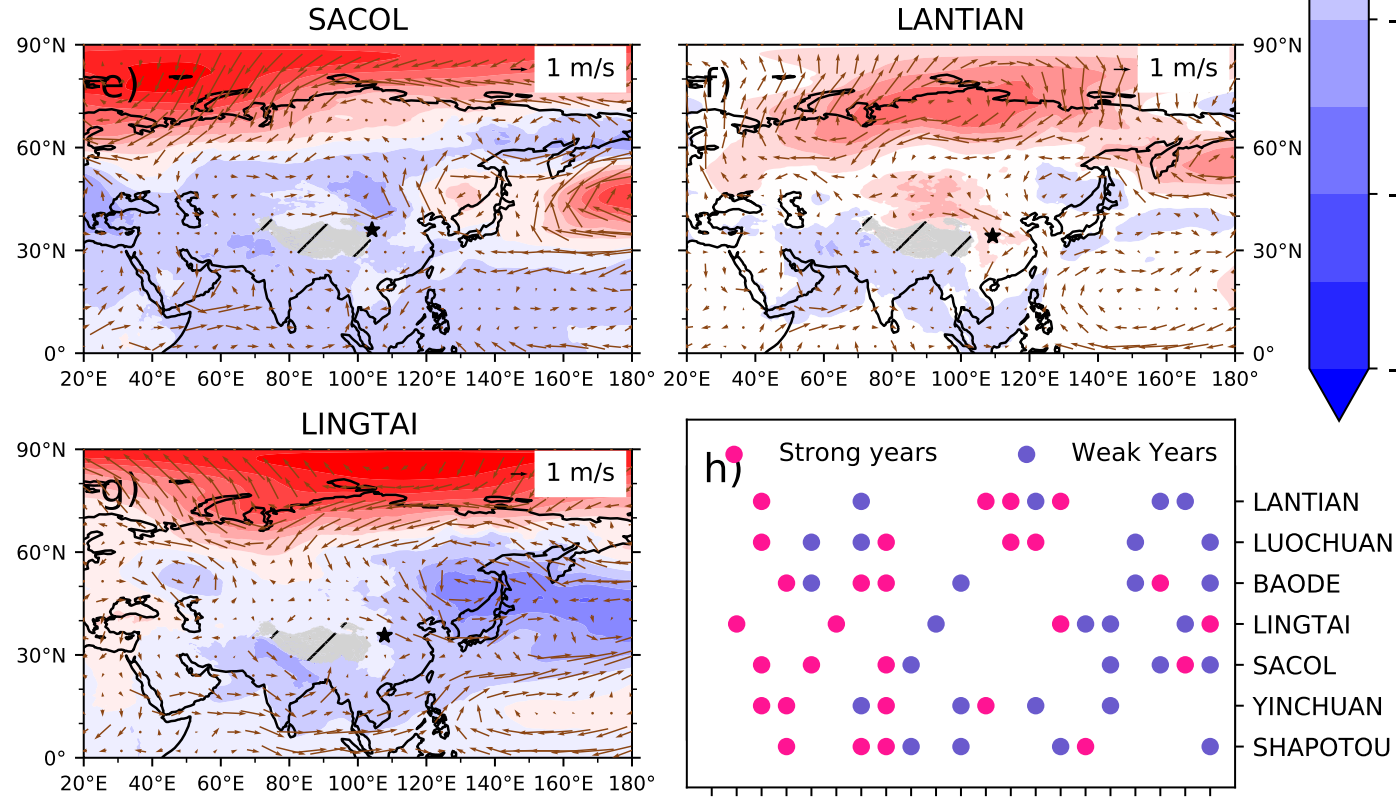

9.

Figure 5.28. Composite difference anomalies of mean sea level pressure and 850hPa strong minus weak deposition years of the "silt" size bin in spring (MAM) for all the locations (a-g). (h) indicates which years are strong and which years are weak. 

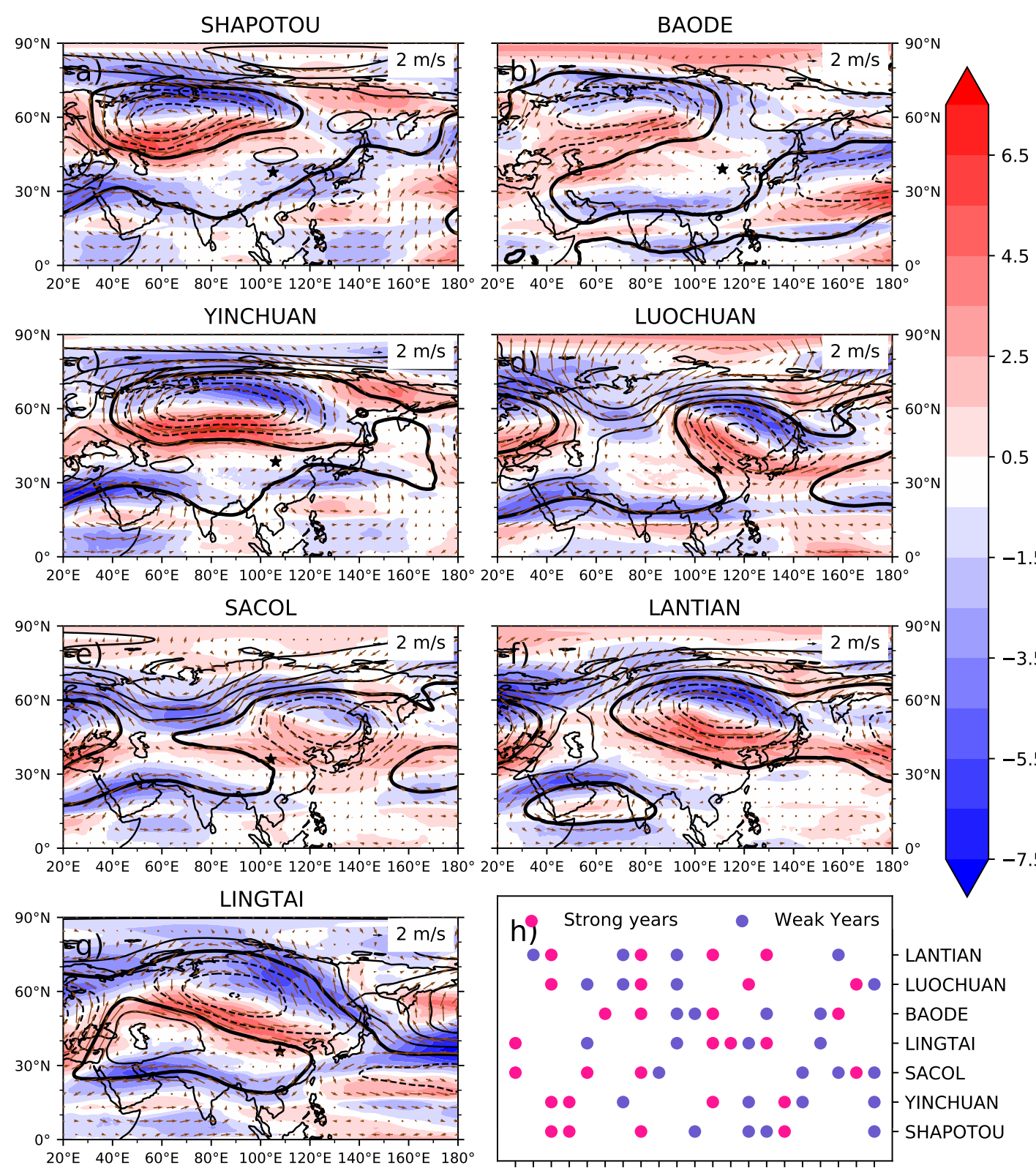

9.0.

Figure 5.29. Winter (DJF) composite difference anomalies of 500hPa geopotential height (contours) and 500hPa wind speed (shading) strong minus weak deposition years of clay in winter (DJF) for all the locations a-g $(h)$ indicates which years are strong and which years are weak. 

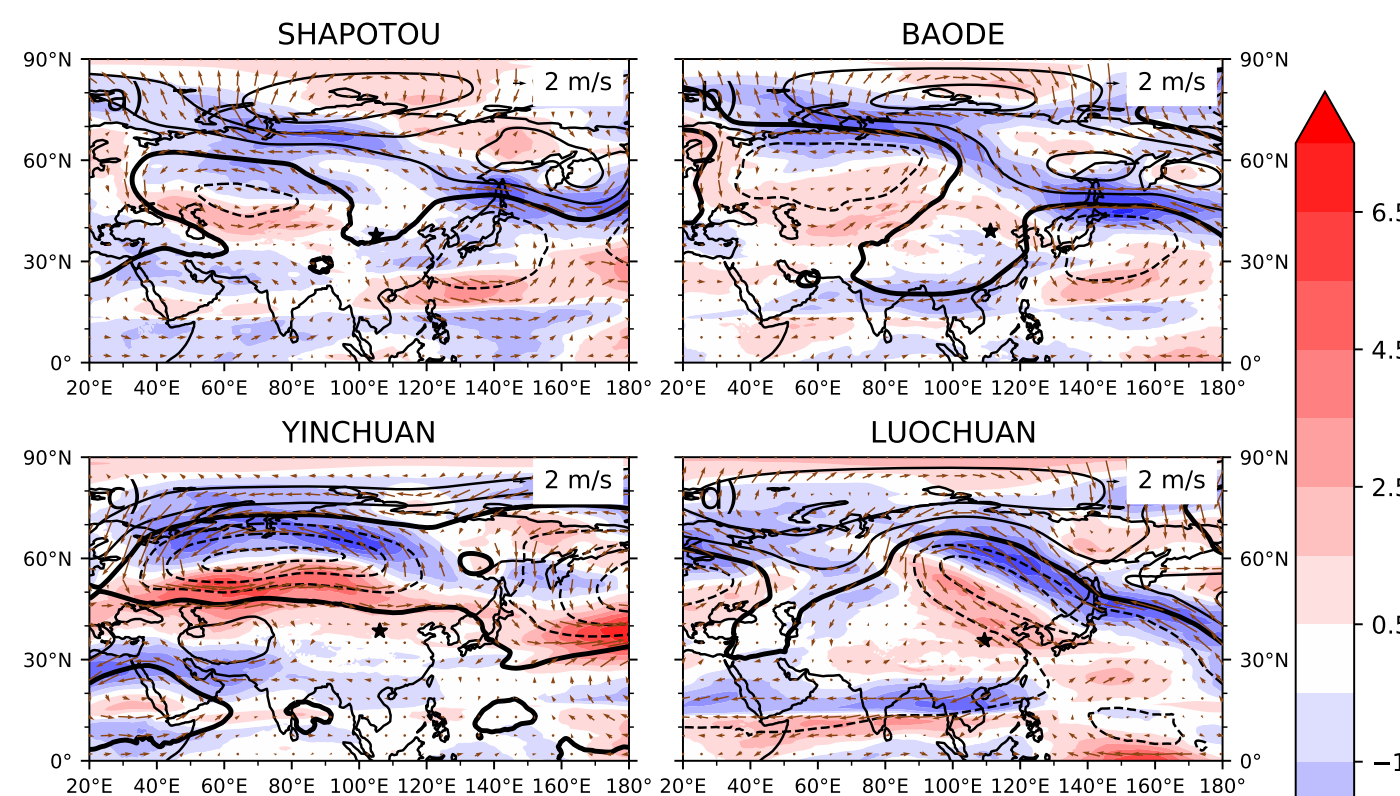

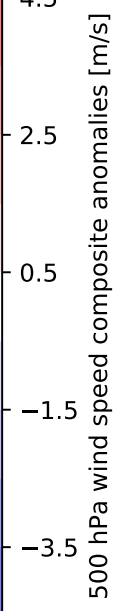
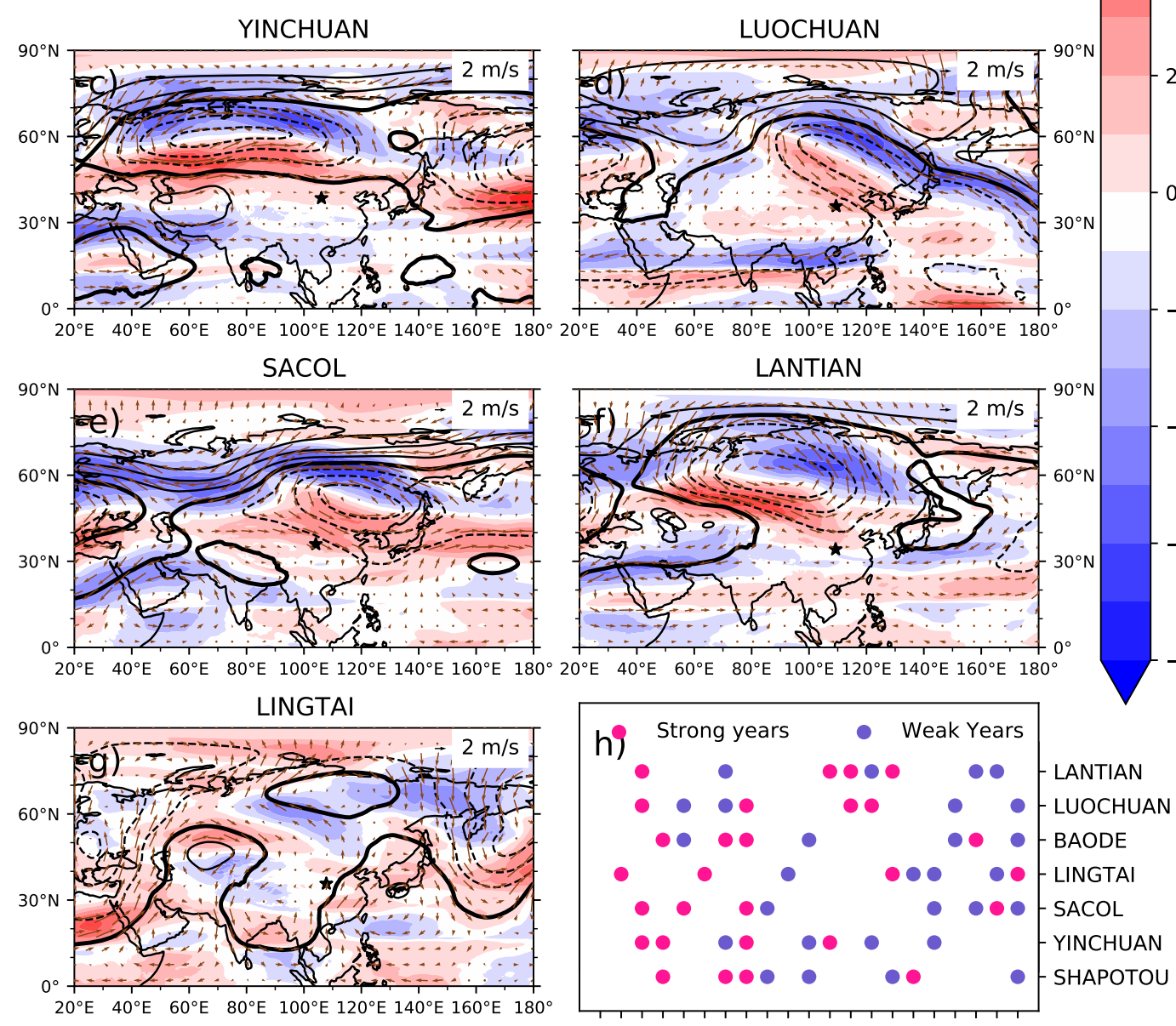

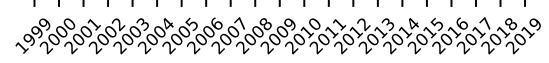

Figure 5.30. Winter (DJF) composite difference anomalies of 500hPa geopotential height (contours) and 500hPa wind speed (shading) strong minus weak deposition years of silt for all the locations $a-g(h)$ indicates which years are strong and which years are weak. 

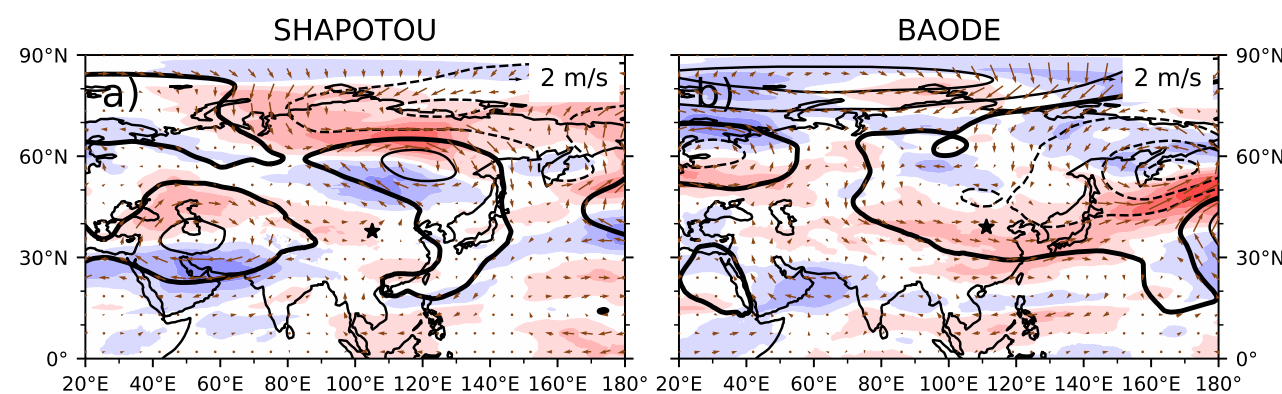

YINCHUAN

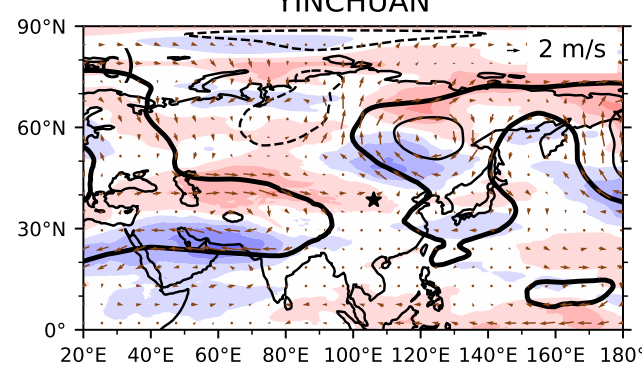

LUOCHUAN

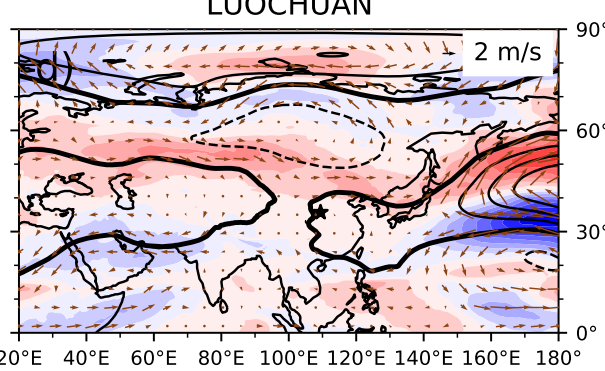

SACOL

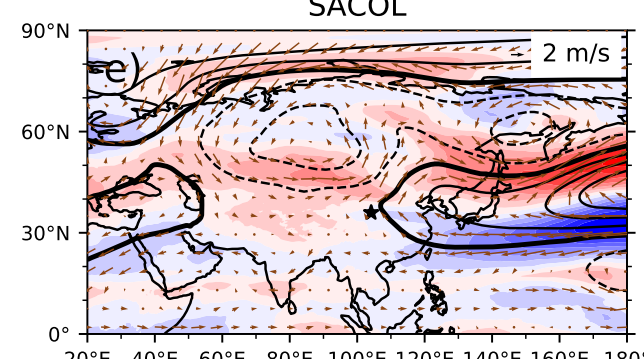

LANTIAN
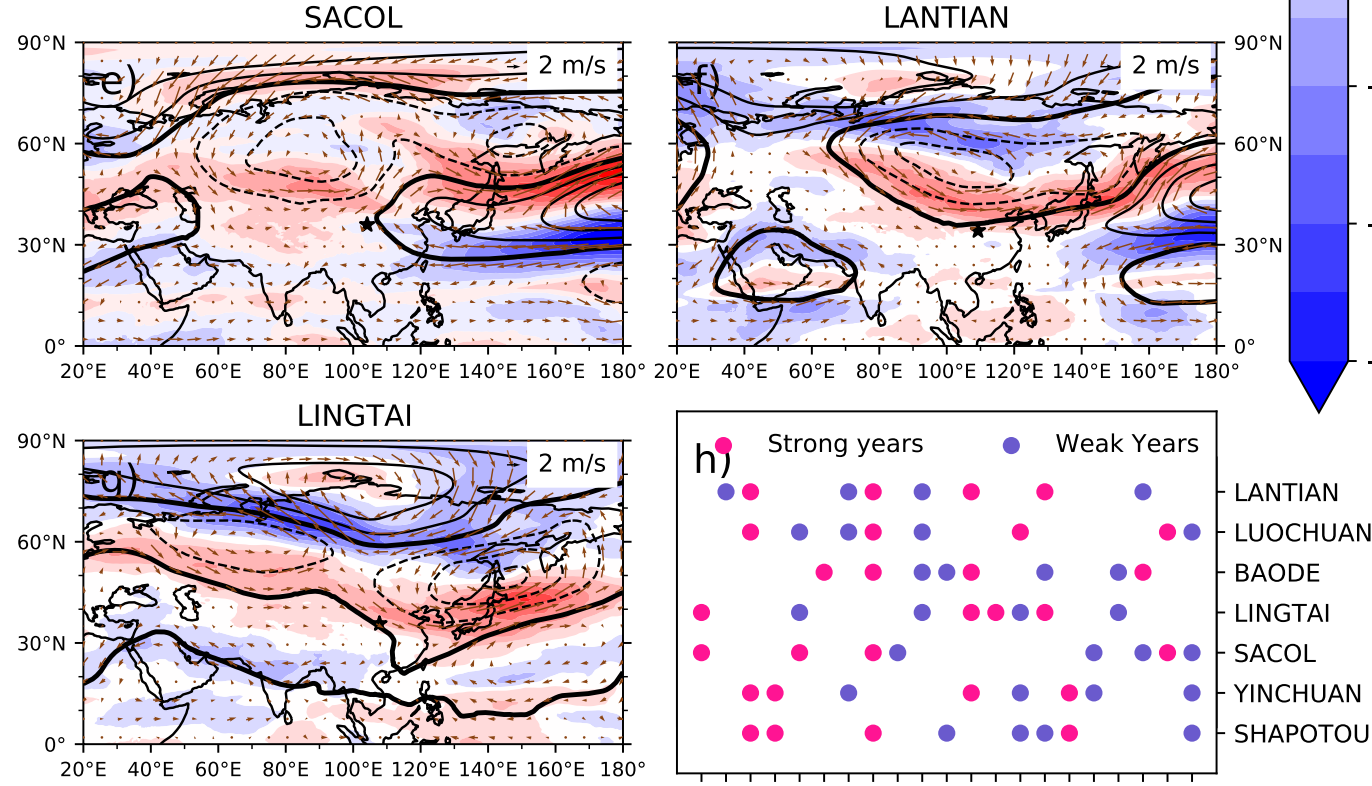

9.00\%

Figure 5.31. Spring (MAM) composite difference anomalies of 500hPa geopotential height (contours) and 500hPa wind speed (shading) strong minus weak deposition years of clay for all the locations $a-g(h)$ indicates which years are strong and which years are weak. 

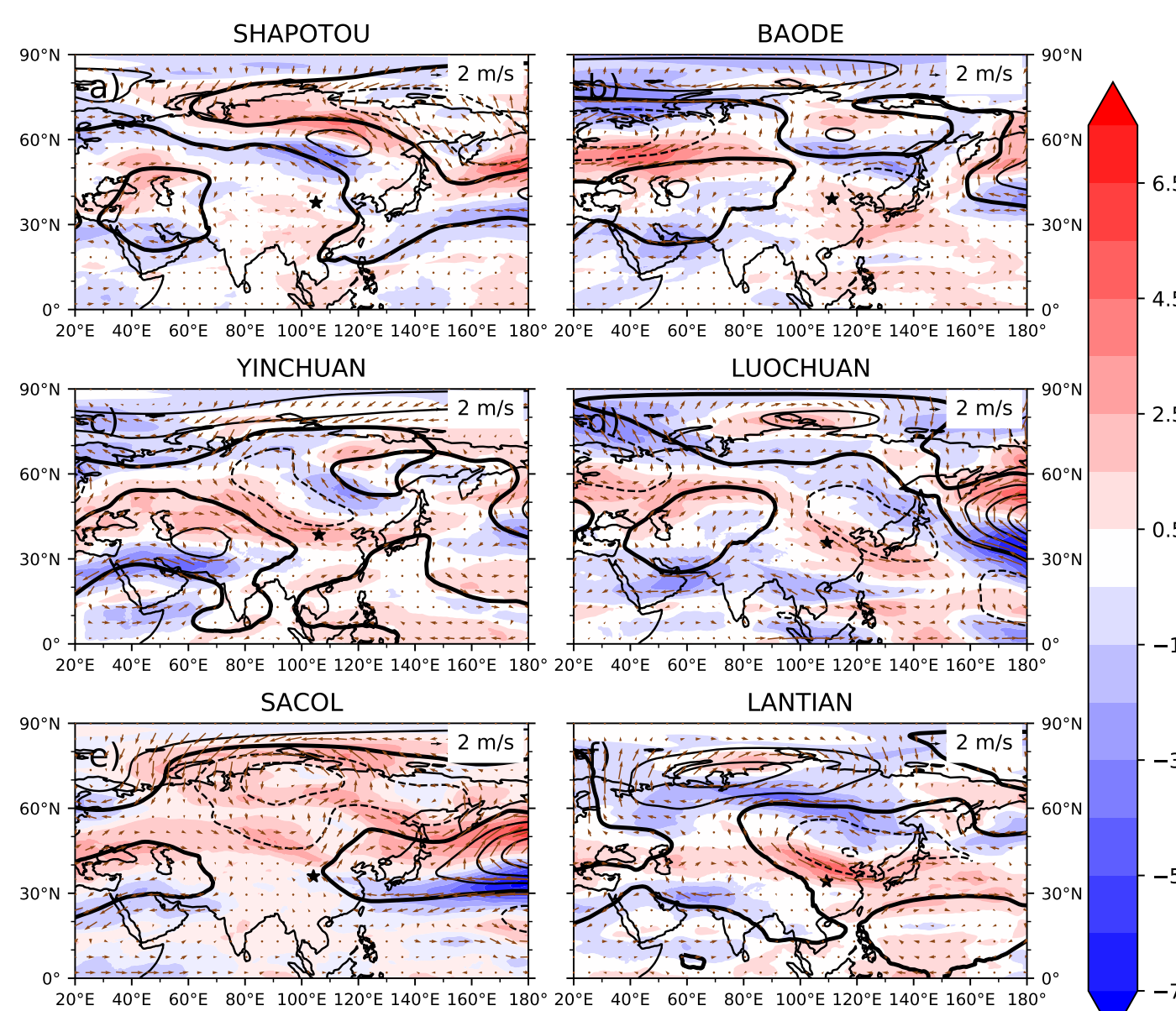

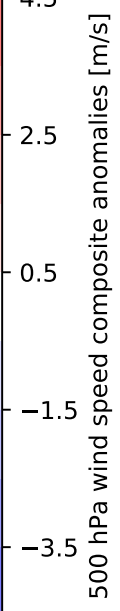
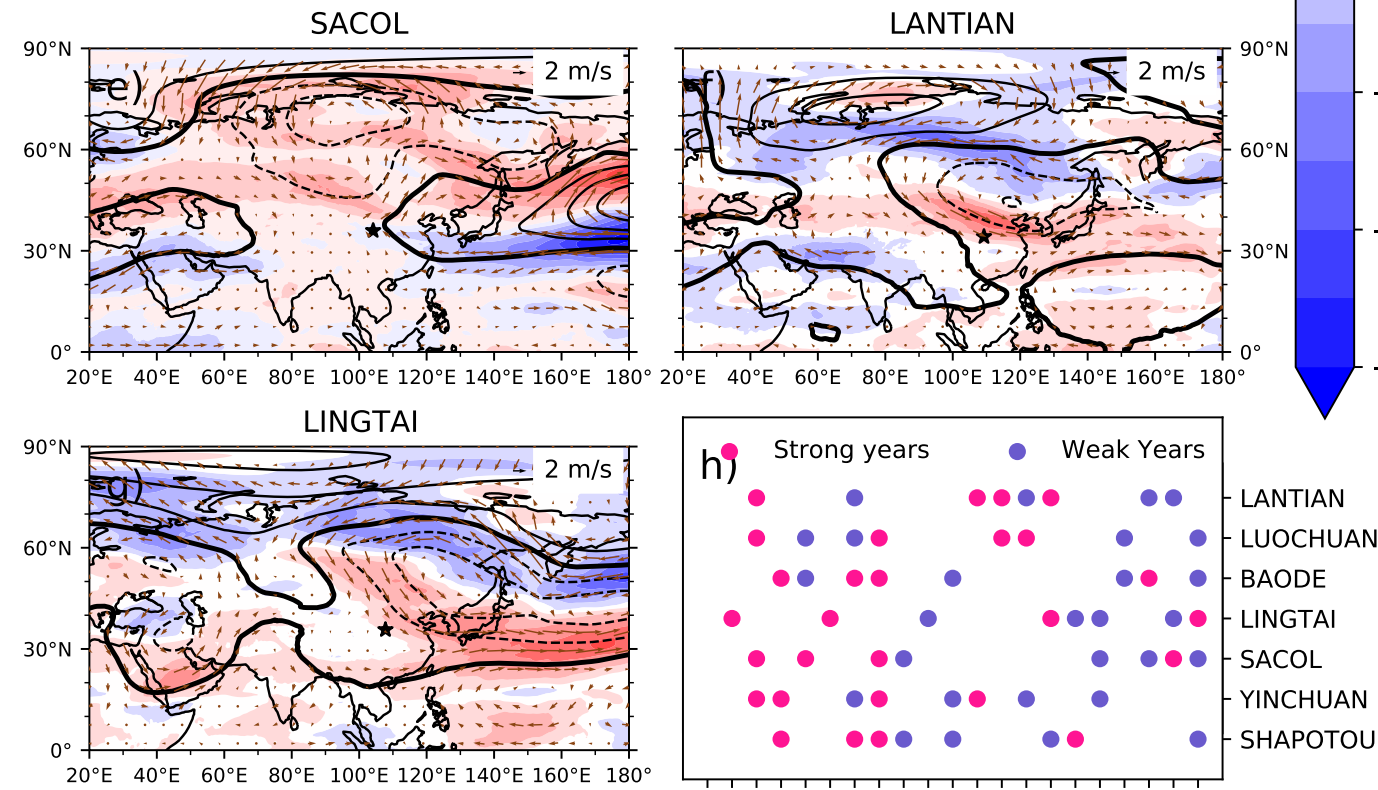

9.

Figure 5.32. Spring (MAM) composite difference anomalies of 500hPa geopotential height (contours) and 500hPa wind speed (shading) strong minus weak deposition years of silt for all the locations $a-g(h)$ indicates which years are strong and which years are weak. 


\section{Chapter 6}

\section{Discussion}

\subsection{Model assessment}

\subsubsection{Model representation of dust emission and deposition}

FLEXDUST estimated an averaged 11Mt of springtime dust emitted from the East Asian source regions. This estimate is lower than previous estimates by Xuan et al. (2004). However, getting the dust emission strength correct is less important in this context because a bias in the total emission strength would not be amplified when multiplied with the emission sensitivity, contrary to errors in the spatial distribution. Validating the spatial distribution of the dust emissions is hard since the dust emission flux is almost impossible to measure directly on a large scale. The absolute emission strength, therefore, has to be validated indirectly based on dust deposition flux measurements. However, comparing the observed and modelled deposition flux does not reliably tell whether the spatial distribution of emissions is reasonably reproduced in the model. Liu et al. (2018) compared the spatial distribution of dust emissions from the MERRA2 reanalysis to satellite-derived Aerosol optical depth (AOD). They found the spatial distribution of AOD to be consistent with the MERRA2 dust emissions. The spatial distribution of dust emissions in MERRA2 is in line with FLEXDUST. This gives some confidence that the spatial distribution of the East Asian dust sources is reasonably well represented in FLEXDUST at least compared to similar dust models. As demonstrated from the sensitivity analysis, achieving a good representation of dust emissions in FLEXDUST relies on an accurate description of the soil and meteorological conditions in the input data.

This is the first modelling study of source attribution of the dust deposited over the CLP with such high spatial resolution, and thus there are not many previous studies relevant for comparison. Shi and Liu (2011) used a dust model coupled with a regional climate model to investigate the provenance of the dust deposited to the CLP. However, they only did source attribution for five source regions and therefore could not examine the inhomogeneities within each source region. In agreement with FLEXPART/FLEXDUST, they found that sources northwest to the CLP had the largest influence on the MAR over the CLP. Still, a more in-depth assessment of the source contribution in our simulations is not possible until more observations or modelling studies doing high-resolution source attribution are available. 
The dust deposition depends on both dust emission and transport. As shown in the model evaluation, the modelled dry deposition does well reproduce both the observed spatial difference and the monthly variability (Figure 5.8), while the modelled wet deposition exhibits larger discrepancies compared to the observation. This is understandable as the dry deposition process is much simpler than wet deposition and has fewer inherent uncertainties in the model. It is noted that the absolute deposition flux is underestimated for both dry and wet deposition. The dry deposition bias is different from the wet deposition bias. The dry deposition bias suggests a more constant underestimation, with the largest bias during strong deposition months. In contrast, the wet deposition bias is less consistent and is not connected to either weak or strong deposition events.

It is noticed that Groot Zwaaftink et al. (2016) did not report such large biases based on their comparison of modelled and observed annual dust deposition fluxes when combining FLEXDUST with a forward FLEXPART simulation. This does not mean the same bias was not present in their study, because the apparent biases on the monthly level compensate each other such that the annual deposition was around the observed value. Furthermore, since Groot Zwaaftink et al. (2016) used a forward simulation, which means that the deposition at the measurement location has to be extrapolated from the output grid. The spatial averaging could also have had a similar compensating effect to taking the annual sum. Besides Groot Zwaaftink et al. (2016), there have not been other studies that have evaluated the performance of FLEXPART and FLEXDUST to simulate the deposition flux of mineral dust at individual measurement stations.

Since the focus of this thesis is more on the interannual variation of the dust deposition than the absolute values of the dust deposition. It is critical that FLEXPART/FLEXDUST get the right interannual variation of the springtime dust deposition to the CLP. Based on the two years of data used for validation here, FLEXPART does agree with the observation on the year to year difference. However, with only two years of data, it is hard to say that this is generally the case. Since the total deposition is so heavily skewed towards wet deposition, the source contribution primarily depicts the source regions during the strong wet deposition episodes. Thus, the bias in wet deposition has the potential to skew the whole analysis.

In conclusion, the East Asian dust emission flux is well represented in FLEXDUST compared to similar dust emission models, but the performance depends on the input data. There are discrepancies between observation and modelled deposition, especially for wet deposition, which will be further discussed next.

\subsubsection{Causes of modelled deposition bias}

There are three main sources for potential biases; (1) errors in the input data, (2) poor choice of model parameters, and (3) internal model biases caused by inadequate representation of the physical processes. The sources of bias are different between FLEXPART and FLEXDUST and therefore, one model might have a larger influence on the bias in the modelled deposition as a whole.

It is found that meteorological forcing data is important for the performance of FLEXDUST and FLEXPART. Changes in the forcing data produce drastically different spatial and temporal variability in the models. For instance, models forced by ERA-Interim are not able to resolve the complex topography surrounding the Taklamakan desert. Both reanalyses cannot resolve weather that occurs on scales smaller than the spatial and 
temporal resolution of the model. This limitation might disproportionally affect the modelled wet deposition since the model and observation see the precipitation differently. Whereas the model forcing provides precipitation in one grid cell, the observation collects precipitation at a single point. Thus, FLEXPART has to parametrise the subgridscale precipitation. Since precipitation can be local, especially during summer showers. Therefore, there might not have been any precipitation occurring at the measurement location, while it might have been raining in the closest ERA5 grid cell. This might explain the larger disagreement between the model and observation on the amount of wet deposited dust in summer compared to spring and winter. This is less of a factor for dry deposition since the dry deposition is strongest during periods with high atmospheric dust concentration and such events cover a broad area (Osada et al. 2014). While the impact of temporal resolution of the forcing was not considered in the sensitivity analysis, it is an aspect that might be important for the model performance. As the processes relevant for the dust cycle occur on timescales less than one day (Shao et al. 2011). Thus having more meteorological data points during dust events could improve the model representation of the dust cycle.

The parameters affecting the dry deposition are only the particle size and density. While wet deposition in addition to the aforementioned parameters also depends on the below and in cloud scavenging efficiencies. While only the sensitivity of particle density and below cloud scavenging were examined in this work. The results for this analysis showed that the density of the particles had a negligible effect on the dry deposition rate. The wet deposition showed a slightly stronger dependence on the particle density, possibly since the dust must be lifted to high altitudes to be scavenged inside the clouds. Still, the overall dependency on the particle density for the modelled deposition was small. Turning the below cloud scavenging off yielded, as expected, a reduction in the contribution from the proximal source regions. Lastly, Grythe et al. (2017) demonstrated that the modelled wet deposition scheme in FLEXPART could be sensitive to in-cloud scavenging parameters. Doing an in-depth analysis of the cloud scavenging parameters and the wet deposition of dust in the model could help better understand this bias. The overestimation of wet deposition compared to observation could be reduced by adjusting cloud scavenging efficiencies.

While Groot Zwaaftink et al. (2016) is the only study that has evaluated the performance of FLEXPART and FLEXDUST to simulate mineral dust, there have been more studies done comparing simulated deposition of black carbon with observations, e.g. Choi et al. (2020) and Grythe et al. (2017). Choi et al. (2020) suggested that FLEXPART was not able to capture the regional variation of blackcarbon due to severely underestimation of the in-cloud scavenging coefficient. Moreover, by diagnosing the relative importance of the input variables they found that the convective available potential energy (CAPE), should be considered an important parameter to improve the in-cloud scavenging scheme. There is also a known issue with the current wet deposition scheme related to the interpolation and disaggregation of the input variables (Tipka and Seibert 2021). This will be worth investigating in the future.

While it is hard based on this work to draw a definitive conclusion on whether biases in FLEXDUST or FLEXPART are the main cause of the discrepancy between the model and observation of the dust deposition at a site. Still, given the good agreement between the modelled and observed dry deposition and that the East Asian dust sources are reasonably well represented compared to other dust models, we suggest that the main cause of the bias in the deposition flux is with the wet deposition in FLEXPART. Several potential 
causes for the deposition bias has been proposed. Note that substantial bias in dust deposition is not exclusive to this modelling approach, and the dust models generally struggle to adequately represent the dust deposition (Shao et al. 2011; Zhang et al. 2019). Therefore, more studies combining fieldwork and dust modelling are necessary to better constrain and improve the modelling of dust deposition.

\subsection{Climatology of the East Asian dust cycle}

\subsubsection{Dry- versus wet deposition}

The main mode of deposition to the CLP, according to the FLEXPART/FLEXDUST model simulations, is wet deposition and is the case for both the clay and silt particles. Compared to dry deposition, wet deposition is influenced by other factors in addition to the mean flow. This was shown both from the sensitivity experiments and the correlation analysis. The wet deposition at most locations was not significantly correlated with any circulation indices (except Lantian and SACOL). Moreover, the correlation between wet deposition at the receptor and emissions was also weak. This implies that the deposition over the CLP is primarily episodic. Furthermore, an examination of the correlation between wet deposition and precipitation at the receptor (not shown) showed no significant relationship between the amount of precipitation and wet deposition. A potential mechanism for how wet deposition could be important for the MAR to CLP must consider dust entrainment and precipitation. The passage of cold fronts is important for the formation of dust events. Precipitation typically forms ahead of or along the surface cold front as the warmer air is lifted over, the denser cold air behind the cold front (Markowski and Richardson 2011). Moreover, as the cold front passes through the source regions, it generates strong winds at the surface, entraining the dust into the upper troposphere (Li et al.2015). The dust can then be swiftly transported to the frontal rain band, efficiently scavenged by the clouds, and rained out.

The dust transport trajectories from FLEXPART support this interpretation. As seen from the increase in altitude of the trajectory, starting around 12 hours before approaching the receptor location. This increase in altitude would be consistent with the convective nature of the cold frontal rainband (Figure 5.11). Moreover, the more southerly orientation of the wet deposition trajectories suggests a larger contribution of moist southerly air masses (Figure 5.11). Conversely, the dry deposition trajectories have a larger northerly component, indicating more dry and cold air arriving at the receptor (Figure 5.11).

The East Asian monsoon (EAM) predominately drives the seasonal shift in the circulation of this region. Therefore, the wet and dry deposition trajectories can also be interpreted in terms of the transition from winter monsoon to summer monsoon, with the wind reversing direction from generally northerly in winter to southerly in summer. Dai et al. (2021) divided the EAM into eight stages. The three stages of the EAM that are relevant for the dust transport is the late winter stage (February to early March), spring stage (March to late May) and pre-Meiyu (late May to late June). Predominately, northwesterly winds characterise the late winter stage. Transitioning into spring, the southerly wind is strengthened, turning the northwesterly winds into predominately westerly winds. With the southerly shift in the predominant wind direction, the amount of precipitation is also enhanced. Finally, in the pre-Meiyu stage, the southerly wind is further enhanced, while the westerly and northerly winds are substantially weakened. 
Thus, based on the predominately northwesterly transport indicated by the dry deposition trajectories, the conditions for strong dry deposition events are most favourable during late winter and early spring. Conversely, the strengthened southerlies in the spring and pre-Meiyu stages suggest that the conditions for wet deposition episodes are more favourable in spring and early summer.

Note that the large contribution of wet deposition to the total dust deposition over the CLP can be due to the bias in the wet deposition, as discussed previously. Although there is observational evidence suggesting that wet and dry deposition could be equally important for the MAR to CLP (Wang et al. 2015). This is in contrast with other studies suggesting that dry deposition is the predominant mode of deposition to the CLP (Shi and Liu 2011; Zhang et al. 1993). Even supposing FLEXPART can capture the relative importance of wet to dry deposition over the CLP under present-day conditions, it is likely that this ratio depends on the climatic conditions. Therefore, one has to be cautious to infer past deposition patterns based on present-day simulations.

\subsubsection{Spatial variation of the dust sources to the CLP}

Based on the FLEXPART/FLEXDUST simulations, the deserts North West of the CLP were the main sources of the dust deposited over the CLP. However, there are still noticeable differences in the source areas for the different sites. Generally, more dust was deposited at western sites compared to the eastern sites. Shapotou, Yinchuan and SACOL, all located on the western side of the Liupan Mountains, have a large contribution from the Tengger and Badain Jaran deserts. As opposed to Baode, Luochuan and Lantian, which are more influenced by the deserts located on the Inner Mongolia Plateau, suggest that the Liupan Mountains could play a role in differentiating the source region to western and eastern CLP. The topography could explain some of the differences in source regions between SACOL and Lingtai. While SACOL experiences less dust transport from the northerly deserts, Lantian is the opposite. This is also consistent with the centroid dust loading trajectories, which are more westerly at SACOL than that at the other locations.

The north-south gradient in precipitation of the CLP offers a possible explanation of the difference in the deposition at Luochuan and Lantian. Luochuan and Lantian have very similar source regions and the amount of dry deposited material (Figure 5.12). However, Luochuan experiences much less wet deposition. As moisture is typically transported from the south, a significant portion of the precipitation might have precipitated before arriving at Luochuan. In fact, the precipitation at the ERA5 grid cell nearest to Luochuan is about $30 \%$ less than Lantian. In addition, the wet deposition centroid dust loading trajectories for the two sites are nearly identical, suggesting that the same frontal systems are causing precipitation at both locations.

\subsubsection{Fine versus coarse dust}

It is found that the spatial difference among the sites was largest for the silt-sized particles (Figure 5.13. The main source regions of the coarse dust are located slightly further from the receptor location than the fine dust. Moreover, while the deposited amount of fine dust does not vary that much between the sites, the deposition of coarse dust varies by more than one order of magnitude between Shapatou, the site experiencing the strongest deposition, and Luochuan, the weakest deposition site. This result is consistent with the 
size distribution of Loess deposits becoming finer along the transect from the northwest to the southeast (Ding et al. 2000; Sun et al. 2003).

As opposed to the silt particles, the clay particles could be transported within the lower troposphere even from the most remote sites (Figure 5.11). This could explain why dry deposition is more efficient for fine particles relative to wet deposition compared to coarse particles. Since the coarse dust entrained into the lower troposphere gets deposited over the source regions before arriving at the receptor, thus the silt size particles have a stronger dependence on upper-level transport to reach the CLP. This also makes it likely for the coarse dust to be scavenged by clouds and wet deposited, as evident from Figure 5.13h. The higher efficiency of wet deposition for the silt-sized particles could also be caused by the higher $\mathrm{CCN}$ efficiency assumed in the simulations.

The following processes that could carry large dust particles into the upper troposphere are turbulent eddies, convection and mechanically forced lifting. The passage of a cold front destabilises the atmosphere producing favourable conditions for deep convection and strong turbulent eddies (Markowski and Richardson 2011). It has been shown by Yumimoto et al. (2009) that slopes of the Northern Tibetan Plateau (NTP) could produce updraft winds strong enough to lift the dust from the Tarim Basin to a height between 9-12 km. Mechanical lifting might be the mechanism for responsible the localised area of high dust contribution over the Taklamakan to the CLP in Figure 5.13

\subsection{Interannual variability of the East Asian dust cycle}

\subsubsection{Dust emissions}

The results from the EOF analysis of the interannual variability of East Asian dust emissions identified two predominant spatial patterns. The first EOF showed a general increase of dust emissions for all the sources, similar to the spatial pattern identified by Liu et al. (2018) and Liu et al. (2020). The DJF composite difference of MSLP and 850hPa wind of EOF1 indicated a negative AO-like pattern, with positive MSLP anomalies over the Arctic region. The composite difference also indicated a weakened $\mathrm{SH}$, suggesting that a strong EAWM is unfavourable for dust emissions from East Asia. This is consistent with the correlation analysis, which showed negative although weak correlations between emissions and the winter monsoon indices. The weakened $\mathrm{SH}$ is also present in the spring composite. This is consistent with the arguments of Roe (2009), that CAOBs occur as a consequence of the breakdown of the $\mathrm{SH}$ and thus, a persistent $\mathrm{SH}$ would cause fewer CAOBs.

The spatial pattern of the second EOF has not been discussed in the literature previously (Figure 5.15). It shows a dipole pattern between emissions in Taklamakan and Mongolia. The composite anomalies for the second EOF resemble a weakened EAWM. However, the centre of the pressure anomaly is located further northeast than the climatological position of the $\mathrm{SH}$ in Figure 3.2. Transitioning into spring, there is now a negative pressure anomaly over the Taklamakan desert producing anomalous easterly wind and enhanced emissions from Taklamakan. However, the easterly wind anomalies make these conditions unlikely to cause an increase in the MAR to the CLP. Therefore the negative mode of the EOF2 would have the larger influence on the deposition CLP. 
Relating the interannual variability of emissions to the deposition at the receptor. The site with the strongest relationship with EOF1 is Lantian. Which share similarities in the composite difference and has a high correlation with emissions in the source regions. From comparing receptor composites to the EOF2 composites, Baode seems to be the site most related to the EOF2. Where strong deposition to Baode is favourable during negative EOF2 years, due to Baode being strongly influenced by emissions from Mongolia (see Figure 5.22 and Figure 5.23.

\subsubsection{Sources and transport in strong versus weak deposition years}

The composite analysis of the source contribution showed the sources were more concentrated during strong than weak deposition years. Wet deposition was the main cause for the increase in the MAR to the CLP in strong deposition years. The more concentrated source contribution suggests that the strong deposition years are distinguished from the weak deposition years by a few strong predominately wet deposition events (Figure 5.22 and Figure 5.23).

Furthermore, looking at how the weak and strong deposition years differ in terms of their transport trajectories. The main difference in the transport of dry deposited dust between the strong and weak deposition years is the strengthening of northwesterly transport (see. Figure 5.18 and Figure 5.19). Moreover, the spread of the trajectories is slightly diminished with a small shift towards the north in strong deposition years. This is consistent with a stronger northerly component. The wet deposition trajectory shows a strengthening of the transport during the strong deposition years like the dry deposition trajectories. However, the difference is less pronounced, except for the transport of fine dust to Shapotou and coarse dust to SACOL, which has weaker transport during strong deposition years. This suggests that more intense dust storms would not be favourable conditions for wet deposition in these two cases. Most of the locations had a more northerly trajectory during strong deposition events, the exception being SACOL, Suggesting that more northwesterly winds would produce unfavourable conditions for wet deposition at SACOL.

\subsubsection{Linking winter circulation and spring deposition}

In the introduction of this thesis, I questioned the conclusion of Wyrwoll et al. (2016) and their claim to have demonstrated for the first time a close link between the occurrence of dust events and the strength of the EAWM. I had three core issues with their study: (1) The correlation between the EAWM and dust storm frequency was based on visibility measurements, which is more analogous to dust concentration. (2) The frequency of cold air outbreak (CAOB) is used as a proxy for EAWM. However, CAOBs occur due to the breakdown of the Siberian High $(\mathrm{SH})$, while a strong EAWM is characterised by a strengthened SH (Roe 2009). (3) They only considered the dust storm frequency; however, infrequent strong deposition events might contribute to most of the deposited dust.

A comprehensive correlation analysis, including spring deposition and several indices representing the EAWM strength, was done to determine the influence of EAWM on spring deposition. The results showed no evidence for a significant influence of the strength of the EAWM on the deposition over the CLP, contradicting the conclusions of Wyrwoll et al. (2016). While there was no link between the EAWM strength and deposition, a strong connection of the winter $\mathrm{AO}$ on the strength of the spring dust deposition was documented 
in our model simulations. This is evident from the positive MSLP anomalies over the arctic shown $850 \mathrm{hPa}$ and MSLP composites anomalies in Figure 5.25 and Figure 5.26, There was no apparent linkage between spring and the preceding winter in the low-level circulation composite. However, the $500 \mathrm{hPa}$ geopotential composite difference showed height anomalies in the winter preceding a strong deposition spring. These anomalous winter conditions persisted into the following spring, with the anomaly being more prominent for the sites with a strong correlation with the winter AO. The geopotential height anomaly and strengthened westerly wind are consistent with a strengthening of the thermal winds and increased temperature gradient.

Liu et al. (2018) examined the relationship between spring dust emissions and preceding winter $\mathrm{AO}$ using the MERRA2 reanalysis. They identified a similar pattern based on regression analysis between the winter $500 \mathrm{hPa}$ geopotential height and the leading EOF of springtime dust emissions. Liu et al. (2018) suggested that negative AO produces anomalous cold conditions over central Siberia that can persist into the following spring. The effect of the cold conditions is amplified by snow-albedo and cloud feedbacks, producing favourable conditions for enhanced dust emissions in spring (Liu et al. 2018). The influence of the winter $\mathrm{AO}$ on the spring surface temperature is confirmed by the correlation analysis, with a negative AO corresponding to a strengthened temperature gradient over East Asia (Figure 5.24). Moreover, the deposition at the receptors all show a negative correlation with the spring EATG, the same is true for the emissions. However, the strength of the EAWM, while being significantly correlated with the winter temperature gradient, has barely any influence on the spring temperature gradient.

Yang et al. (2020) examined the interdecadal variations in the paths of the CAOBs influencing East Asia. They found a transition in the direction of the CAOBs to favour a more northerly path since 1995 . The maximum probability density distribution of the CAOB paths since 1995 over Mongolia/Eastern Siberia (Yang et al. (2020), Figure 4) coincide with the location of the negative anomaly in the $500 \mathrm{hPa}$ geopotential height composite difference for SACOL and Lantian. In addition, they showed that the northerly $\mathrm{CAOB}$ path was associated with negative $\mathrm{AO}-$ like composite anomalies and thus consistent with SACOL and Lantian being the two sites exhibiting the strongest correlation with the AO.

The winter AO only weakly influences the deposition at Shapotou. The location of the winter $500 \mathrm{hPa}$ geopotential height anomaly suggests a stronger influence by the westerly CAOBs, common before 1995. This also illustrates another issue with the study of Wyrwoll et al. (2016), since in addition to the frequency and intensity of the CAOBs, the path of the CAOB also has an influence on the MAR to the CLP.

\subsection{Implications for interpreting loess records}

The attention of the discussion so far has been concerned with the processes of the dust cycle of up to annual time scale. Many of the important points brought up also have strong implications for understanding long-term changes in the EADC and the interpretation of the loess records. Perhaps most importantly was the weak relationship between EAWM and spring deposition. This suggests that the aeolian dust records at the CLP at present are not a valid indicator of the EAWM strength. Based on this work, it is not possible to say whether this is generally the case, because the climatic conditions during the glacial 
stages are very different from today. However, this could be answered by driving this modelling setup using data from a paleoclimate simulation, e.g., Last Glacial Maximum. The Red Clays are considered to be formed under relatively humid conditions due to being pedeogenically more developed than the Quaternary loess. As suggested from the modelling results, dry deposition is more favourable under winter-like conditions, while wet deposition is more favourable under more summer-like conditions. This could imply that the Red Clays might be mainly wet deposited, while the Quaternary Loess primarily is dry deposited. Furthermore, this modelling approach could also be used to better constrain the uncertainties in the geochemical provenance proxies by analysing present-day dust samples using various single-grain geochemical provenance proxies and comparing with the modelled source contribution.

\subsection{FLEXDUST/FLEXPART as a tool for studying the dust cycle}

The ability of FLEXPART/FLEXDUST to directly establish which dust sources are contributing to the dust deposition is what makes this modelling setup such a potent tool for examining the spatial variability in the dust sources to the CLP. Furthermore, this setup can be applied in a broader context beyond the modelling of EADC to study the origin of loess sequences worldwide.

Nonetheless, this modelling approach is not without flaws. A major weakness of FLEXPART is the complicated setup process. Compared to the similar HYSPLIT model developed by NOAA (Draxler and Rolph 2010), which has a graphical interface and even the possibility to run simulations directly from the browser, the difference is substantial. Even though HYSPLIT is less capable compared to FLEXPART in certain applications, due to how easy HYSPLIT is to use, the userbase of HYSPLIT is about six times that of FLEXPART 1 . Thus, there is a clear advantage to having an easy to use model for the amount of science produced. Nevertheless, the difficulty and amount of effort required to set up and use a model are seldom given much attention. This modelling setup is further complicated by the lack of proper tools for post processing and analysis of the model output. For me, this meant that probably $50 \%$ of the time spent working on this thesis have been spent on creating post analysis scripts and figuring out the model setup. So far, FLEXPART lacks a strong community effort to develop proper tools for analysing and post-processing.

Another deficiency is the lack of proper trajectory clustering capabilities similar to that of HYSPLIT. This made it impossible to diagnose the dust transport trajectories properly. Even though it is possible to do a proper cluster analysis in FLEXPART by saving the individual trajectories and then do the clustering as a post-processing step. However, this easily gets quite computationally demanding. In addition, one has to store a lot of additional data, which increases the storage requirements. Thus, this was disregarded as an option for this work.

This section has discussed the biases, sensitivities, advantages and disadvantages of the FLEXPART/FLEXDUST modelling setup. FLEXPART/FLEXDUST can become an indispensable tool for examining the dust sources and transport pathways involved in loess formation worldwide. However, this work has shown that there are issues that have to be addressed first. Foremost, the wet deposition bias, a first step would be to

\footnotetext{
${ }^{1}$ Based on the number of hits on google scholar between 2020 and 2021
} 
test FLEXPART with the new interpolation scheme. Moreover, to properly diagnose the dust transport, the clustering routine in FLEXPART should be improved upon. Such that the clustering takes into account the trajectory of the particles as a whole. This could be achieved by reading the trajectory file at each step and assigning the clustered points to the closest cluster centroid. In FLEXDUST, future work should involve properly validating the ISRIC soil texture data implemented and tested out for the first time in this work. Moreover, implementing different dust emission schemes in FLEXDUST would allow for investigating the sensitivity of the model setup to the choice of emission scheme, and allow different particle sizes to be simulated explicitly. Lastly, creating good online documentation and a community forum where it is easy to ask questions and seek support would be a good step in the right direction to bring the FLEXPART user experience up to modern standards. 


\section{Chapter 7}

\section{Conclusion}

\subsection{Conclusion}

In this thesis, the dust emission model FLEXDUST combined with backwards FLEXPART simulations were applied for the first time to simulate the EADC over the CLP. An indepth assessment of the performance, sensitivities, advantages and disadvantages of this modelling setup was done. Overall, this setup performed well compared both to limited observations and to previous modelling studies. However, there were considerable uncertainties of the model in depicting wet deposition fluxes. The distinguishing feature of this modelling setup is the derivation of dust source contribution for specific sites, which makes it possible to examine the sources of dust deposited over the CLP in more detail than before.

After ensuring the reliability and validity of the modelling setup, the FLEXPART and FLEXDUST models were applied to simulate the spring EADC for seven sites across the CLP between 1999-2019. The simulations were then used to examine the climatology and interannual variability of the EADC. The following conclusions were drawn:

1. The main source of the dust deposited over the CLP was the deserts located northwest of the CLP, with the Taklamakan having only a weak influence on the MAR. More dust was deposited at the western sites, possibly due to the Liupan Mountains.

2. The spatial difference in the amount of deposited dust was the largest for the silt particles. The transport of the coarse dust was more dependent on upperlevel transport, whereas the fine dust could be transported throughout the lower troposphere. There was a higher source contribution from the northeastern side of the Taklamakan for the coarse silt dust than for the fine clay dust, suggesting that the slopes of the NTP could be important for transporting coarse dust from the Taklamakan to the CLP.

3. Wet deposition was the main mode of deposition to CLP according to the model, even though there were large model uncertainties regarding wet deposition. The wet deposited dust was transported along a predominantly westerly trajectory, whereas the dry deposited dust followed a more northwesterly trajectory. This was attributed 
to wet deposition events being more favourable later in the spring, opposed to dry deposition which was more favourable in late winter / early spring.

4. The interannual variation in spring dust deposition and emissions were closely related to the AO. The strong deposition years were linked to winter $500 \mathrm{hPa}$ geopotential height anomalies that persisted into spring. The location and intensity of the anomaly varied between the sites. However, this anomaly was more pronounced for sites that had a strong relation to the AO. The location of the geopotential anomaly was suggested to be related to the path of the CAOBs (Yang et al. 2020). Notably, stronger and more intense CAOBs were favourable during negative AO winter conditions (Yang et al. 2020). Several previous studies have found a strong relationship between the AO and the EADC (Gong et al. 2006b; Liu et al. 2018; Mao et al. 2011). However, this is the first study that directly links the deposition over the CLP and the AO.

5. The interannual variability of the EADC under present-day climatic conditions revealed no significant influence of the EAWM. Even though the strength of the EAWM was significantly correlated with the winter EATG, the EAWM had barely any influence on the spring EATG. Unlike the conclusions of Wyrwoll et al. (2016) and in contrast with the typical presumption of paleoclimate studies.

\subsection{Future work}

To further improve the representation of the EADC in FLEXPART and FLEXDUST, the wet deposition bias has to be examined further. A natural first step would be to investigate whether the new interpolation scheme would improve performance. A more in-depth sensitivity analysis to find the optimal parameters for representing dust FLEXPART is also needed. This would help to alleviate some of the uncertainties regarding the wet deposition. Moreover, to rule out the possibility of biases in the observations, observations from more than one source should be considered.

The information from the dust modelling can be used to validate the provenance information from geochemical proxies. During the spring of 2020 several active and passive dust traps were installed at SACOL, Shapotou, Yinchuan and Baode as a part of the Tracing the Winds project. These traps have been collecting dust for the past two dust seasons. The plan is to analyse the collected dust samples using various single-grain geochemical provenance traces and compare the information from the geochemical proxies with dust modelling. Finally, to bridge the gap between this work on the present-day EADC and the Neogene Red Clay, the focus of the Tracing the Winds project. This model setup could be forced by output from a paleoclimate simulation. 
Appendices 



\section{Appendix A}

\section{Supplementary figures and tables}

Table A.1. The coordinates of the locations for where the FLEXPART backward simulations are initiated

\begin{tabular}{lll}
\hline & Longitude & Latitude \\
\hline SACOL & 104.137 & 35.964 \\
Shapotou & 105.0475 & 37.749 \\
Yinchuan & 106.101 & 38.50 \\
Lingtai & 107.789 & 35.710 \\
Lantian & 109.256 & 34.18 \\
Luochuan & 109.424 & 35.710 \\
Badoe & 111.17 & 39.003 \\
\hline
\end{tabular}

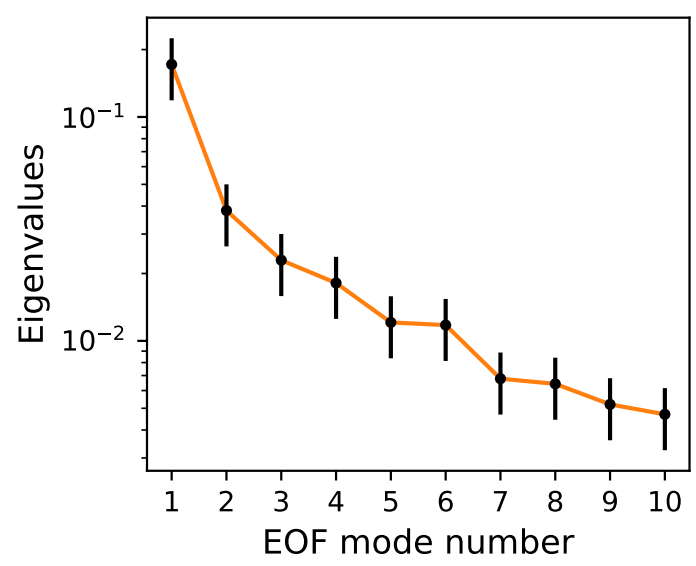

Figure A.1. The eigenvalues of the 10 first leading EOFs. The error bars correspond to the typical error of each EOF 
Table A.2. Setting specified in the COMMAND file for the main FLEXPART simulations. Dry deposition (Wet deposition)

\begin{tabular}{ll}
\hline LDIRECT & -1 \\
LOUTSTEP & 10800 \\
LOUTAVER & 10800 \\
LOUTSAMPLE & 900 \\
ITSPLIT & 9999999 \\
LSYNCTIME & 900 \\
CTL & -5.000 \\
IFINE & 4 \\
IOUT & 13 \\
IPOUT & 0 \\
LSUBGRID & 1 \\
LCONVECTION & 1 \\
LAGESPECTRA & 1 \\
IPIN & 0 \\
IOUTPUTFOREACHRELEASE & 1 \\
IFLUX & 0 \\
MDOMAINFILL & 0 \\
IND_SOURCE & 1 \\
IND_RECEPTOR $\left(^{*}\right)$ & $(4) 3$ \\
\hline
\end{tabular}




\section{Appendix B}

\section{Source receptor relationships within the framework of LPDMs}

The problem with using an ordinary Lagrangian trajectory model to calculate trajectories is that measurements often represent large volumes of air and not infinitesimally small air parcels (from now on referred to as particles). Therefore a single particle trajectory is usually not representative of the trajectory of the whole volume element. This is to due the deformation and stretching of the fluid elements. This deformation happens for example if the flow has to pass an obstacle, e.g. a mountain range, the initially compact fluid elements would be torn apart and distributed over large areas. Moreover, the separation and distortion of the volume element would be even more effective in the presence of strong vertical wind shear causing fluid elements to travel in opposite directions. This means that two particles that are at the beginning close to each other would, given enough time would eventually be separated by large distances. Another issue with the single particle approach is that the atmosphere's turbulence would increase the volume of the initial fluid element over time, increasing the horizontal dispersion. This could make trajectories that encounter deep convection or are travelling within the boundary layer even less accurate. This is even more apparent for trajectories based only on the mean wind fields, which cannot represent the effect of turbulent mixing on the fluid element.

A Lagrangian particles dispersion model LPDM can solve both of the issues of the traditional Lagrangian trajectory model. Deformation of the fluid element can accurately be represented by computing the trajectories of several thousand particles giving a statistical description of the dispersion of each volume element. The LPDM can also accurately represent turbulence by adding a stochastic term to the mean wind. LPDM also have an advantage over Eulerian grid-based transport models in that they do not require a computational grid, which means they are essentially free from numerical diffusion, except for errors related to interpolating the meteorological input data to the particle positions (Cassiani et al.2016).

LPDMs allows in the same way as traditional Lagrangian trajectory models to be run forward or backwards in time by simply switching the sign of the advection. Forward simulation is a natural choice for studying the dispersion of tracers from known sources, such as the dispersion of nuclear fallout where you have one point source but an unknown number of receptors. While a forward simulation indicate where an atmospheric tracer will go, a backward simulation indicate where the tracer came from. Therefore backward 
simulations are useful for interpreting measurements of atmospheric trace substances and to establish relationships between the sources and their receptors.

However, interpreting the output from a backward simulation is not as straightforward. The simplest interpretation is to think about it analogues to forward calculation and consider the LPDM as a tool to calculate the air mass trajectories which include both mean wind and turbulent motions, and think of the particle cloud as a retroplume. The retroplume can then be used to calculate the centroid trajectory which would give a more representative trajectory than a single particle trajectory

Another approach is to use the LPDM to establish a source-receptor relationship, to describe the sensitivity of a receptor to a source. A LPDM can only simulate linear s-r relationship. Therefore a LPDM cannot be used to simulate nonlinear chemical reactions. However, all the other processes that affect the tracer during atmospheric transport are linear; advection, diffusion, convective mixing dry and wet deposition, and radio active decay (Seibert and Frank 2004). Then the linear s-r relationship can be defined as a s-r matrix (SRM) $\mathbf{M}$ whose elements $m_{i l}$ are defined as

$$
m_{i l}=\frac{y_{l}}{x_{i}}
$$

Where the $y_{l}$ is receptor element and $x_{i}$ is the source elements. The receptor elements are often defined in terms of concentrations $C$ (unit $\mathrm{kg} \mathrm{m}^{-3}$ ) and sources are usually specified as mass fluxes $Q$ (unit $\mathrm{kg} \mathrm{m}^{-3} \mathrm{~s}^{-1}$ ). This means that by definition, the unit of the SRM in Equation (B.1) has to be $\mathrm{s}^{-1}$, to be clear, this is by construction and is not a measure of the residence time of the particles within a grid box. Another important point is that when the SRM is known for a given source vector the receptor values can be obtained by a simple vector-matrix multiplication. Determining the SRM can be computationally demanding, especially in a forward simulation where the number of source elements greatly outnumbers the number of receptor elements since the SRM has to be determined for each source element. However, in a backwards simulation the number of simulations required is equal to the number of receptor points.

The following paragraph aims to show how the s-r relationship is derived within the LPDM framework both in a source and receptor oriented view of transport. The formalism is the same for both a forward and a backward simulation however, in a backward simulation the particles are only a means to probe for the possible processes affecting the substance being transported. There are no advective changes in the Lagrangian reference frame (think about experiences of unconscious mosquito suspended in the air), so the mixing ratio $\chi$ of the tracer is only affected by the sources $q$ and any linear removal process proportional to $\chi$. We consider the tracer mixing ratio rather than concentration, since concentration depends on the local air density, which changes with temperature and pressure, whereas the mixing ratio $\chi$ is the volume of a trace substance per volume of air, which remains constant with density. Converting between concentration and mixing ratio is just a matter of dividing by the local air density. Thus the change in mixing ratio with time is given by Equation (B.2), where $\alpha(t)$ is the net removal constant and $\frac{q(t)}{\rho(t)}$ is the source term.

$$
\frac{d \chi(t)}{d t}=\frac{q(t)}{\rho(t)}+\alpha(t) \chi(t)
$$

Solving this differential equation gives the following solution:

$$
\chi(t)=\chi_{0} \exp \left\{\left(-\int_{0}^{t} \alpha(t) d t^{\prime}\right)\right\}+\int_{0}^{t} \frac{q(t)}{\rho(t)} \exp \left\{\left(\int_{t^{\prime}}^{t} \alpha\left(t^{\prime \prime}\right)\right) d t^{\prime \prime}\right\} d t^{\prime}
$$


This yields the mixing ratio at time $t$ at the receptor location for a given trajectory and $\chi_{0}$ is the initial mixing ratio. In (Seibert and Frank 2004) they introduced the following abbreviation Equation (B.4) and called it the transmission function. The transmission function determines the fraction of material that is transmitted along a single trajectory.

$$
p\left(t^{\prime}\right)=\exp \left\{\left(\int_{t^{\prime}}^{t} \alpha\left(t^{\prime \prime}\right)\right) d t^{\prime \prime}\right\} d t^{\prime}
$$

The mixing ratio derived in Equation (B.3) is valid for instantaneous mixing rations including turbulent motions. However, observations at the measurement station do not usually represent a point in time, and rather it is an average. Consequently, the mean mixing ratio should be obtained by taking an ensemble average of all the trajectories arriving within an interval between $t_{1}$ and $t_{2}$. If the averaging window exceeds the time scale of the turbulent fluctuation, the temporal average of the instantaneous values are the same as the temporal average of the ensemble means $\bar{\chi}$. Substituting the transmission function, we obtain the following expression for the mean mixing ratio $\bar{\chi}$.

$$
\overline{\chi\left(t_{1}, t_{2}\right)}=\frac{1}{t_{2}-t_{1}} \int_{t_{1}}^{t_{2}} \chi(t) d t=\frac{1}{t_{2}-t_{1}} \int_{t_{1}}^{t_{2}}\left(\chi_{0}(t) p(t, 0)+\int_{0}^{t} \frac{q\left(t, t^{\prime}\right) p\left(t, t^{\prime}\right.}{\rho\left(t, t^{\prime}\right)} d t^{\prime}\right) d t
$$

where the time variable $t$ now appears in $q \rho$ and $p$ to signify different trajectories arriving at different times. Next we need to discretize Equation (B.5). Seibert and Frank (2004) introduce the following discretisation:

$$
\chi \approx \overline{\chi_{0} p(0)}+\frac{1}{J} \sum_{j} \sum_{i} \sum_{n}\left(\frac{q_{i n}}{\rho_{i n}} p_{j n} \Delta t_{i j n}^{\prime}\right)
$$

Where the arrival time $t$ is discretized into $J$ time slots which each represented one back trajectory, where the trajectories arrive at equal intervals between $t_{1}$ and $t_{2}$ and are designated by index j. Space is gridded by index $\mathrm{i}$ and the discretisation of $t^{\prime}$ is designated by index $n$. The $\Delta t_{i j n}^{\prime}$ is the residence time of a back trajectory $j$ in a grid cell $(i, n)$, which in addition to being the discrete representation of $d t$ also indicate the trajectory movement. The source function does only depend on when back trajectory passes over the source and not the arrival time therefore Equation (B.6) can be rearranged to:

$$
\chi \approx \overline{\chi_{0} p(0)}+\sum_{i} \sum_{n}\left[\frac{q_{i n}}{\rho_{i n}} p_{j n} \frac{1}{J} \sum_{j}\left(p_{j n} \Delta t_{i j n}^{\prime}\right)\right]
$$

Thus we can calculate the s-r relationship between the receptor and spatial temporal grid cell $(i, n)$ :

$$
\frac{\partial \bar{\chi}}{q_{i n}}=\frac{1}{J} \sum_{j} \frac{p_{j n} \Delta t_{i j n}^{\prime}}{\rho_{i} n}
$$

If $\alpha=0$ then $p=1$ the s-r relationship is expressed as mass mixing ratio $\frac{q}{\rho}$ becomes just the average residence time of the grid cell of consideration. Then the different processes the tracer might experience are expressed by "correcting" the residence time by the transmission function. 


\section{Appendix C}

\section{Cluster analysis of FLEXPART trajectories}

In addition to the emission sensitivity, FLEXPART can output the centroid position of the particle cloud and cluster the particles into a specified number of cluster groups at each output interval (Stohl et al. 2002). However, the clusters produced by FLEXPART are not very informative due to the clustering only being based on the position of the particles at the output time and does not consider which cluster it was previously assigned to. Therefore, rather than using the cluster trajectories, the centroid trajectories of every particle release are re-clustered using the procedure described by Dorling et al. (1992).

The Dorling et al. (1992) clustering algorithm is an adaptive clustering method, which starts by clustering the trajectories into many clusters (30) using K-means clustering. Here the K-means implementation in the scikit-learn python package is used (Pedregosa et al. 2011), which cluster the trajectories based on their euclidean distance from the cluster centroid trajectory. K-means works by separating the data in k groups with equal variance and minimising the within cluster sum of squares also called the inertia:

$$
\sum_{i=0}^{n} \min _{\mu_{j} \in C}\left(\left\|x_{i}-\mu_{j}\right\|^{2}\right)
$$

Where $x_{i}$ represent a single trajectory, and $\mu_{j}$ is the cluster centroid.

The K-means algorithm is quite sensitive to the initial cluster centroid. Therefore, the $\mathrm{K}$-means is repeated 20 times with different seeds, and the run with the lowest inertia is selected.

Then the two closest cluster centroids are found by calculating which two cluster centroids have the shortest great circle distance. The clusters are then merged, and their combined centroid is calculated and used together with the remaining centroid clusters as initial centroid in the next K-means clustering. This is repeated until there are only two clusters left.

After each merger, the relative change in the clustering score between the previous and the merged cluster is calculated. A large relative change in the score is interpreted as two distinct clusters merged and the clusters before the merger are kept. This allows for a more objective method for determining the optimal number of clusters. 


\section{Appendix D}

\section{Analysis software}

The code developed during this work is available under this GitHub organisation https: //github.com/MasterOnDust. Five packages where developed: (1) DUST python package for reading and processing the FLEXPART and FLEXDUST output. (2) Flexpart_cluster which processes the trajectory files, the trajectory plotting and the code for doing the clustering as decribed in Chapter C. (3) Thesis_toolbox is a collection of several functions and scripts that were used in the analysis. (4) Master_thesis_UiO_workflow the snakemake workflow that ties all the aforementioned Python packages togheter. (5) FLEXPART-script is used to set up the FLEXPART simulations.

The full Anaconda environment listing the specific Python libraries used also available on Github. The setup for setting up the workflow and installing all the Python packages are documented on Github. The docker image running on the NIRD analysis platform is also available there. 


\section{Bibliography}

Adebiyi, A. A., J. F. Kok, Y. Wang, A. Ito, D. A. Ridley, P. Nabat, and C. Zhao (2020). “Dust Constraints from joint Observational-Modelling-experiMental analysis (DustCOMM): comparison with measurements and model simulations". In: Atmospheric Chemistry and Physics 20.2, pp. 829-863.

Alfaro, S. C. and L. Gomes (2001). "Modeling mineral aerosol production by wind erosion: Emission intensities and aerosol size distributions in source areas". In: Journal of Geophysical Research: Atmospheres 106.D16, pp. 18075-18084.

An, Z. et al. (2014). "Late Cenozoic Climate Change in Monsoon-Arid Asia and Global Changes". en. In: Late Cenozoic Climate Change in Asia: Loess, Monsoon and Monsoon-arid Environment Evolution. Ed. by Z. An. Developments in Paleoenvironmental Research. Dordrecht: Springer Netherlands, pp. 491-581. ISBN: 978-94-007-7817-7. DOI: 10.1007/ 978-94-007-7817-7_6.

Aoki, I., Y. Kurosaki, R. Osada, T. Sato, and F. Kimura (2005). “Dust storms generated by mesoscale cold fronts in the Tarim Basin, Northwest China". In: Geophysical Research Letters 32.6. DOI: https://doi .org/10.1029/2004GL021776.

Bagnold, R. A. (1941). The physics of blown sand and desert dunes. Courier Corporation.

Bergametti, G., B. Marticorena, J.-L. Rajot, G. Foret, S. Alfaro, and B. Laurent (2018). "Size-Resolved Dry Deposition Velocities of Dust Particles: In Situ Measurements and Parameterizations Testing". In: Journal of Geophysical Research: Atmospheres 123.19, pp. 11-080.

Bergametti, G. and G. Forêt (2014). “Dust deposition”. In: Mineral dust. Springer, pp. 179_ 200.

Bird, A., T. Stevens, M. Rittner, P. Vermeesch, A. Carter, S. Andò, E. Garzanti, H. Lu, J. Nie, L. Zeng, et al. (2015). "Quaternary dust source variation across the Chinese Loess Plateau". In: Palaeogeography, Palaeoclimatology, Palaeoecology 435, pp. 254-264. DOI: https://doi.org/10.1016/j.palaeo.2015.06.024

Brandt, J., J. Christensen, and L. Frohn (2002). "Modelling transport and deposition of caesium and iodine from the Chernobyl accident using the DREAM model". In: Atmospheric Chemistry and Physics 2.5, pp. 397-417.

Cassiani, M., A. Stohl, D. Olivié, Ø. Seland, I. Bethke, I. Pisso, and T. Iversen (2016). “The offline Lagrangian particle model FLEXPART-NorESM/CAM (v1): model description and comparisons with the online NorESM transport scheme and with the reference FLEXPART model". In: Geoscientific Model Development 9.11, pp. 4029-4048. DOI: 10 5194/gmd-9-4029-2016

Chen, S., J. Huang, Y. Qian, C. Zhao, L. Kang, B. Yang, Y. Wang, Y. Liu, T. Yuan, T. Wang, et al. (2017). "An overview of mineral dust modeling over East Asia". In: Journal of Meteorological Research 31.4, pp. 633-653. 
Choi, Y., Y. Kanaya, M. Takigawa, C. Zhu, S.-M. Park, A. Matsuki, Y. Sadanaga, S.-W. Kim, X. Pan, and I. Pisso (Nov. 2020). "Investigation of the wet removal rate of black carbon in East Asia: validation of a below- and in-cloud wet removal scheme in FLEXible PARTicle (FLEXPART) model v10.4". English. In: Atmospheric Chemistry and Physics 20.21. Publisher: Copernicus GmbH, pp. 13655-13670. ISSN: 1680-7316. DOI: 10.5194/acp-20-13655-2020.

Choobari, O. A., P. Zawar-Reza, and A. Sturman (2014). “The global distribution of mineral dust and its impacts on the climate system: A review". In: Atmospheric Research 138, pp. 152-165.

Da, J., Y. G. Zhang, H. Wang, W. Balsam, and J. Ji (2015). “An Early Pleistocene atmospheric $\mathrm{CO} 2$ record based on pedogenic carbonate from the Chinese loess deposits". In: Earth and Planetary Science Letters 426, pp. 69-75.

Dai, L., T. F. Cheng, and M. Lu (2021). "Define East Asian monsoon annual cycle via a selforganizing map-based approach". In: Geophysical Research Letters 48.1, e2020GL089542.

Darmenova, K., I. N. Sokolik, Y. Shao, B. Marticorena, and G. Bergametti (2009). "Development of a physically based dust emission module within the Weather Research and Forecasting (WRF) model: Assessment of dust emission parameterizations and input parameters for source regions in Central and East Asia". en. In: Journal of Geophysical Research: Atmospheres 114.D14. ISSN: 2156-2202. DOI: https://doi.org/10. 1029/2008JD011236.

Dawson, A. (2016). "eofs: A library for EOF analysis of meteorological, oceanographic, and climate data". In: Journal of Open Research Software 4.1.

Derbyshire, E., R. Kemp, and X. Meng (1995). "Variations in loess and palaeosol properties as indicators of palaeoclimatic gradients across the Loess Plateau of North China". In: Quaternary Science Reviews 14.7-8, pp. 681-697.

Ding, Z., N. Rutter, J. Sun, S. Yang, and T. Liu (2000). “Re-arrangement of atmospheric circulation at about 2.6 Ma over northern China: evidence from grain size records of loess-palaeosol and red clay sequences". In: Quaternary Science Reviews 19.6, pp. 547558.

Does, M. V. D., L. F. Korte, C. I. Munday, G.-J. A. Brummer, and J.-B. W. Stuut (2016). "Particle size traces modern Saharan dust transport and deposition across the equatorial North Atlantic". In: Atmospheric Chemistry and Physics 16.21, pp. 1369713710.

Dong, Z., G. Qian, P. Lv, and G. Hu (2013). "Investigation of the sand sea with the tallest dunes on Earth: China's Badain Jaran Sand Sea". In: Earth-Science Reviews 120, pp. 20 39.

Dorling, S., T. Davies, and C. Pierce (1992). “Cluster analysis: A technique for estimating the synoptic meteorological controls on air and precipitation chemistry-Method and applications". In: Atmospheric Environment. Part A. General Topics 26.14, pp. 2575-2581.

Draxler, R. and G. Rolph (2010). “HYSPLIT (HYbrid Single-Particle Lagrangian Integrated Trajectory) model access via NOAA ARL READY website (http:/ / ready. arl. noaa. gov/HYSPLIT. php), NOAA Air Resources Laboratory". In: Silver Spring, MD 25.

Eckhardt, S., A. Prata, P. Seibert, K. Stebel, and A. Stohl (2008). "Estimation of the vertical profile of sulfur dioxide injection into the atmosphere by a volcanic eruption using satellite column measurements and inverse transport modeling". In: Atmospheric Chemistry and Physics 8.14, pp. 3881-3897.

Eckhardt, S., M. Cassiani, N. Evangeliou, E. Sollum, I. Pisso, and A. Stohl (2017). "Sourcereceptor matrix calculation for deposited mass with the Lagrangian particle dispersion 
model FLEXPART v10.2 in backward mode". In: Geoscientific Model Development 10.12, pp. 4605-4618. DOI: 10.5194/gmd-10-4605-2017.

Falkovich, A. H., E. Ganor, Z. Levin, P. Formenti, and Y. Rudich (2001). "Chemical and mineralogical analysis of individual mineral dust particles". In: Journal of Geophysical Research: Atmospheres 106.D16, pp. 18029-18036. DOI: 10.1029/2000JD900430 eprint: https://agupubs.onlinelibrary.wiley.com/doi/pdf/10.1029/2000JD900430.

Fécan, F., B. Marticorena, and G. Bergametti (1998). "Parametrization of the increase of the aeolian erosion threshold wind friction velocity due to soil moisture for arid and semi-arid areas". In: Annales Geophysicae. Vol. 17. 1. Springer, pp. 149-157.

Ginoux, P., M. Chin, I. Tegen, J. M. Prospero, B. Holben, O. Dubovik, and S.-J. Lin (2001). "Sources and distributions of dust aerosols simulated with the GOCART model". In: Journal of Geophysical Research: Atmospheres 106.D17, pp. 20255-20273. DOI: 10.1029/ 2000JD000053. eprint: https : / / agupubs . onlinelibrary · wiley . com/doi / pdf / 10 1029/2000JD000053.

Gong, D.-Y., R. Mao, and Y.-D. Fan (2006a). "East Asian dust storm and weather disturbance: possible links to the Arctic Oscillation". In: International Journal of Climatology: A Journal of the Royal Meteorological Society 26.10, pp. 1379-1396.

Gong, S., X. Zhang, T. Zhao, X. Zhang, L. Barrie, I. McKendry, and C. Zhao (2006b). “A simulated climatology of Asian dust aerosol and its trans-Pacific transport. Part II: Interannual variability and climate connections". In: Journal of Climate 19.1, pp. 104122.

Groot Zwaaftink, C. D., H. Grythe, H. Skov, and A. Stohl (2016). "Substantial contribution of northern high-latitude sources to mineral dust in the Arctic". In: Journal of Geophysical Research: Atmospheres 121.22, pp. 13, 678-13, 697. DOI: 10.1002/2016JD025482, eprint: https://agupubs.onlinelibrary.wiley.com/doi/pdf/10.1002/2016JD025482.

Grythe, H., N. I. Kristiansen, C. D. Groot Zwaaftink, S. Eckhardt, J. Ström, P. Tunved, R. Krejci, and A. Stohl (2017). "A new aerosol wet removal scheme for the Lagrangian particle model FLEXPART v10". In: Geoscientific Model Development 10.4, pp. 1447-1466. DOI: $10.5194 / \mathrm{gmd}-10-1447-2017$

Hannachi, A., I. T. Jolliffe, and D. B. Stephenson (2007). "Empirical orthogonal functions and related techniques in atmospheric science: A review". In: International Journal of Climatology: A Journal of the Royal Meteorological Society 27.9, pp. 1119-1152.

He, S., Y. Gao, F. Li, H. Wang, and Y. He (2017). "Impact of Arctic Oscillation on the East Asian climate: A review". In: Earth-Science Reviews 164, pp. 48-62.

Heisel, M., B. Chen, J. F. Kok, and M. Chamecki (2021). “Gentle topography increases vertical transport of coarse dust by orders of magnitude". In: Journal of Geophysical Research: Atmospheres, e2021JD034564.

Hersbach, H. et al. (2020). "The ERA5 global reanalysis". en. In: Quarterly Journal of the Royal Meteorological Society 146.730, pp. 1999-2049. ISSN: 1477-870X. DOI: https: //doi.org/10.1002/qj.3803

Huang, J., B. Lin, P. Minnis, T. Wang, X. Wang, Y. Hu, Y. Yi, and J. K. Ayers (2006). “Satellitebased assessment of possible dust aerosols semi-direct effect on cloud water path over East Asia". In: Geophysical Research Letters 33.19.

Huang, Y., J. F. Kok, K. Kandler, H. Lindqvist, T. Nousiainen, T. Sakai, A. Adebiyi, and O. Jokinen (2020). "Climate models and remote sensing retrievals neglect substantial desert dust asphericity". In: Geophysical Research Letters 47.6, e2019GL086592.

Huneeus, N., M. Schulz, Y. Balkanski, J. Griesfeller, J. Prospero, S. Kinne, S. Bauer, O. Boucher, M. Chin, F. Dentener, et al. (2011). “Global dust model intercomparison in AeroCom phase I". In: Atmospheric Chemistry and Physics 11.15, pp. 7781-7816. 
Iversen, J. D. and B. R. White (1982). "Saltation threshold on earth, mars and venus". In: Sedimentology 29.1, pp. 111-119.

Jhun, J.-G. and E.-J. Lee (2004). “A new East Asian winter monsoon index and associated characteristics of the winter monsoon". In: Journal of Climate 17.4, pp. 711-726.

Johnson, M. S., N. Meskhidze, and V. Praju Kiliyanpilakkil (2012). “A global comparison of GEOS-Chem-predicted and remotely-sensed mineral dust aerosol optical depth and extinction profiles". In: Journal of Advances in Modeling Earth Systems 4.3.

Jung, E. and Y. Shao (2006). "An intercomparison of four wet deposition schemes used in dust transport modeling". In: Global and Planetary Change 52.1-4, pp. 248-260.

Klose, M. and Y. Shao (2013). "Large-eddy simulation of turbulent dust emission". In: Aeolian Research 8, pp. 49-58.

Kohfeld, K. and S. Harrison (2003). "Glacial-interglacial changes in dust deposition on the Chinese Loess Plateau". In: Quaternary Science Reviews 22.18-19, pp. 1859-1878.

Kok, J. F., E. J. Parteli, T. I. Michaels, and D. B. Karam (2012). "The physics of wind-blown sand and dust". In: Reports on progress in Physics 75.10, p. 106901.

Kok, J. F. (Jan. 2011). "A scaling theory for the size distribution of emitted dust aerosols suggests climate models underestimate the size of the global dust cycle". en. In: Proceedings of the National Academy of Sciences 108.3. ISBN: 9781014798107 Publisher: National Academy of Sciences Section: Physical Sciences, pp. 1016-1021. ISSN: 00278424, 1091-6490. DOI: 10.1073/pnas.1014798108.

Kurosaki, Y. and M. Mikami (2003). "Recent frequent dust events and their relation to surface wind in East Asia". In: Geophysical Research Letters 30.14.

Kyrö, E.-M., T. Grönholm, H. Vuollekoski, A. Virkkula, M. Kulmala, and L. Laakso (2009). "Snow scavenging of ultrafine particles: field measurements and parameterization". In:

Laakso, L., T. Grönholm, Ü. Rannik, M. Kosmale, V. Fiedler, H. Vehkamäki, and M. Kulmala (2003). "Ultrafine particle scavenging coefficients calculated from 6 years field measurements". In: Atmospheric Environment 37.25, pp. 3605-3613.

Li, R., J. Gong, J. Zhou, W. Sun, A. N. Ibrahim, et al. (2015). “Multi-satellite observation of an intense dust event over southwestern China". In: Aerosol and Air Quality Research 15.1, pp. 263-270.

Licht, A., M. Van Cappelle, H. Abels, J.-B. Ladant, J. Trabucho-Alexandre, C. FranceLanord, Y. Donnadieu, J. Vandenberghe, T. Rigaudier, C. Lécuyer, et al. (2014). “Asian monsoons in a late Eocene greenhouse world". In: Nature 513.7519, pp. 501-506.

Liu, H., X. Liu, and B. Dong (2018). "Influence of Central Siberian Snow-Albedo Feedback on the Spring East Asian Dust Cycle and Connection With the Preceding Winter Arctic Oscillation". In: Journal of Geophysical Research: Atmospheres 123.23, pp. 13-368.

Liu, J., D. Wu, G. Liu, R. Mao, S. Chen, M. Ji, P. Fu, Y. Sun, X. Pan, H. Jin, et al. (2020). "Impact of Arctic amplification on declining spring dust events in East Asia". In: Climate Dynamics 54.3, pp. 1913-1935.

Liu, M., D. L. Westphal, S. Wang, A. Shimizu, N. Sugimoto, J. Zhou, and Y. Chen (2003). "A high-resolution numerical study of the Asian dust storms of April 2001". In: Journal of Geophysical Research: Atmospheres 108.D23.

Liu, T.-s. (1985). Loess and the Environment. China Ocean Press, p. 251.

Lohmann, U. and K. Diehl (2006). "Sensitivity studies of the importance of dust ice nuclei for the indirect aerosol effect on stratiform mixed-phase clouds". In: Journal of the Atmospheric Sciences 63.3, pp. 968-982.

Maher, B. A. (2016). "Palaeoclimatic records of the loess/palaeosol sequences of the Chinese Loess Plateau". In: Quaternary Science Reviews 154, pp. 23-84. 
Maher, B. A. and R. Thompson (1992). "Paleoclimatic significance of the mineral magnetic record of the Chinese loess and paleosols". In: Quaternary Research 37.2, pp. 155-170.

Mahowald, N., S. Albani, J. F. Kok, S. Engelstaeder, R. Scanza, D. S. Ward, and M. G. Flanner (2014). "The size distribution of desert dust aerosols and its impact on the Earth system". In: Aeolian Research 15, pp. 53-71.

Mahowald, N. M., S. Kloster, S. Engelstaedter, J. K. Moore, S. Mukhopadhyay, J. R. McConnell, S. Albani, S. C. Doney, A. Bhattacharya, M. Curran, et al. (2010). “Observed 20th century desert dust variability: impact on climate and biogeochemistry". In: Atmospheric Chemistry and Physics 10.22, pp. 10875-10893.

Mallios, S. A., E. Drakaki, and V. Amiridis (2020). "Effects of dust particle sphericity and orientation on their gravitational settling in the earth's atmosphere". In: Journal of Aerosol Science 150, p. 105634.

Mao, R., D. Gong, Y. Shao, G. Wu, and J. Bao (2013). “Numerical analysis for contribution of the Tibetan Plateau to dust aerosols in the atmosphere over the East Asia". In: Science China Earth Sciences 56.2, pp. 301-310.

Mao, R., C.-H. Ho, Y. Shao, D.-Y. Gong, and J. Kim (2011). “Influence of Arctic Oscillation on dust activity over northeast Asia". In: Atmospheric environment 45.2, pp. 326-337.

Markowski, P. and Y. Richardson (2011). Mesoscale meteorology in midlatitudes. Vol. 2. John Wiley \& Sons.

Marticorena, B. and G. Bergametti (1995). "Modeling the atmospheric dust cycle: 1. Design of a soil-derived dust emission scheme". In: Journal of Geophysical Research: Atmospheres 100.D8, pp. 16415-16430. DOI: 10.1029/95JD00690, eprint: https : // agupubs.onlinelibrary.wiley.com/doi/pdf/10.1029/95JD00690.

Miao, X., Y. Sun, H. Lu, and J. Mason (2004). "Spatial pattern of grain size in the Late Pliocene 'Red Clay'deposits (North China) indicates transport by low-level northerly winds". In: Palaeogeography, Palaeoclimatology, Palaeoecology 206.1-2, pp. 149-155.

Mölder, F., K. P. Jablonski, B. Letcher, M. B. Hall, C. H. Tomkins-Tinch, V. Sochat, J. Forster, S. Lee, S. O. Twardziok, A. Kanitz, et al. (2021). "Sustainable data analysis with Snakemake". In: F1000Research 10.

Muhs, D. R., S. R. Cattle, O. Crouvi, D.-D. Rousseau, J. Sun, and M. A. Zárate (2014). "Loess records". In: Mineral Dust. Springer, pp. 411-441.

Nickling, W. G. and C. M. Neuman (2009). "Aeolian sediment transport". In: Geomorphology of desert environments. Springer, pp. 517-555.

North, G. R., T. L. Bell, R. F. Cahalan, and F. J. Moeng (1982). "Sampling errors in the estimation of empirical orthogonal functions". In: Monthly weather review 110.7, pp. 699706.

Osada, K., S. Ura, M. Kagawa, M. Mikami, T. Tanaka, S. Matoba, K. Aoki, M. Shinoda, Y. Kurosaki, M. Hayashi, et al. (2014). "Wet and dry deposition of mineral dust particles in Japan: factors related to temporal variation and spatial distribution". In: Atmospheric Chemistry and Physics 14.2, pp. 1107-1121.

Park, T.-W., C.-H. Ho, and S. Yang (2011). "Relationship between the Arctic Oscillation and cold surges over East Asia". In: Journal of Climate 24.1, pp. 68-83.

Pedregosa, F. et al. (2011). "Scikit-learn: Machine Learning in Python". In: Journal of Machine Learning Research 12, pp. 2825-2830.

Pisso, I. et al. (2019). "The Lagrangian particle dispersion model FLEXPART version 10.4". In: Geoscientific Model Development 12.12, pp. 4955-4997. DOI: 10.5194/gmd-12-49552019 .

Qiang, X., Z. An, Y. Song, H. Chang, Y. Sun, W. Liu, H. Ao, J. Dong, C. Fu, F. Wu, et al. (2011). "New eolian red clay sequence on the western Chinese Loess Plateau linked to 
onset of Asian desertification about 25 Ma ago". In: Science China Earth Sciences 54.1, pp. 136-144.

Roe, G. (2009). "On the interpretation of Chinese loess as a paleoclimate indicator". In: Quaternary Research 71.2, pp. 150-161.

Ryder, C., E. Highwood, T. Lai, H. Sodemann, and J. H. Marsham (2013). "Impact of atmospheric transport on the evolution of microphysical and optical properties of Saharan dust". In: Geophysical Research Letters 40.10, pp. 2433-2438.

Sakai, K. and R. Kawamura (2009). "Remote response of the East Asian winter monsoon to tropical forcing related to El Niño-Southern Oscillation". In: Journal of Geophysical Research: Atmospheres 114.D6.

Seibert, P. and A. Frank (2004). "Source-receptor matrix calculation with a Lagrangian particle dispersion model in backward mode". In: Atmospheric Chemistry and Physics 4.1, pp. 51-63.

Seinfeld, J. H., S. N. Pandis, and K. Noone (1998). "Atmospheric chemistry and physics: from air pollution to climate change". In: Physics Today 51.10, p. 88.

Shang, Y., C. J. Beets, H. Tang, M. A. Prins, Y. Lahaye, R. van Elsas, L. Sukselainen, and A. Kaakinen (2016). "Variations in the provenance of the late Neogene Red Clay deposits in northern China". In: Earth and Planetary Science Letters 439, pp. 88-100.

Shao, Y. and C. Dong (2006). "A review on East Asian dust storm climate, modelling and monitoring". In: Global and Planetary Change 52.1-4, pp. 1-22. DOI: https://doi.org/ 10.1016/j.gloplacha.2006.02.011.

Shao, Y. (2004). "Simplification of a dust emission scheme and comparison with data". In: Journal of Geophysical Research: Atmospheres 109.D10.

- (2008). Physics and Modelling of Wind Erosion. eng. 2. Aufl. Vol. 37. Atmospheric and Oceanographic Sciences Library. Dordrecht: Springer Netherlands. ISBN: 9789048180202.

Shao, Y. and H. Lu (2000). "A simple expression for wind erosion threshold friction velocity". In: Journal of Geophysical Research: Atmospheres 105.D17, pp. 22437-22443.

Shao, Y., K.-H. Wyrwoll, A. Chappell, J. Huang, Z. Lin, G. H. McTainsh, M. Mikami, T. Y. Tanaka, X. Wang, and S. Yoon (2011). "Dust cycle: An emerging core theme in Earth system science". In: Aeolian Research 2.4, pp. 181-204.

Shi, Z. and X. Liu (2011). "Distinguishing the provenance of fine-grained eolian dust over the Chinese Loess Plateau from a modelling perspective". In: Tellus B: Chemical and Physical Meteorology 63.5, pp. 959-970.

Shirahata, L. M., K. Iizuka, A. Yusupujiang, F. R. Rinawan, R. Bhattarai, and X. Dong (2017). "Production of Global Land Cover Data-GLCNMO2013". In: Journal of Geography and Geology 9.3.

Slinn, W. (1982). "Predictions for particle deposition to vegetative canopies". In: Atmospheric Environment (1967) 16.7, pp. 1785-1794.

Sousa, L. M. de, L. Poggio, N. H. Batjes, G. B. M. Heuvelink, B. Kempen, E. Riberio, and D. Rossiter (2020). "SoilGrids 2.0: producing quality-assessed soil information for the globe". In: SOIL Discussions 2020, pp. 1-37. DOI: 10.5194/soil-2020-65.

Spassov, S. (2002). "Loess magnetism, environment and climate change on the Chinese Loess Plateau". PhD thesis. ETH Zurich.

Stevens, T., D. S. Thomas, S. J. Armitage, H. R. Lunn, and H. Lu (2007). "Reinterpreting climate proxy records from late Quaternary Chinese loess: a detailed OSL investigation". In: Earth-Science Reviews 80.1-2, pp. 111-136. 
Stohl, A., C. Forster, A. Frank, P. Seibert, and G. Wotawa (2005). “Technical note: The Lagrangian particle dispersion model FLEXPART version 6.2". In: Atmospheric Chemistry and Physics 5.9, pp. 2461-2474. DOI: 10.5194/acp-5-2461-2005.

Stohl, A., S. Eckhardt, C. Forster, P. James, N. Spichtinger, and P. Seibert (2002). "A replacement for simple back trajectory calculations in the interpretation of atmospheric trace substance measurements". In: Atmospheric Environment 36.29, pp. 4635-4648. ISSN: 1352-2310. DOI: https://doi.org/10.1016/S1352-2310(02)00416-8.

Sun, D., J. Bloemendal, D. Rea, J. Vandenberghe, F. Jiang, Z. An, and R. Su (2002). "Grain-size distribution function of polymodal sediments in hydraulic and aeolian environments, and numerical partitioning of the sedimentary components". In: Sedimentary geology 152.3-4, pp. 263-277.

Sun, D., F. Chen, J. Bloemendal, and R. Su (2003). "Seasonal variability of modern dust over the Loess Plateau of China". In: Journal of Geophysical Research: Atmospheres 108.D21.

Sun, J., M. Zhang, and T. Liu (2001). "Spatial and temporal characteristics of dust storms in China and its surrounding regions, 1960-1999: Relations to source area and climate". In: Journal of Geophysical Research: Atmospheres 106.D10, pp. 10325-10333.

Sun, Y. and Z. An (2005). "Late Pliocene-Pleistocene changes in mass accumulation rates of eolian deposits on the central Chinese Loess Plateau". In: Journal of Geophysical Research: Atmospheres 110.D23.

Sun, Y., H. Lu, and Z. An (2006). "Grain size of loess, palaeosol and Red Clay deposits on the Chinese Loess Plateau: Significance for understanding pedogenic alteration and palaeomonsoon evolution". In: Palaeogeography, Palaeoclimatology, Palaeoecology 241.1, pp. 129-138.

Ta, W., H. Xiao, J. Qu, Z. Xiao, G. Yang, T. Wang, and X. Zhang (2004). “Measurements of dust deposition in Gansu Province, China, 1986-2000". In: Geomorphology 57.1-2, pp. 41-51.

Tada, R., H. Zheng, and P. D. Clift (2016). "Evolution and variability of the Asian monsoon and its potential linkage with uplift of the Himalaya and Tibetan Plateau". In: Progress in Earth and Planetary Science 3.1, pp. 1-26.

Takemi, T. and N. Seino (2005). "Dust storms and cyclone tracks over the arid regions in east Asia in spring". In: Journal of Geophysical Research: Atmospheres 110.D18.

Tang, H., J. T. Eronen, A. Micheels, and B. Ahrens (2013). "Strong interannual variation of the Indian summer monsoon in the Late Miocene". In: Climate dynamics 41.1, pp. 135153.

Task, G. S. D. (2014). "Global soil data products CD-ROM contents (IGBP-DIS)". In: ORNL $D A A C$.

Tegen, I., A. A. Lacis, and I. Fung (1996). "The influence on climate forcing of mineral aerosols from disturbed soils". In: Nature 380.6573, pp. 419-422.

Tegen, I. and M. Schulz (2014). “Numerical dust models". In: Mineral Dust. Springer, pp. 201-222.

Thompson, D. W. and J. M. Wallace (1998). "The Arctic Oscillation signature in the wintertime geopotential height and temperature fields". In: Geophysical research letters 25.9, pp. 1297-1300.

Tipka, A., L. Haimberger, and P. Seibert (Nov. 2020). “Flex_extract v7.1.2 - a software package to retrieve and prepare ECMWF data for use in FLEXPART". English. In: Geoscientific Model Development 13.11. Publisher: Copernicus GmbH, pp. 5277-5310. ISSN: 1991-959X. DOI: https://doi.org/10.5194/gmd-13-5277-2020.

Tipka, A. and P. Seibert (2021). "Effects of improved interpolation in the wet-scavenging scheme of FLEXPART". In: EGU General Assembly Conference Abstracts, EGU21-15805. 
Van Der Does, M., P. Knippertz, P. Zschenderlein, R. G. Harrison, and J.-B. W. Stuut (2018). "The mysterious long-range transport of giant mineral dust particles". In: Science advances 4.12 , eaau 2768 .

Wang, L. and W. Chen (2010). "How well do existing indices measure the strength of the East Asian winter monsoon?" In: Advances in Atmospheric Sciences 27.4, pp. 855-870.

Wang, X., L. Lang, H. Li, T. Hua, G. Wang, N. Zhou, and L. Jiao (2015). “Geochemical evidence for seasonal variations in potential loess sources of the western Chinese Loess Plateau". In: Atmospheric Environment 120, pp. 369-375.

Wasiljeff, J., A. Kaakinen, J. M. Salminen, and Z. Zhang (2020). “Magnetostratigraphic constraints on the fossiliferous Ulantatal sequence in Inner Mongolia, China: Implications for Asian aridification and faunal turnover before the Eocene-Oligocene boundary". In: Earth and Planetary Science Letters 535, p. 116125.

Williams, M. (2014). Climate Change in Deserts: Past, Present and Future. en. New York: Cambridge University Press. ISBN: 978-1-139-06178-0. DOI: 10.1017/CB09781139061780.

Wittmann, M., C. D. Groot Zwaaftink, L. Steffensen Schmidt, S. Guðmundsson, F. Pálsson, O. Arnalds, H. Björnsson, T. Thorsteinsson, and A. Stohl (2017). "Impact of dust deposition on the albedo of Vatnajökull ice cap, Iceland". In: The Cryosphere 11.2, pp. 741-754.

Wu, B. and J. Wang (2002). “Winter Arctic oscillation, Siberian high and East Asian winter monsoon". In: Geophysical research letters 29.19, pp. 3-1.

Wyrwoll, K.-H., J. Wei, Z. Lin, Y. Shao, and F. He (2016). "Cold surges and dust events: Establishing the link between the East Asian Winter Monsoon and the Chinese loess record". In: Quaternary Science Reviews 149, pp. 102-108.

Xiao, J., S. C. Porter, Z. An, H. Kumai, and S. Yoshikawa (1995). "Grain size of quartz as an indicator of winter monsoon strength on the Loess Plateau of central China during the last 130,000 yr". In: Quaternary Research 43.1, pp. 22-29.

Xuan, J. and I. N. Sokolik (2002). "Characterization of sources and emission rates of mineral dust in Northern China". In: Atmospheric Environment 36.31, pp. 4863-4876. DOI: https://doi.org/10.1016/S1352-2310(02)00585-X.

Xuan, J., I. N. Sokolik, J. Hao, F. Guo, H. Mao, and G. Yang (2004). “Identification and characterization of sources of atmospheric mineral dust in East Asia". In: Atmospheric Environment 38.36, pp. 6239-6252. DOI: https://doi.org/10.1016/j.atmosenv . 2004 06.042

Yang, S. and Z. Ding (2004). "Comparison of particle size characteristics of the Tertiary 'red clay'and Pleistocene loess in the Chinese Loess Plateau: implications for origin and sources of the 'red clay'". In: Sedimentology 51.1, pp. 77-93.

Yang, X., G. Zeng, G. Zhang, and Z. Li (2020). "Interdecadal variation of winter cold surge path in East Asia and its relationship with Arctic sea ice". In: Journal of Climate 33.11, pp. 4907-4925.

Yoshiike, S. and R. Kawamura (2009). "Influence of wintertime large-scale circulation on the explosively developing cyclones over the western North Pacific and their downstream effects". In: Journal of Geophysical Research: Atmospheres 114.D13.

Yu, H., M. Chin, T. Yuan, H. Bian, L. A. Remer, J. M. Prospero, A. Omar, D. Winker, Y. Yang, Y. Zhang, et al. (2015). "The fertilizing role of African dust in the Amazon rainforest: A first multiyear assessment based on data from Cloud-Aerosol Lidar and Infrared Pathfinder Satellite Observations". In: Geophysical Research Letters 42.6, pp. 1984-1991.

$\mathrm{Yu}, \mathrm{S}$. and J. Sun (2021). "Conditional impact of boreal autumn North Atlantic SST anomaly on winter tropospheric Asian polar vortex". In: Climate Dynamics 56.3, pp. 855-871. 
Yumimoto, K., K. Eguchi, I. Uno, T. Takemura, Z. Liu, A. Shimizu, and N. Sugimoto (Nov. 2009). "An elevated large-scale dust veil from the Taklimakan Desert: Intercontinental transport and three-dimensional structure as captured by CALIPSO and regional and global models". English. In: Atmospheric Chemistry and Physics 9.21. Publisher: Copernicus GmbH, pp. 8545-8558. ISSN: 1680-7316. DOI: https://doi .org/10.5194/ acp-9-8545-2009.

Zender, C. S., H. Bian, and D. Newman (2003). "Mineral Dust Entrainment and Deposition (DEAD) model: Description and 1990s dust climatology". In: Journal of Geophysical Research: Atmospheres 108.D14.

Zeng, Y., M. Wang, C. Zhao, S. Chen, Z. Liu, X. Huang, and Y. Gao (2020). "WRF-Chem v3.9 simulations of the East Asian dust storm in May 2017: modeling sensitivities to dust emission and dry deposition schemes". In: Geoscientific Model Development 13.4, pp. 2125-2147. DOI: 10.5194/gmd-13-2125-2020.

Zhang, X.-X., B. Sharratt, J.-Q. Lei, C.-L. Wu, J. Zhang, C. Zhao, Z.-F. Wang, S.-X. Wu, S.-Y. Li, L.-Y. Liu, et al. (2019). "Parameterization schemes on dust deposition in northwest China: Model validation and implications for the global dust cycle". In: Atmospheric environment 209, pp. 1-13.

Zhang, X., R. Arimoto, Z. An, T. Chen, G. Zhang, G. Zhu, and X. Wang (1993). "Atmospheric trace elements over source regions for Chinese dust: Concentrations, sources and atmospheric deposition on the Loess Plateau". In: Atmospheric Environment. Part A. General Topics 27.13, pp. 2051-2067.

Zhao, T., S. Gong, X. Zhang, and I. McKendry (2003). "Modeled size-segregated wet and dry deposition budgets of soil dust aerosol during ACE-Asia 2001: Implications for trans-Pacific transport". In: Journal of Geophysical Research: Atmospheres 108.D23.

Zhou, Z. and G. Zhang (2003). "Typical severe dust storms in northern China during 1954-2002". In: Chinese Science Bulletin 48.21, pp. 2366-2370.

Zhuang, G., J. Guo, H. Yuan, and C. Zhao (2001). "The compositions, sources, and size distribution of the dust storm from China in spring of 2000 and its impact on the global environment". In: Chinese Science Bulletin 46.11, pp. 895-900. 